JULIANA ANDREA GARCÍA GALLEGO

DESARROLLO DE REVESTIMIENTOS ARQUITECTONICOS A BASE DE RESÍDUOS LIGNOCELULÓSICOS

São Paulo 


\title{
DESARROLLO DE REVESTIMIENTOS ARQUITECTONICOS A BASE DE RESÍDUOS LIGNOCELULÓSICOS
}

\author{
Orientador \\ Prof. Dr. Vanderley M. John
}

Disertación presentada a la Escuela Politécnica de la Universidad de São Paulo para la obtención del título de Master en Ciencias en Ingeniería Civil, en el área de concentración: materiales para la construcción civil y urbana.

São Paulo 
Catalogação na publicação

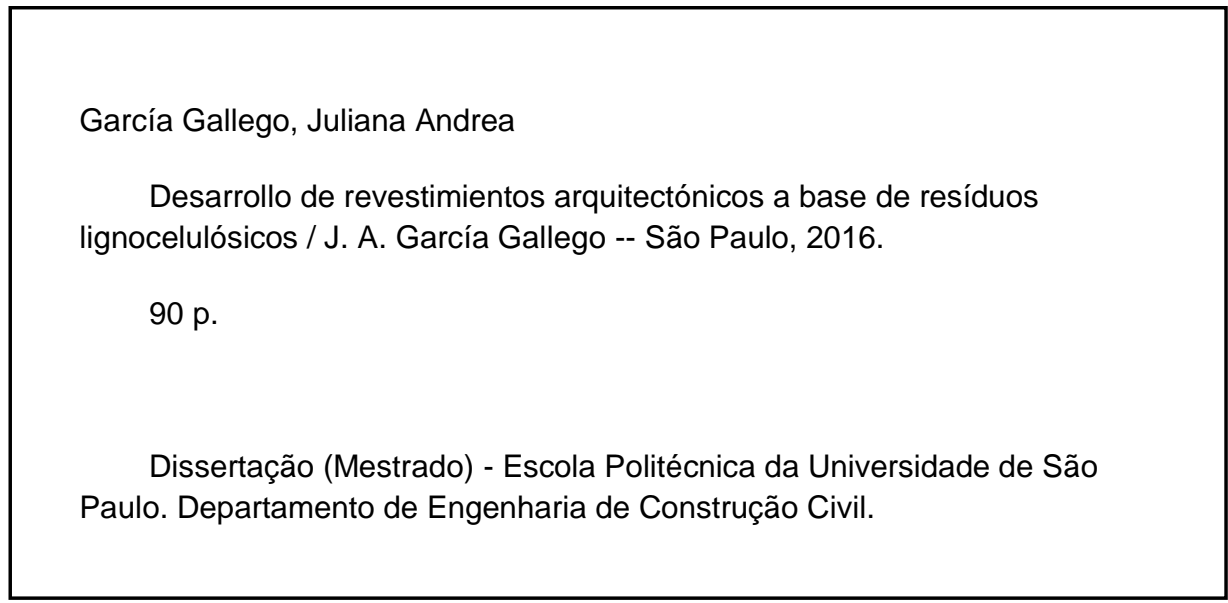


Para mi Mamá,

\section{Gloria Gallego.}




\section{Agradecimientos}

Este trabajo se lo ofrezco a toda mi familia que con mucho amor y dedicación estuvieron apoyándome todo este a tiempo a la distancia. Especialmente mi mamá Gloria Gallego y mi hermano Julián García. A Juan Sebastián Ruiz por todo el apoyo y cariño en este tiempo. A Julio Cesar Delgado y a mi tía Elizabeth Gallego por haber cuidado de los míos en mi ausencia.

Al Prof. Vanderley M. John por la oportunidad de haber continuado mis estudios aquí en Brasil, por toda las enseñanzas y el aprendizaje que me brindo.

A la empresa MADEPAR por la donación del material para realizar los ensayos.

A mis compañeros de laboratorio que estuvieron acompañando todo el desarrollo del trabajo con sus comentarios técnicos, Yazmin, Marylinda, Ana Paula, Victor, Gabi, Lidiane, Winnie, Ricardo, Debora y Felipe.

A los técnicos de laboratorio, especialmente Mario Takeashi y Liz Zanchetta, quienes con tanto esfuerzo me colaboraron en el área de estudios de microscopia óptica y electrónica.

Al área administrativa, Engracia M. Bartucioti y Carla Cordeiro por estar siempre al tanto de todo.

Al Prof. Rafael Pielegi, por el apoyo y otorgación de incentivos en este último semestre.

Al Prof. Juliano Fiorelli y Holmer Savastano por haber abierto las puertas de su laboratorio y haber colocado a disposición toda su área técnica para desarrollo del proyecto. A Mariana Pavessi y Diego Ferrari, técnicos del laboratorio de Construcciones rurales y ambiencia de la USP, campus Pirassununga, y a los colegas compatriotas de este laboratorio, Julian Mejía y su esposa, por la estadía.

A la Sr. Paulette Alberis de Mello, por haber acogido en su hogar y en su familia, cuando llegue a Brasil.

A la entidad CAPES y la FDTE por la otorgación de las becas de estudio y el apoyo económico para mi sostenimiento y el desarrollo del proyecto durante este tiempo.

A todos muchas gracias. 


\section{Resumen}

Los residuos lignocelulósicos son los sub-productos agroindustriales de mayor abundancia en el sector agrícola, por esta razón, se ha propuesto el uso de estos en diferentes aplicaciones de materiales compuestos. El objetivo de este trabajo es explorar el potencial del uso de la hoja caulinar del bambú (HCB) y el peciolo envainador de la hoja de la palmera (PHP), para la producción de laminados decorativos, con el fin de ser usados en revestimientos de interiores de edificios. Se realizó primero la caracterización de la HCB y el PHP en estado natural, luego se realizó un prototipo de fabricación del revestimiento y por último, la caracterización del laminado que se obtuvo en este proceso. Los resultados muestran que el comportamiento termodinámico de la HCB y el PHP, en el proceso de laminación no debe superar los $\sim 135^{\circ}$. El análisis físico-químico muestra que la porosidad y la presencia de minerales son mayores en las HCB en relación a la PHP. En el envejecimiento acelerado por CUV, se determinó que las HCB son más susceptibles al cambio de color en su superficie. En cuanto al proceso de laminación, las HCB necesariamente deben pasar por el proceso de rectificado antes de la laminación. En el proceso de laminación, se determinó que el uso del substrato de papel kraft impregnado es el más conveniente para la conservación de la estética de la superficie de ambos residuos. De acuerdo con la topografía de la superficie, podemos afirmar que los patrones de rugosidad disminuyen con respecto al proceso de laminación, en la HCB pasan de $0,017 \mathrm{~mm}$ para $0,008 \mathrm{~mm}$ y de $0,015 \mathrm{~mm}$ para $0,027 \mathrm{~mm}$ en la superficie externa e interna respectivamente; en el PHP pasan de 0,076 para 0,016 y de $0,106 \mathrm{~mm}$ para $0,029 \mathrm{~mm}$. Aunque en la $\mathrm{HCB}$, se observe el perfil (y) un aumento de la ondulación. Después del proceso de laminación la porosidad disminuye en ambos residuos y los valores de absorción de agua disminuyen 7,25\% en la HCB y aumentan $1,33 \%$ en el PHP. Podemos concluir que ambas superficies son aptas para uso en revestimientos. 


\begin{abstract}
Lignocellulosic residues are the most abundant agri-bussiness product in the agricultural sector, therefore, it has been proposed for use in various applications of these composites. The aim of this paper is to explore the potential of using sheath bamboo leaf (SBL) and the petiole leaf palm (PLP), for the production of decorative laminates, in order to be used in coatings inside buildings. Characterization of SBL and PLP unprocessed was performed, then a prototype process manufacturing and finally characterization laminate coating obtained was performed. The results show that the thermodynamic behavior of SBL and PLP in the lamination process should not exceed $135{ }^{\circ} \mathrm{C}$. The physico-chemical analysis shows that the porosity and the presence of mineral on SBL are greater than PHP. In the accelerated aging by CUV method, it was determined that SBL are suseptible to color change on the surface. The SBL necessarily have to go through the process of grinding prior to lamination. In the lamination process, it was determined that the use of kraft paper impregnated substrate is most suitable for preserving the aesthetics of the surface of both residues. According to the topography of the surface, we can say that the patterns of roughness decrease with respect to the lamination process, on SBL change from $0,017 \mathrm{~mm}$ to $0,008 \mathrm{~mm}$ and $0,015 \mathrm{~mm}$ to $0,027 \mathrm{~mm}$ in the outer and inner surface, respectively; PLP roughness change from 0.076 to 0.016 and $0,106 \mathrm{~mm}$ to $0,029 \mathrm{~mm}$. Although the profile (y) increased ripple is observed at the SLB. After the lamination process the porosity decreases in both waste and water absorption values decrease on SLB 7.25\% and $1.33 \%$ increase in the PLP. We concluded that both surfaces are suitable for use in coatings.
\end{abstract}




\section{Contenido}

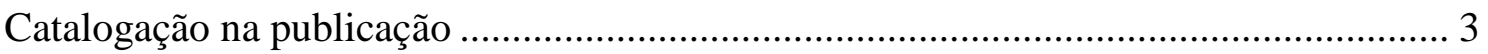

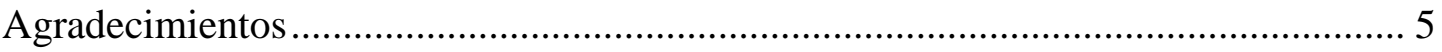

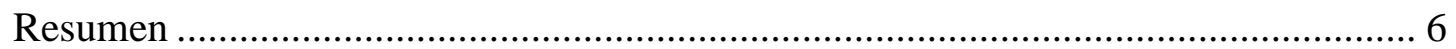

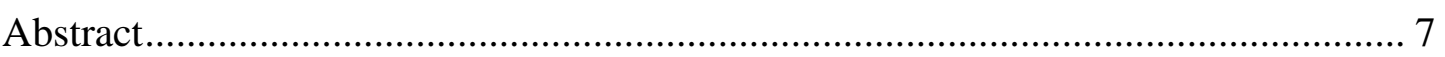

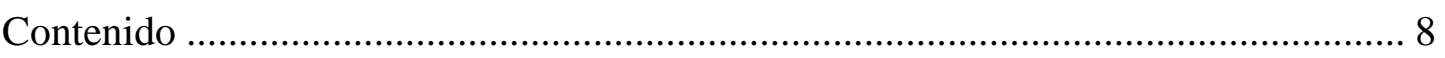

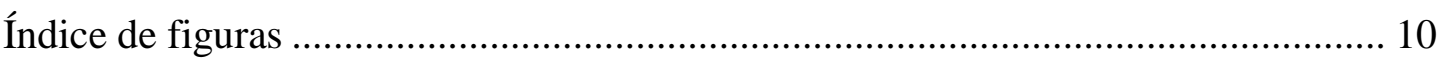

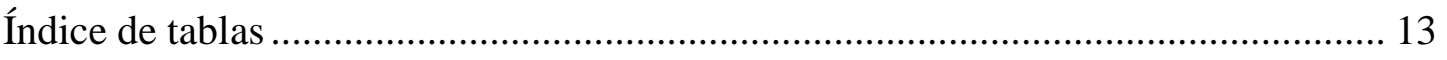

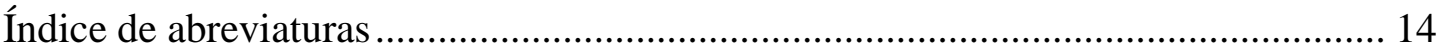

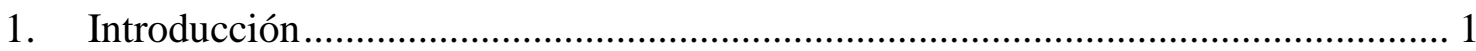

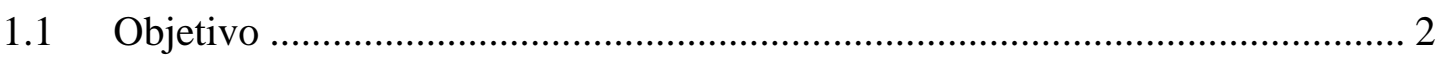

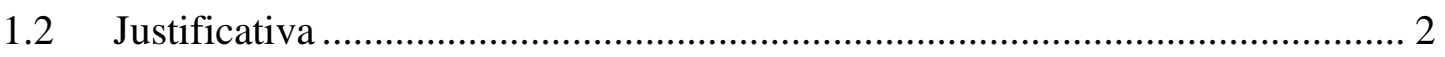

1.3 Contenido de la disertación............................................................................ 4

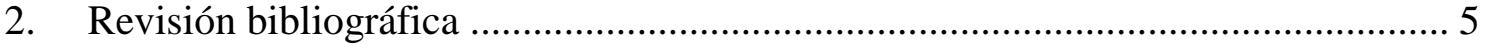

2.1 Compuestos lignocelulósicos naturales ......................................................... 5

2.1.1 Hoja Caulinar del Bambú (Guadua angustifolia) .................................... 7

2.1.2 Peciolo envainador de la hoja de la palmera real (Roystonea regia).......... 9

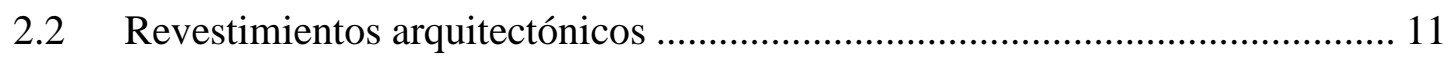

2.2.1 Chapas de madera (Wood veneer) ............................................................ 12

2.2.2 Laminados melamínicos de alta presión............................................... 15

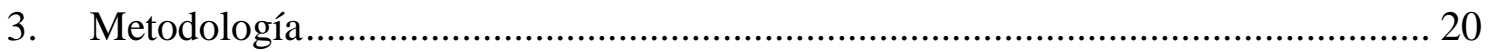

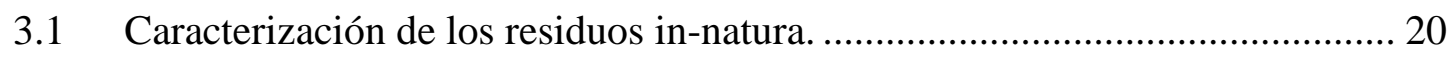

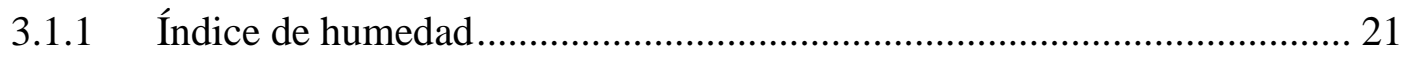

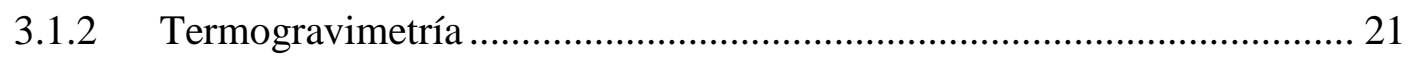

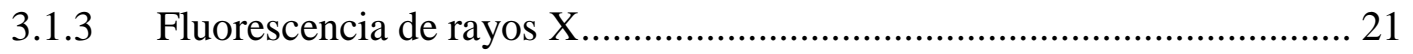

3.1.4 Microscopia Electrónica de Barredura y EDS ......................................... 22

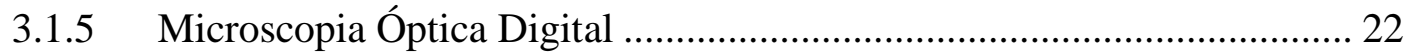

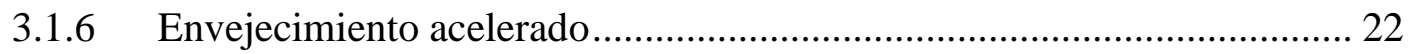

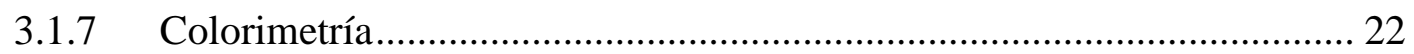

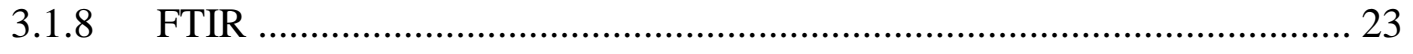

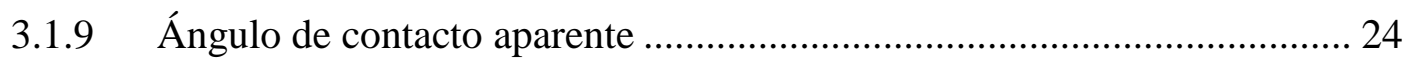

3.2 Fabricación de los Revestimientos .............................................................. 24

3.2.1 Pre-tratamiento de los residuos ............................................................. 24 
3.2.2 Conformado del residuo con diferente substratos .................................. 26

3.3 Caracterización del revestimiento................................................................. 30

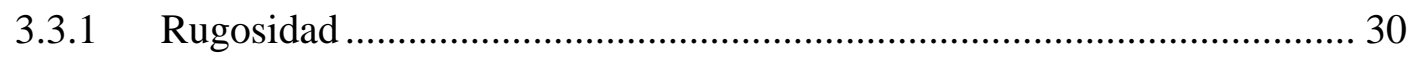

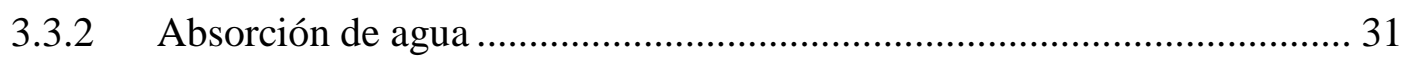

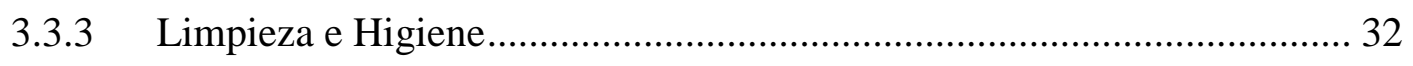

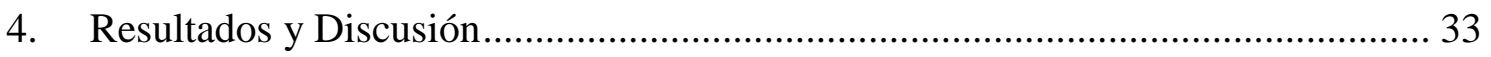

4.1 Resultados de la caracterización Físico-química de la HCB y el PHP............ 33

4.1.1 Índice de humedad natural............................................................... 33

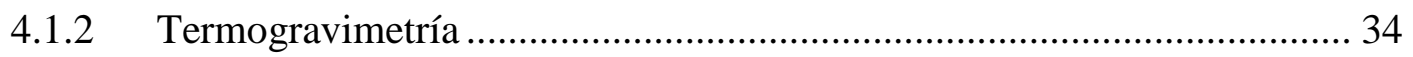

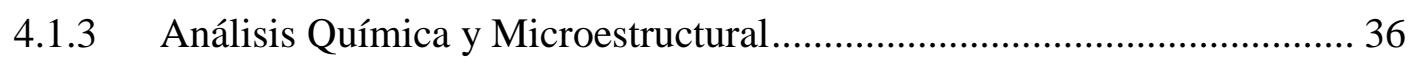

4.1.4 Cambio de color por envejecimiento acelerado (QUV) ......................... 40

4.1.1 Química de la superficie: análisis por medio de FTIR ............................ 42

4.1.2 Angulo de Contacto Aparente. ............................................................... 44

4.2 Prototipo de fabricación del revestimiento: Pre-tratamientos.......................... 48

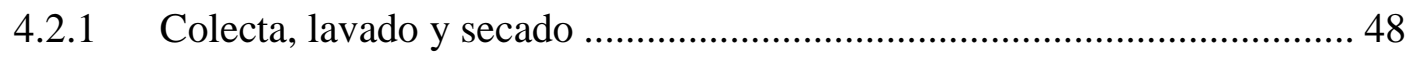

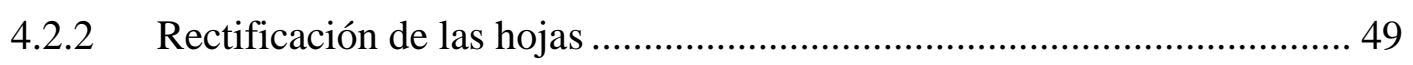

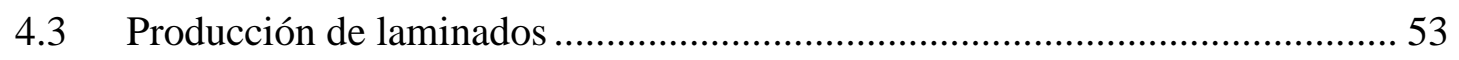

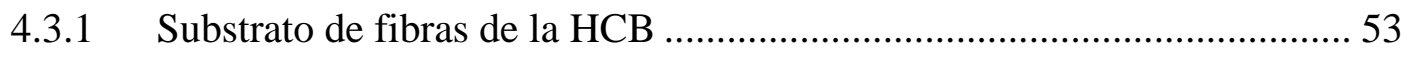

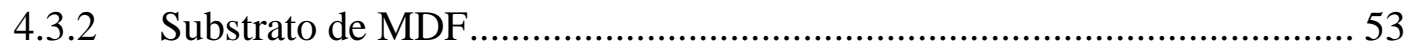

4.3.3 Substrato de Papel Kraft Pre-impregnado ............................................. 54

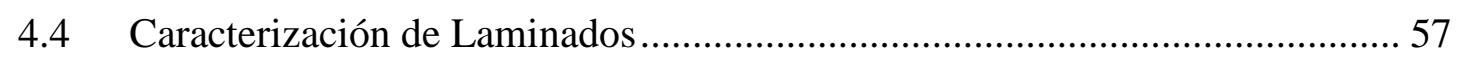

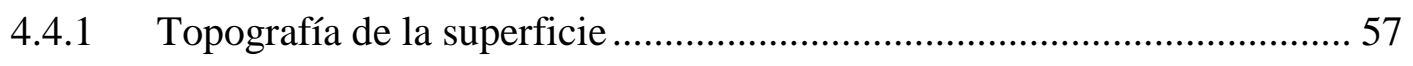

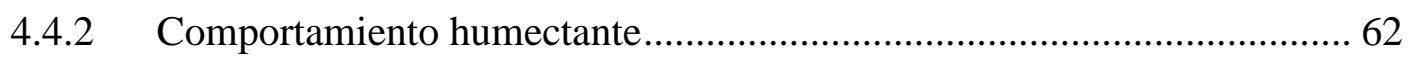

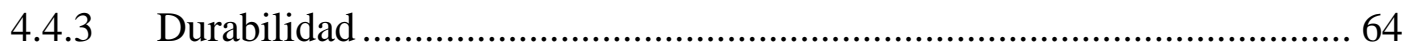

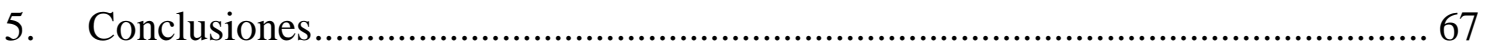

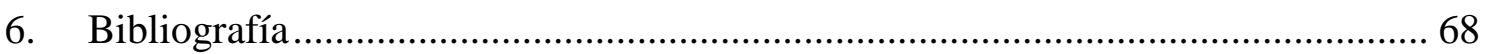




\section{Índice de figuras}

Figura 1 - Flujograma estructural de la revisión bibliográfica ...................................... 5 Figura 2 - Estructura de la biomasa lignocelulósicos. Celulosa, hemicelulosa y Lignina

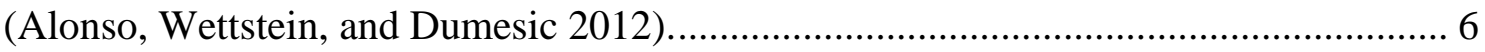
Figura 3 - Hoja Caulinar en el tallo del bambú (Izquierda). Hoja caulinar del bambú después de caer del tallo del bambú (Centro). Descripción morfológica de la hoja del

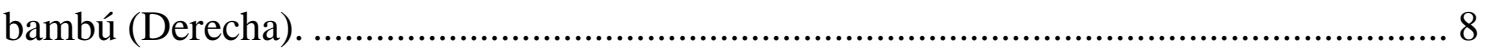
Figura 4 - Usos comerciales de la Hoja Caulinar del Bambú, principalmente en empaques desechables de comida, comercializados por panda bambú (Izquierda y Centro). (Derecha) 8

Figura 5 - Peciolo envainador de la hoja de la palmera real (Conrad 2012)................. 10

Figura 6 - Usos del peciolo de la palmera: Esquema de un bohío cubano (Izquierda y

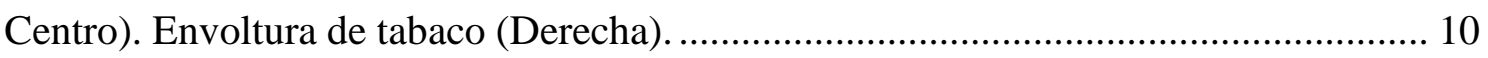

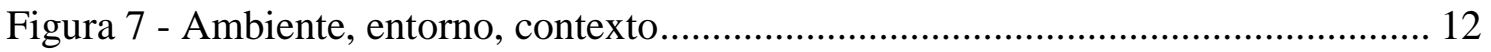

Figura 8 - Esquema representativo del conformado de las chapas de madera. .............. 12

Figura 9 - Urea (Izquierda) Formaldehido (Derecha)................................................. 13

Figura 10 - Condensación de la Urea-formaldehido................................................... 13

Figura 11 - polimerización de una resina poliuretano común con enlaces uretanos. .... 14

Figura 12 - polimerización de una resina poliuretana a base de aceite de ricino ........... 14 Figura 13 - Esquema representativo de la composición de un laminado de alta presión a base de papel kraft impregnado, papel decorativo impreso e impregnado y overlay $99 \%$ celulosa. 16

Figura 14 - Reacción química entre el fenol (grupo hidroxilo) y el formaldehído (grupo hidrocarboneto aromático). Resultado monômero de resina fenólica. ........................... 16 Figura 15 - Polimerización de la melamina con el formaldehido, por medio de condensación reaccionan formando un monómero de resina melamínica formaldehído 16 Figura 16 - Flujograma representativo de la metodología aplicada en el proyecto........ 20 Figura 17 - Sistema de medición del color CIELab ................................................... 23 Figura 18 - Medidas del Angulo de contactos realizados en ambos sentidos de orientación de las fibras (a) perpendicular (b) paralelo................................................. 24 Figura 19 - Proceso de obtención de las materias primas para laminación con fibras de

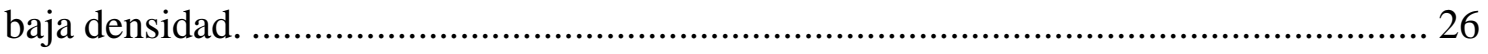

Figura 20 - Proceso de conformado paso a paso. ....................................................... 28

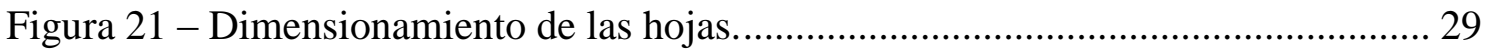

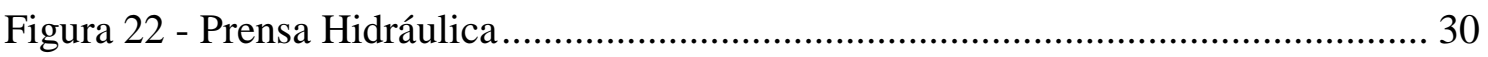

Figura 23 - Contenido de Humedad de los residuos ...................................................... 34

Figura 24 - Curvas TG y DTG de las HCB y la PHP naturales. .................................. 35

Figura 25 - Sección Transversal de la HCB, mostrando la anatomía compuesta por

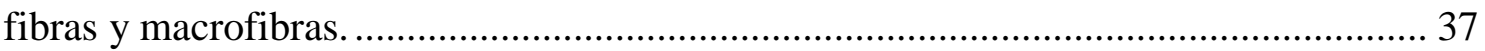

Figura 26 - Sección Transversal del PHP, mostrando la anatomía compuesta por fibras y

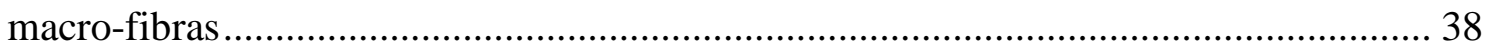

Figura 27 - Superficies Externas: HCB (izquierda) y PHP (derecha) ........................... 39

Figura 28 - Superficies Interna: HCB (izquierda) y PHP (derecha) .............................. 39 
Figura 29 - Superficies Internas: HCB (izquierda) y PHP (derecha) ............................ 40 Figure 30 - Imágenes representativas de las superficies antes y después del

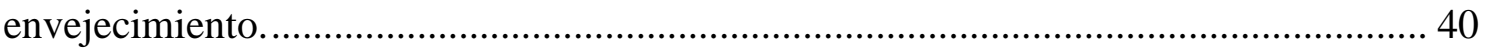

Figura 31 - Cambio total del color en cada superficie ............................................. 42 Figura 32 - Espectros en la región infrarroja entre 400 y $2000 \mathrm{~cm}^{-1}$ en la superficie externa (izquierda) y superficie interna (derecha) de la HCB antes y después del

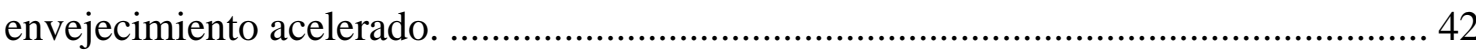

Figura 33 - Espectros en la región infrarroja entre 400 y $2000 \mathrm{~cm}^{-1}$ en la superficie externa (izquierda) y superficie interna (derecha) de la HCB antes y después del

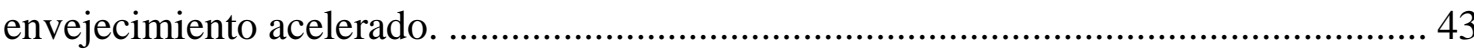
Figura 34 - Vista superior de una gota de agua sobre la superficie natural de la HCB y el PHP. 44

Figura 35 - Vista esquemática que muestra el despliegue de la gota de agua sobre siguiendo la organización de las fibras (paralela o perpendicular). 45 Figura 36 - Interacción del agua con la superficie externa de la HCB a) 15 segundos b) 5 minutos c) 10 minutos después de la aplicación.................................................... 45 Figura 37 - interacción del agua con la superficie interna de la HCB a) 15 segundos b) 5 minutos c) 10 minutos después de la aplicación. ..................................................... 45 Figura 38 - Angulo de contacto de la superficie externa y de la superficie interna de la

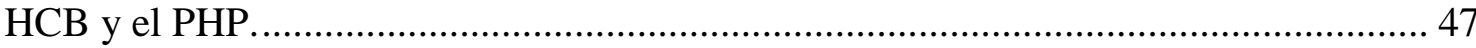
Figura 39 - Primera etapa de recolección de las HCB .................................................... 48 Figura 40 - Residuos de la colecta, vaina de la hoja después del lavado....................... 49 Figura 41 - Microscopia transversal de la HCB antes (a) y después (b) del tratamiuento con $\mathrm{NaClO}$ 50

Figura 42 - Superficie de los cuerpos de Prueba después del tratamiento con $\mathrm{NaClO}$.. 51 Figura 43 - Microscopia transversal de la PHP antes (a) y después (b) del tratamiento con $\mathrm{NaClO}$ 51

Figura 44 - Superficie externa (arriba) y superficie interna de la HCB después de la rectificación manual.

Figura 45 - Resultado final: Panel de fibras de baja densidad, con núcleo de fibras de HCB. (a) Superficie externa da HCB (b) Superficie externa da HCB ........................... 53

Figura 46 - Revestimiento de HCB utilizando MDF como substrato. ............................ 54

Figura 47 - HCB con substrato de papel Kraft sin barrera ............................................ 55

Figura 48 - HCB con substrato kraft y una barrera .................................................. 55

Figura 49- HCB con substrato kraft y dos barreras, superficie interna visible (arriba)

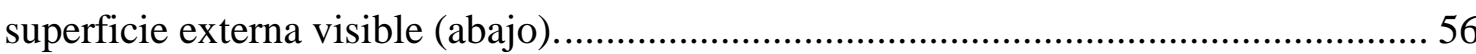

Figura 50 - laminado a base de papel kraft utilizando ambas superficies del PHP56 Figura 51 - Superficies de la HCB. Arriba: Superficie externa natural (izquierda) laminada (derecha). Abajo: Superficie externa natural (izquierda) laminada (derecha). 57 Figura 52 - Superficies del PHP. Arriba: Superficie externa natural (izquierda) laminada (derecha). Abajo: Superficie externa natural (izquierda) laminada (derecha)................ 58 Figura 53 - Topografía de la superficie medidas por interferométria óptica en diferentes magnitudes sobre un área de 5x5mm. 
Figura 54 - Perfil representativo de rugosidad (y) de las superficies de la HCB antes y después de la laminación. Superficie natural (arriba), superficie laminadas (abajo) ..... 60 Figura 55 - Topografía de la superficie medidas por interferométria óptica en diferentes magnitudes sobre un área de $5 \times 5 \mathrm{~mm}$.

Figura 56 - Perfil representativo de rugosidad (y) de las superficies del PHP antes y después de la laminación. Superficies naturales (arriba), superficies laminadas (abajo).

Figura 57 - Angulo de contacto aparente de las superficies de la HCB antes y después del proceso de laminación

Figura 58 - Angulo de contacto aparente de las superficies de la PHP antes y después del proceso de laminación 63

Figura 59 - Absorción de agua en HCB (Arriba) y del PHP (Abajo). Natural (izquierda) Laminado (Derecha) 63 Figura 60 - Superficies de la HCB durante el proceso de manchado y después del procedimiento de limpieza. Superficie externa (arriba) y superficie interna (abajo)..... 65 Figura 61 - Superficies del PHP durante el proceso de manchado y después del procedimiento de limpieza. Superficie externa (arriba) y superficie interna (abajo)..... 65 


\section{Índice de tablas}

Tabla 1 - Referencias bibliográficas sobre conformado de laminados decorativos de alta

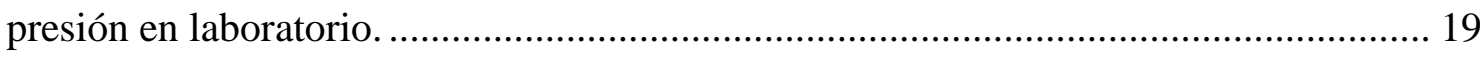

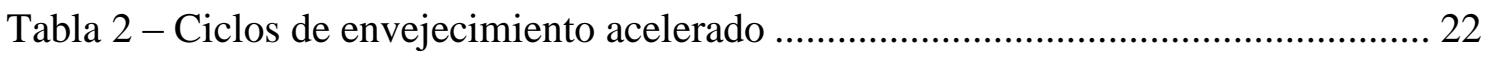

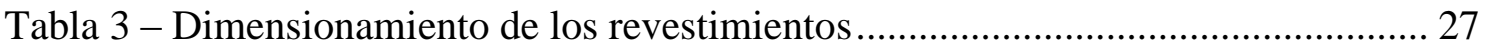

Tabla 4 - Parámetros de laminación en laboratorio ......................................................... 30

Tabla 5 - Valores cuantitativos resultantes del ensayo por fluorescencia de rayos x.... 36

Tabla 6 - Imágenes representativas de las superficies antes y después del envejecimiento acelerado.

Tabla 7 - Valores promedios de cambios de color. Valores entre paréntesis representan la desviación estándar.

Tabla 8 - picos característicos de las superficies de ambos residuos antes y después de

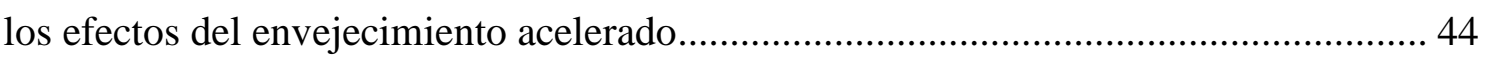

Tabla 9 - Promedio del ángulo de contacto aparente en las superficies. ......................... 46

Tabla 10 - Medidas de Rugosidad promedio de cada Superficie................................... 62

Tabla 11 - Reacción de agentes manchadores sobre la superficie................................. 64 


\section{Índice de abreviaturas}

HCB - Hoja Caulinar del Bambú

PHP - Peciolo envainador de la Hoja de la Palmera

APG - Angiospherm Phylogeny Group

COV - Compuestos Organicos Volatiles

ANSI - American National Standards Institute

UV - Ultravioleta

MDF - Medium Density Fiber

MDP - Medium Density Particle board

UF - Urea Formaldehido

MUF - Melamin Urea Formaldehido

PF - Phenol Formaldehide

ISO - International Organization for Standardization

ABNT NBR - Associação Brasileira de Normas Técnicas

SEM - Scaning Electron Microscopy

EDS - Electronic Data Systems

QUV - Q-panel Laboratory UltraViolet testing

FTIR - Fourier transform infrared spectroscopy

DTGS - Sulfato de Triglicina Deuterado

DRIFT - Diffuse Reflectance for Infrared Fourier Transform Spectroscopy

$\mathrm{TG}$ - Termogravimetria

DTG - Derivada termogravimétrica

MS - Massa Residual 


\section{Introducción}

El sector agroindustrial es uno de los principales sectores económicos del mundo. Este sector está directamente ligado al crecimiento poblacional, generando así un aumento en la producción agraria, debido a la expansión demográfica del último siglo. Consecuentemente a este crecimiento, se observa, inevitablemente, la generación de grandes cantidades de residuos sólidos provenientes de la intensa actividad económica en este sector (Food and agriculture organization 2015).

Uno de los principales residuos del sector agroindustrial son los residuos lignocelulósicos (residuos compuestos principalmente de celulosa, hemicelulosa y lignina), los cuales son usados de manera incipiente a nivel industrial en la elaboración de productos de consumo. Sin embargo, se encuentran algunas iniciativas con respecto a la transformación de estos residuos en combustibles tales como el bio-diesel, el bioetanol, leña, aceite vegetal, entro otros. Los cuales son sometidos a un proceso de quema para la transformación del combustible. (John and Ângulo 2003).

Otra alternativa que se ha venido evaluando es el uso de residuos lignocelulósicos en la creación de nuevos materiales; de esta manera son encontrados algunos trabajos en los cuales son triturados estos residuos y, posteriormente, el material particulado es aglomerado con adhesivos sintéticos creando así paneles de partículas (Fiorelli, J et al. 2012) (Martins Carvalho 2012) (Monteiro de Barros et al. 2011) (Rios, Chicurel, and Castillo 2001). Igualmente, diferentes residuos lignocelulósicos han sido usados como refuerzos en matrices poliméricas y cerámicas con el fin de mejorar las propiedades mecánicas del material (Mohanty, Misra, and Drzal 2001) (Kaddami et al. 2006). Entre los residuos lignocelulósicos que han sido usados en la creación de nuevos materiales se encuentran el bagazo de caña (Mendes, Mendes, and Almeida 2011) (Sartori 2012), la cascara de maní (Gatani et al. 2013), las fibras de la hoja de bananera (Gomes, Visconte, and Pacheco 2013), fibras de coco (Fiorelli, J et al. 2012) y la cascara de arroz (Vu and Cao 2013).

Hoy en día, el uso de residuos lignocelulósicos a escala industrial es una práctica incipiente en la elaboración de productos de consumo. Aunque, estudios científicos han demostrado que este tipo de residuos puede ser utilizado como materia prima, principalmente en forma de partículas aglomeradas con adhesivos sintéticos, como lo es el caso de los paneles de partículas (Fiorelli, J et al. 2012; Martins Carvalho 2012; Monteiro de Barros et al. 2011; Rios, Chicurel, and Castillo 2001) y otros estudios donde se utilizan residuos lignocelulósicos como refuerzo dentro de una matriz polimérica para mejorar las propiedades mecánicas del material (Mohanty, Misra, and Drzal 2001; Kaddami et al. 2006).

De aquí parte la iniciativa de desarrollar revestimientos arquitectónicos utilizando residuos lignocelulósicos de grande área superficial, incentivando el consumo de residuos en vez de recursos naturales, con el fin de evitar la contaminación del ambiente 
y el deterioro de la salud poblacional, por medio del secuestro de $\mathrm{CO}_{2}$ durante el ciclo de vida útil del revestimiento.

Los revestimientos arquitectónicos son superficies creadas a partir de un material compuesto. Siendo ampliamente utilizados en el campo de la arquitectura, en productos como: pisos, superficies de apoyo, puertas, revestimientos de pared, paneles delimitadores de espacio y/o divisorias (Composite Panel Association 2016).

La funcionalidad de los revestimientos arquitectónicos es variada y definida por el contexto, el espacio y el ambiente (Gökay Nemli, Örs, and Kalaycioğlu 2005). Esta función puede ser práctica, como los revestimientos utilizados para aislamiento acústico o térmico. Sin embargo, la función más destacada para los revestimientos arquitectónicos es la función estética, la cual es definida por el usuario (Ashby and Johnson 2014).

La necesidad de obtener nuevos productos que promuevan una diferenciación en el mercado, con atributos que generen valor agregado a los productos, que sean aptos para competir en la industria, es el principal fundamento para innovar en este campo, incentivando así el desarrollo de propuestas de nuevos productos.

\subsection{Objetivo}

Por esto, el principal objetivo de este proyecto es explorar el potencial del uso de la hoja caulinar del bambú y el peciolo envainador de la hoja de la palmera, para la producción de laminados decorativos, con el fin de ser usados en revestimientos de interiores de edificios.

Para alcanzar este objetivo, es necesario:

- Reconocer las características físico-químicas de la hoja caulinar del bambú y el peciolo envainador de la hoja de la palmera, por medio de análisis químicas y físicas.

- Evaluación de las características físicas del desempeño visual de las superficies obtenidas a partir del uso de la hoja caulinar del bambú y el peciolo envainador de la hoja de la palmera, sometidas a envejecimiento acelerado.

- Especificar una metodología de fabricación de revestimientos arquitectónicos, usando hojas caulinares, buscando conservar y mantener la apariencia visual de los residuos lignocelulósicos utilizados, tales como: texturas, colores, matices y geometría.

\subsection{Justificativa}

La búsqueda de la conservación de la apariencia visual de la superficie de la hoja caulinar del bambú (HCB) y el peciolo envainador de la hoja de la palmera (PHP), es el inicio de este proyecto. Con el fin de aprovechar el área superficial, que a simple vista para el ojo humano es estéticamente agradable, ya que evoca la "naturalidad de la 
madera" que muchos productos del mercado actual aparentan mediante impresión digital. Por esto, este proyecto busca la conservación de la apariencia superficial de la HCB y el PHP, evitando el uso de tintas y pinturas.

Según Karana (2010), el significado de un material es una propiedad relacional que implica interacciones entre los usuarios, los productos y los materiales. Estas interacciones abarcan aspectos como la técnica, la funcionalidad y la estética, etc. Por esta razón, los diseñadores de productos tienen la responsabilidad de considerar estas interacciones con el fin de utilizar los materiales de manera eficiente para transferir ciertos significados (Karana, Hekkert, and Kandachar 2008).

Para desarrollo revestimientos utilizando la HCB y el PHP, no existiría deforestación y sí la posibilidad de convertir estos residuos en productos industriales. Ya que, el uso de residuos en la producción de nuevos materiales, contribuye con la reducción del impacto ambiental causado por el consumo de recursos naturales (European Environment Agency 2010).

La HCB y el PHP son residuos que usualmente se degradan al aire libre. Estas hojas representan el 2,03\% del peso total del árbol, las cuales tiene un índice promedio de $39 \%$ de $\mathrm{CO}_{2}$ que será emitido a la atmósfera a lo largo del ciclo de degradación de las hojas (Niro Higuchi et al. 1998). Lo anterior, afirma que uso de estas en revestimientos es una oportunidad para el secuestro de carbono.

El uso de la superficie total del residuo, evita con que este tenga que ser triturado o molido, contribuyendo con el ahorro energético en el proceso de producción.

Por otro lado, se busca potencializar la mano de obra artesanal, que es una de las ramificaciones por las cuales se pretende llegar a la esfera social de este proyecto, buscando la creación de nuevos empleos.

Para finalizar, en los siguientes capítulos, se demuestra a través de la ciencia el potencial del uso de la hoja caulinar del bambú y el peciolo envainador de la hoja de la palmera, como materias primas, para la creación de revestimientos arquitectónicos usados para la ambientación de espacios interiores. 


\subsection{Contenido de la disertación}

La disertación está dividida en cuatro capítulos, el primer capítulo compuesta de: introducción, objetivo y justificativa del proyecto.

El segundo capítulo trata la revisión bibliográfica, introduciendo los conceptos sobre residuos lignocelulósicos, acto seguido, una revisión de la literatura sobre revestimientos arquitectónicos.

En el tercer capítulo, se presenta la metodología utilizada en esta investigación. Dividida en tres partes: 1. Caracterización de los residuos lignocelulósicos, explorando propiedades físico-químicas de las hojas caulinares del bambú y el peciolo envainador de las hojas de la palmera. 2. Proceso de fabricación de los revestimientos, y las técnicas utilizadas antes y después del proceso de laminación. 3. Caracterización físico-química del revestimiento, análisis de desempeño y durabilidad en las superficies del prototipo laminado.

En el cuarto capítulo se presentan los resultados y la discusión. Finalmente, en el quinto capítulo se encuentran las conclusiones derivadas del análisis de los resultados físicoquímicos, seguido de las sugerencias para trabajos futuros. 


\section{Revisión bibliográfica}

La revisión bibliográfica de este texto, está basada en el objetivo principal del proyecto, siguiendo el siguiente flujograma (Figura 1) en orden a los objetivos que se buscan alcanzar.

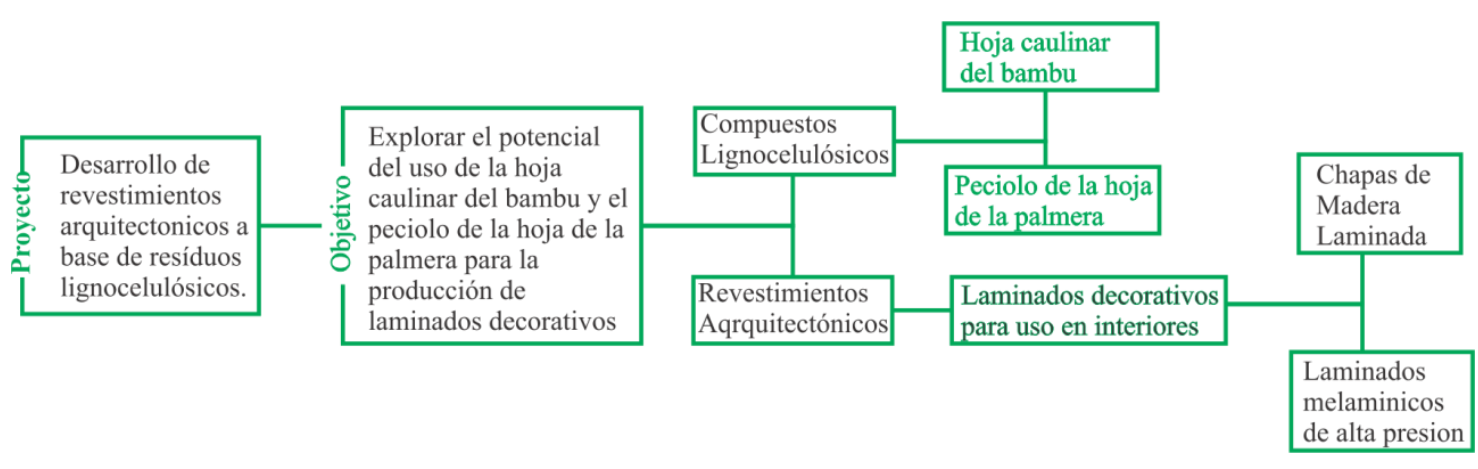

Figura 1 - Flujograma estructural de la revisión bibliográfica

\subsection{Compuestos lignocelulósicos naturales}

Los residuos lignocelulósicos se definen como biomasa, la cual es representada por grandes cantidades de materia viva que existe en un ecosistema o en una población vegetal, o sea, materia orgánica que se origina en la fotosíntesis. (Taiz and Zeiger 2006). Estos residuos están compuestos principalmente de tres polímeros: celulosa (40-50\%), hemicelulosa (25-35\%) y lignina (15-25\%), como se muestra en la (Figura 2). Cada uno está compuesto por una larga cadena polimérica formada por macromoléculas (Alonso, Wettstein, and Dumesic 2012).

La celulosa es la bio-molécula orgánica más abundante sobre la faz de la tierra, ya que conforma la mayor parte de la biomasa terrestre. Es un poli-sacárido compuesto exclusivamente de moléculas monosacáridas de D-glicose, los cuales mantienen una estructura molecular plana y lineal. En la celulosa natural, las cadenas están alineadas, formando un complejo de fibras organizadas. La estructura molecular de la celulosa se puede encontrar en forma cristalina o amorfa. Los enlaces intra e inter moleculares de hidrogeno hacen que las fibras de celulosa sean más estables entre sí. Las cuales, individualmente no presentan una buena resistencia mecánica, pero colectivamente su resistencia aumenta notablemente (Pereira Jr, Couto, and Anna 2008).

Uno de los ejemplos más cercanos de celulosa pura y comercialmente distribuida, es el papel periódico, ya que está compuesto de celulosa al 62\%, hemicelulosa al $16 \%$ y lignina al $21 \%$. En los revestimientos arquitectónicos es favorable que la cristalinidad de la celulosa, ya que, para la celulosa tornarse amorfa en agua se necesita de temperatura $\left(\sim 320^{\circ} \mathrm{C}\right)$ y presión $(\sim 25 \mathrm{MPa})$ (Shigeru Deguchi, Kaoru Tsuji, and Koki Horikoshi 2006). 


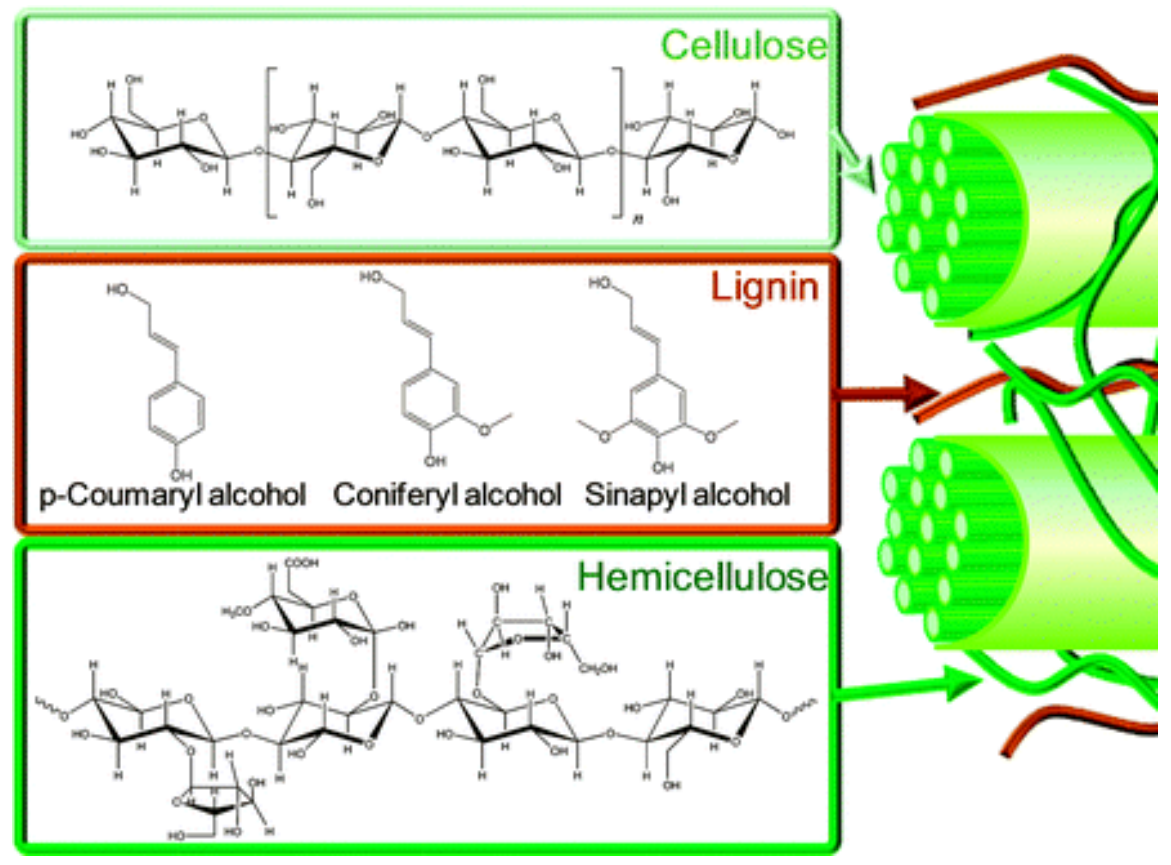

Figura 2 - Estructura de la biomasa lignocelulósicos. Celulosa, hemicelulosa y Lignina (Alonso, Wettstein, and Dumesic 2012).

Después de la celulosa, la lignina es la substancia más abundante en las plantas, siendo el principal compuesto de la pared celular. Esta es producida por la fotosíntesis y está formada por la extracción irreversible del agua de los azucares excedentes del proceso fotosintético, en el cual se crean compuestos aromáticos que permiten distinguir entre los diferentes tipos de ligninas existentes (Taiz and Zeiger 2006). Por esto, no es posible describir una estructura molecular definitiva para la lignina.

La lignina es un polímero no carbohidratado que representa un elevado peso molecular, que resulta de la unión de varios ácidos y alcoholes fenilpropanos (monómeros) (Fukushima et al. 1999). Los polímeros de la lignina son estructuras transconectadas, que presentan un acoplamiento aleatorio de estos radicales y dan origen a una estructura tridimensional, dando como resultado un polímero amorfo el cual es característico de la lignina (Taiz and Zeiger 2006).

La lignina ayuda a retardar la degradación de la celulosa en las plantas y le da rigidez al conjunto de fibras celulósicas (Castro 2009), siendo un polímero insoluble en ácidos y soluble en álcalis, tales como el hidróxido de sodio (Eric Adler 1977). Esta va aumentando de manera ostensible en la pared celular de las plantas a medida que la planta madura, ayudando a la planta a resistir la degradación bacteriana (ChávezSifontes and Domine 2013; Alvarez-Castillo et al. 2012).

Fiorelli et al. (2014) en su trabajo sobre caracterización físico-química de residuos de fibras lignocelulósicas, afirma que el contenido de lignina en las fibras está estrechamente relacionado con las propiedades mecánicas de paneles particulados, ya que la lignina contribuye en el mecanismo de adhesión de las partículas. 
En cuanto a la caracterización química, algunos autores han utilizado la técnica de análisis por fluorescencia de rayos $\mathrm{x}$, para determinar cuantitativamente la composición (porcentaje en peso) y la concentración de varios elementos químicos de las muestras. (Braz Mendes 2014). Autores como Barreto (2008) han verificado la presencia de iones metálicos como el $\mathrm{K}^{+}, \mathrm{Al}^{3+}, \mathrm{Cl}^{-}, \mathrm{Fe}^{3+}, \mathrm{Si}^{4+}, \mathrm{Ca}^{2+}$ en las fibras naturales de la bananera y el sisal, los cuales aumentan su peso en porcentaje debido a los tratamientos alcalinos realizados para potencializar la absorción de iones de metales tóxicos.

Marinho N. P. et al. (2013) ha desarrollado compuestos elaborados con partículas de bambú, los cuales han sido analizados por medio de termogravimetría, afirmando que la degradación de estos compuestos se da en una franja entre 120 y $250^{\circ} \mathrm{C}$. Es importante conocer el comportamiento termodinámico de estos compuestos, con el fin de conocer la temperatura de degradación de los mismos (Guimarães and Tannous 2014), ya que serán sometidos a altas temperaturas durante su transformación en laminados.

La hoja caulinar del bambú y el peciolo envainador de la hoja de la palmera son los compuestos lignocelulósicos utilizados en este proyecto, con el fin de ser transformados en revestimientos arquitectónicos.

\subsubsection{Hoja Caulinar del Bambú (Guadua angustifolia)}

Debido a su rápido crecimiento, las plantaciones de bambú, han recibido bastante atención, en el ámbito comercial. Dado que algunas especies pueden llegar a alcanzar su altura máxima en tan solo 45-90 días (Tian-Ming Yen, Yi-Jia Ji, and Joou-Shian Lee 2010). Dado el hecho que el bambú no es un árbol, es una gramínea que crece con el tamaño de su tronco definido. (Yu, L.Y. 1995). En este caso, el tamaño de este tronco define el tamaño de la hoja caulinar.

La mayoría de estudios relacionados al bambú son realizados en torno a las propiedades mecánicas del tallo (Jain, S., Kumar, R., and Jindal, U.C. 1992) (Ghavami and Marinho 2005b), el uso de las fibras en materiales compuestos (Khalil et al. 2012) y algunos a laminados de bambú a partir del tallo (Porras and Maranon 2012).

Las hojas caulinares son un residuo de la producción y la industrialización de los tallos del bambú. Por cada nudo del tallo del bambú se obtiene una hoja caulinar, como se aprecia en la Figura 3 (Izquierda).

La función principal de las $\mathrm{HCB}$ es proteger las gemas que originan las ramas basales de los tallos del bambú que crecen de los rizomas. Estas hojas revisten el entrenudo, hasta que la parte esencial del crecimiento del tallo se haya completado. (Rúgolo and Rodriguez 2002). O sea, en los primeros seis meses del crecimiento del tallo, las hojas también han completado su crecimiento. En este momento, las hojas se secan y comienzan a desprenderse del tallo (Figura 3 - centro). 

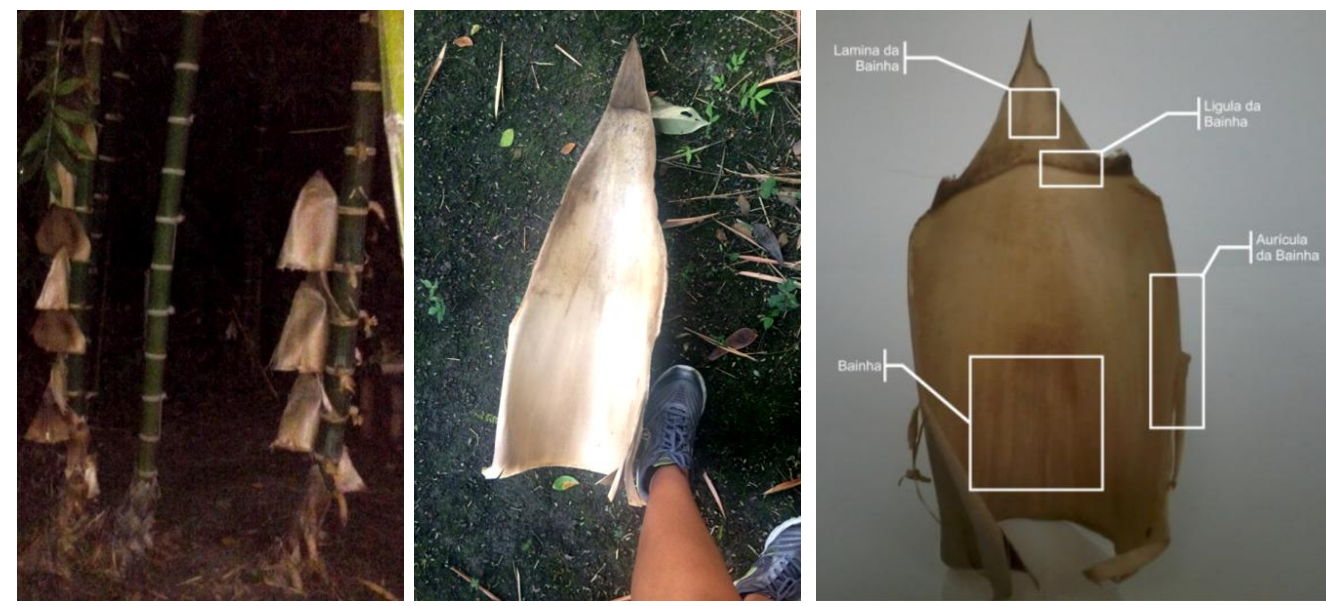

Figura 3 - Hoja Caulinar en el tallo del bambú (Izquierda). Hoja caulinar del bambú después de caer del tallo del bambú (Centro). Descripción morfológica de la hoja del bambú (Derecha).

La filotáxia de las hojas del bambú es altamente especializada (Figura 3 - Izquierda), buscando así, el mayor grado de protección del tallo, en su primera fase de crecimiento (Marinho 2012). A esto se debe las propiedades físico-químicas características de la hoja. Ya la hoja caulinar como tal posee cuatro partes: la lámina de la vaina y la lígula de la vaina en la parte superior, en el centro de la hoja está la vaina y en los extremos la aurícula (Figura 3 - Derecha).

Las hojas caulinares de bambú (HCB) son un residuo lignocelulósico, con grande potencial para la fabricación de revestimientos arquitectónicos, dadas sus características morfológicas, tales como: texturas físicas y visuales, semejanzas aparentes a la madera, colores y tonalidades. Estas características han sido poco estudiadas.

Para destacar, algunos proyectos comerciales y sociales se han realizado en algunas regiones asiáticas utilizando la $\mathrm{HCB}$. En algunas regiones asiáticas las HCB son procesadas y transformadas en empaques desechables para alimentos (Figura 4 Izquierda y Centro), los comercializadores cuentan en su descripción, que estas son usadas naturalmente y el acabado final es realizado a mano por artesanos. La Figura 4 Derecha, muestra el producto final del proyecto: Bamboo sheath cup making an innovative approach to tap the untapped $n r$. (Subhani Syed 2016), realizado en una villa cercana de la ciudad de Gaddana, India. Donde en conjunto con la comunidad se desarrollo una taza biodegradable a partir de las HCB.
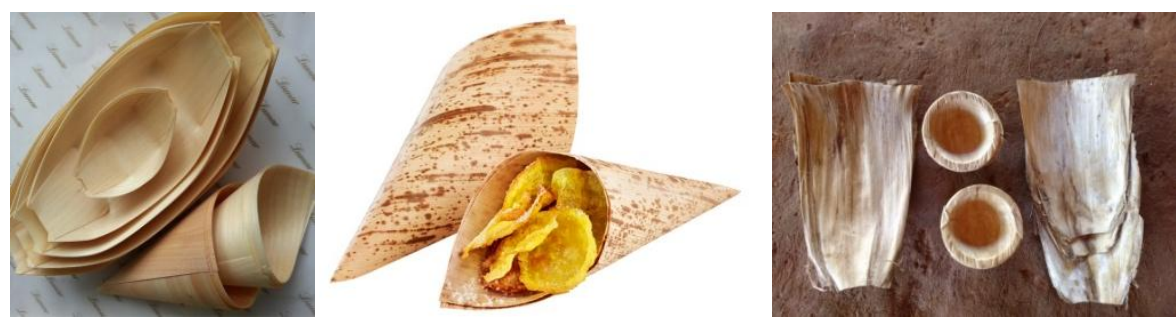

Figura 4 - Usos comerciales de la Hoja Caulinar del Bambú, principalmente en empaques desechables de comida, comercializados por panda bambú (Izquierda y Centro). (Derecha)

En la literatura científica, se encuentran trabajos como los de Peng et al. (2013) donde se han caracterizado las hojas del bambú, en general, con la finalidad de producir un 
polímero carbohidratado, por medio de degradación alcalina en medios acuosos. Del cual obtuvo como resultado 5 tipos de hemicelulosas, consideradas como una importante fuente de moléculas bio-activas, dado su alto contenido de polisacáridos.

Mientras que, autores como Zhu et al. (2013) han utilizado las hojas de bambú como fuente de carbono para sintetizar nanotubos de $6 \mathrm{H}-\mathrm{SiC}$, por medio de infiltración de tetraethyl orthosilicate (TEOS). Dado el comportamiento hidrófilo en la superficie superior y el comportamiento hidrófobo en la superficie interior de la hoja del bambú, estos autores han infiltrado las dos superficies. Obteniendo como resultado una estructura ramificada de $\mathrm{SiC}$ de alto rendimiento sobre la superficie hidrófila, mientras que en la superficie hidrófila se obtuvo una estructura organizada "semejante a los tallos del bambú".

Otros estudios, muestran las hojas caulinares de bambú trituradas han sido usadas con el fin de remover mercurio en superficies acuosas (Mondal, Nandi, and Purkait 2013), los resultados experimentales mostraron que estas se puede utilizar como un adsorbente eficaz para la eliminación de mercurio (II) a partir de los iones de soluciones acuosas.

Por otra parte, otros estudios demuestran que la biomasa de las plantaciones de bambú ha sido utilizada para la fabricación de filmes de celulosa de alto rendimiento, demostrando que la resistencia al agua y la estabilidad térmica mejoran con la presencia de la biomasa de bambú, ya que esta forma una excelente barrera al oxigeno (Song et al. 2015).

$\mathrm{Al}$ respecto del comportamiento termodinámico de las $\mathrm{HCB}$, algunos autores como Villar-Cociña et al. (2013), han estudiado las cenizas restantes del proceso de quema, para utilizarlas como puzolanas en materiales cementícios. Estos autores observaron altos contenidos de sílice en estas.

Aunque los estudios anteriormente nombrados se limiten a la caracterización de la composición química de la hoja, son datos importantes para corroborar la caracterización realizada en este proyecto, ya que permite confirmar resultados de los análisis químicas realizadas.

\subsubsection{Peciolo envainador de la hoja de la palmera real (Roystonea regia)}

La palmera es una planta de la familia Arecaceae (APG III 2009). Entre las plantas más conocidos de esta familia, son vulgarmente conocidas el coquero, la tamareira y el Jeriva. Las especies de la familia Arecaceae están distribuidas por el mundo entero, pero se centralizan en las regiones tropicales y sub-tropicales.

Las palmeras, de igual forma que el bambú, nacen con el diámetro de su tallo determinado (APG III 2009). Muchas de las especies de las palmeras son plantadas para obtener sus frutos, aceites y vinos. Otras especies son plantadas solamente para uso ornamental. 

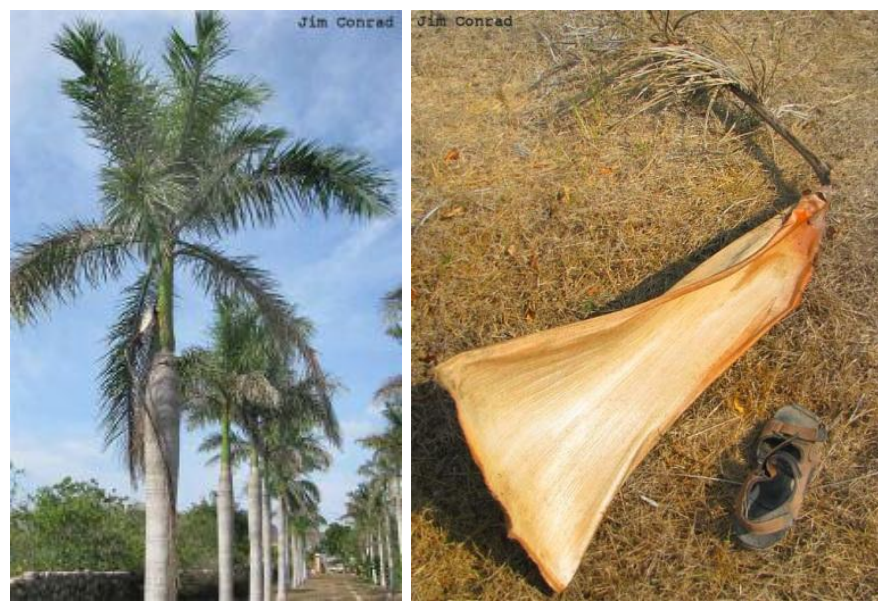

Figura 5 - Peciolo envainador de la hoja de la palmera real (Conrad 2012).

En botánica el peciolo envainador es la base de las hojas de las plantas, donde estas se ligan con el tallo. Este a su vez, forma un conjunto con otras hojas extendiéndose a lo largo del tallo y formando una envoltura alrededor de él (Figura 5 - .

En distintas regiones latino-americanas este peciolo envainador es conocido con el nombre de "yagua" o "parlote". El tamaño de este peciolo varía de acuerdo al diámetro del tallo de la hoja. En países como cuba el uso de este peciolo es tradicional en la construcción de tejados (Figura 6 - Izquierda); también es común que este peciolo sea utilizado en el empaque de cigarrillos (Figura 6 - Derecha).
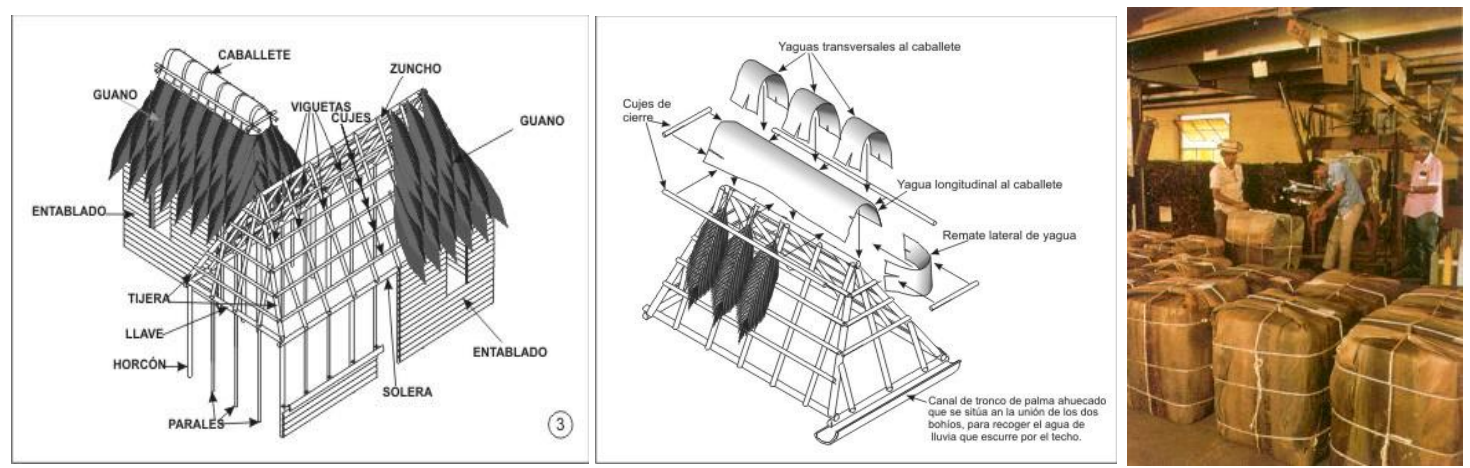

Figura 6 - Usos del peciolo de la palmera: Esquema de un bohío cubano (Izquierda y Centro). Envoltura de tabaco (Derecha).

En la literatura científica, se encuentran estudios sobre el uso de las fibras de la palmera, que se obtienen de las ramas, para ser utilizadas como refuerzo en polímeros. En el caso de Abu-Sharkh and Hamid (2004), el autor manifiesta un estudio de degradación térmico y mecánico, de los cuerpos de prueba sometidos a envejecimiento natural y acelerado, quien afirma que las fibras de la palmera le dan mayor estabilidad térmica y mecánica al polipropileno en las condiciones meteorológicas naturales de Arabia Saudita.

Otro autores como Kriker et al. (2005), quienes estudiaron el comportamiento mecánico de concreto reforzado con fibras de palmera, sometido a dos tipos de condiciones climáticas: clima caliente/seco y temperatura ambiente/humedad relativa promedio. 
Donde, demostraron que en clima caliente y seco disminuye la resistencia del material a medida que este envejece. Nuevamente, Kriker et al. (2008) analizó el concreto reforzado con fibras de palmera, pero en este caso fue investigada la durabilidad del material, al ser sometido en tres soluciones alcalinas diferentes, en las mismas condiciones climáticas (caliente y seco); mostrando como resultado la vulnerabilidad de las fibras al ataque alcalino.

El peciolo de la palmera, también ha sido estudiado con fines alimenticios. En el caso de Tramonte (2009) lo ha estudiado con el objetivo de investigar el jugo obtenido a partir del prensado del peciolo, para consumo humano en el mercado agroindustrial y de alimentos.

Otros estudios han sido realizados en cuestiones anatómicas de las fibras del peciolo de la palmera (Bendahou et al. 2007) y (Shengcheng Zhai et al. 2014), los cuales arrojan resultados físico-químicos de relevancia a la hora de realizar la caracterización e identificación morfológica de los residuos propuestos.

\subsection{Revestimientos arquitectónicos}

El mercado de los materiales para construcción civil posee una gran variedad de productos de acabado superficial. Estos productos pueden ser diseñados para exteriores o para interiores de edificios. La función principal de estos revestimientos es ofrecer protección y acabado superficial agradable para el usuario sobre la superficie de un edificio u obra de ingeniería. Estas superficies se utilizan inclinadas (paredes) o verticales (pisos) (Composite Panel Association 2016).

Los revestimientos son utilizados en la construcción civil para decorar paredes, columnas, forros, techos, pisos, etc. Y en el área de diseño de producto, estos revestimientos son utilizados para mobiliario, vehículos y diferentes objetos de uso cotidiano. Dada la gran versatilidad de uso estos están disponibles en un amplio rango de materiales, formas, texturas, brillos y mates (Composite Panel Association 2016). Revestimientos que buscan imitar la naturaleza, reproducir fielmente texturas visuales de la madera, el metal, piedras y pieles, ya sea por medio de impresión digital o diseños plasmados manualmente.

Los revestimientos pueden ser reproducidos por medio de diversas pinturas y tintas, placas metálicas, de maderas, cerámicas o de vidrio, laminados a base de celulosa y compuestos poliméricos a base de resinas o minerales.

Algunos revestimientos son diseñados para una aplicación específica. Atendiendo requisitos como la asepsia del espacio, tales como las superficies auto-limpiantes (Ragesh et al. 2014) confort visual, tales como los papeles decorativos (Gökay Nemli, Örs, and Kalaycıŏlu 2005) aislamiento acústico y/o térmico, tales como los paneles particulados (Martins Carvalho 2012; Vieira 2008). Por esto, propiedades como la resistencia, durabilidad, limpieza, etc. Son requisitos que definen las propiedades del material, dependiendo del contexto. 
La percepción visual de cualquier tipo de revestimientos arquitectónico es tan importante como su desempeño a largo plazo (Dias, M. R. A. C. 2009). Por lo tanto, es importante afirmar que los materiales llevan consigo un significado que es atribuido por el usuario a través de la experiencia (Karana 2010).

La durabilidad de los revestimientos arquitectónicos depende del entorno, contexto, ambiente. La Figura 7 ilustra la definición de ambiente, entorno y contexto que será utilizada en este proyecto. Sin embargo, características como la estética y apariencia, el uso y el mantenimiento son un factores importantes, que son definidos única y exclusivamente por el usuario.

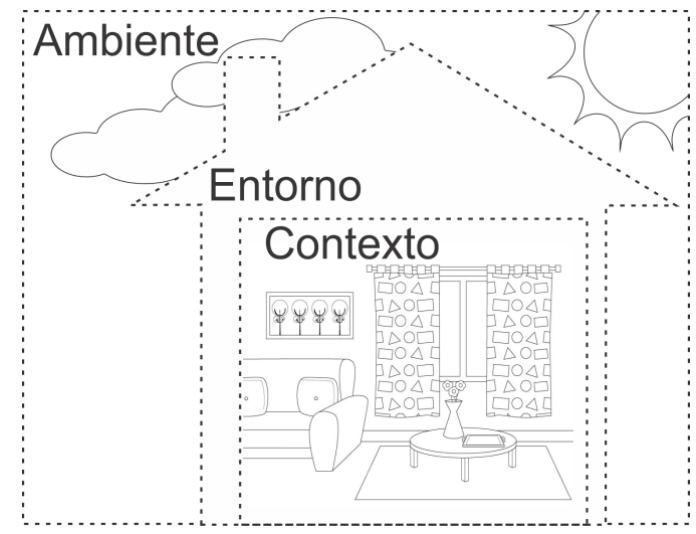

Figura 7 - Ambiente, entorno, contexto

La revisión bibliográfica sobre revestimientos arquitectónicos se centrará en el desempeño de dos tipos de revestimientos: chapas de madera y laminados melaminicos de alta presión.

\subsubsection{Chapas de madera (Wood veneer)}

Las chapas de madera natural son la superficie decorativa más común usada en la industria de laminación y se obtienen directamente de los troncos de madera virgen. Las chapas están disponibles en diversas especies de madera.

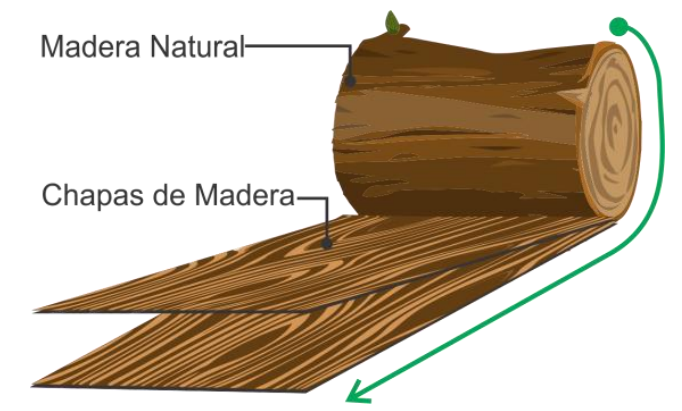

Figura 8 - Esquema representativo del conformado de las chapas de madera.

El substrato más utilizado para fijar las chapas son los paneles compuestos, como aglomerados de MDF y MDP debido a sus cualidades superficiales superiores, ya que son planos, lisos, uniformes, densos y sin nudos ni patrones de grano. Además de su estabilidad dimensional, propiedades de resistencia y ventajas de costos. Las chapas son 
rodajas finas entre 0,51 a $1,0 \mathrm{~mm}$; comercialmente no poseen un formato definido (Composite Panel Association 2016).

Las chapas pueden ser adheridas al substrato, ya sea con resinas activadas con calor o frío, por medio de prensado de las superficies. El adhesivo más utilizado en los sistemas de prensado en caliente es una resina a base de urea-formaldehido. La Figura 9 muestra la estructura química de la urea y el formaldehido, que por medio de la condensación, los átomos de la urea crean puentes metílicos, que eliminan el agua a partir del grupo carbonilo del formaldehido y de los átomos del hidrogeno de los grupos amino, se obtiene una estructura tridimensional semi-organizada, constituida por enlaces covalentes, que da origen a la urea-formaldehido Figura 10. La cual se caracteriza por ser un polímero rígido y termoestable, que actúa como aglutinante (IUPAC 2005).<smiles>NC(N)=O</smiles>

Figura 9 - Urea (Izquierda) Formaldehido (Derecha).
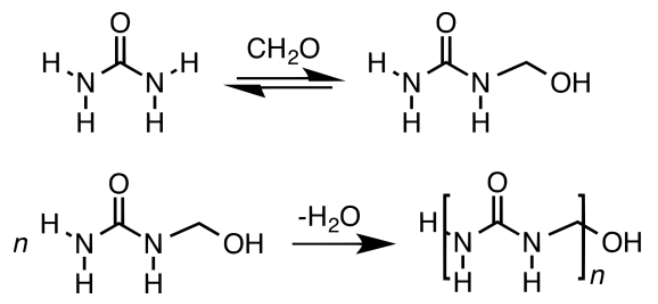

Figura 10 - Condensación de la Urea-formaldehido

El uso de adhesivos a base de urea-formaldehido es muy frecuente, debido a su capacidad para hacer el panel más rígido, los parámetros de procesamiento más rápidos y el substrato de menor costo.

No obstante, las regulaciones de las emisiones del formaldehido son ahora un tema importante en la industria (Composite Panel Association 2015). Ya que varios estudios evidencian que la emisión de compuestos orgánicos volátiles (COVs) dentro de un entorno cerrado pueden causar efectos adversos a la salud humana ( $\mathrm{Yu}$ and Crump 1998) (Wiglusz et al. 2002) (Kandelbauer et al. 2009).

Por esto, para fines comerciales, existen certificados otorgados a los fabricantes que adoptan procesos ambientalmente responsables, como: Certified Green y el GREENGUARD, los cuales muestran a los consumidores que estos productos poseen bajas emisiones de compuestos químicos volátiles. La norma que rige los ensayos de COVs es la ANSI/ASHARE 62, 1-2.007. El ensayo consiste en una sala de ocupación individual, donde se verifica la calidad del aire interna y la calidad del aire de la ventilación externa.

Una tendencia global en el mercado de los adhesivos, son los adhesivos poliuretanos que se obtienen de fuentes renovables, como lo son los aceites de base vegetal o NOPs por su sigla en ingles Natural oil polyols. Los cuales son utilizados en función de la 
substitución parcial de las materias-primas petroquímicas, evitando el uso de formaldehidos.

La Figura 11 representa la polimerización de una resina poliuretana común y la Figura 12 muestra la polimerización de una resina poliuretana a base de aceite de ricino, donde el polioles del aceite de ricino substituye los polioles de poliéter convencionales usados no poliuretano convencional. En este caso las hidroxilas $(\mathrm{OH})$ son los principales son el principal intermediario entre los polioles (Vilar 1998).

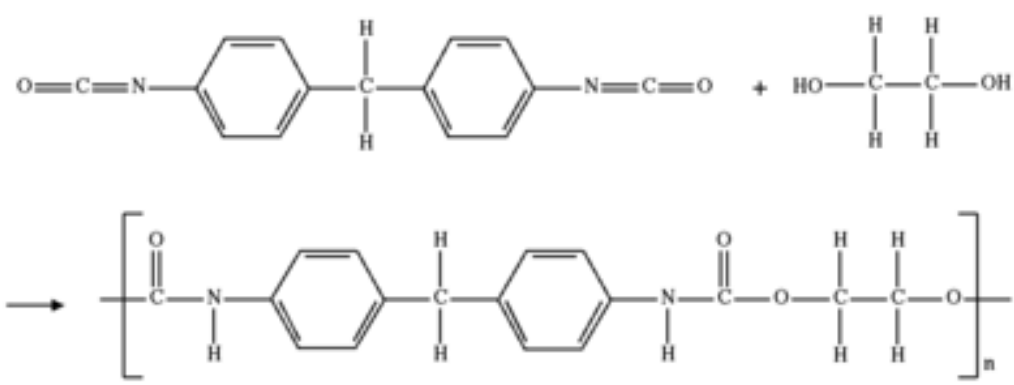

Figura 11 - polimerización de una resina poliuretano común con enlaces uretanos.

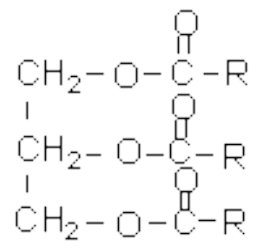

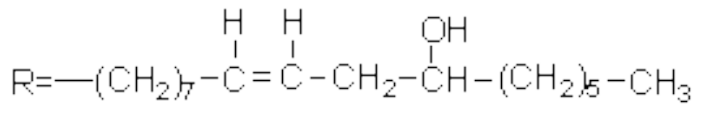

Figura 12 - polimerización de una resina poliuretana a base de aceite de ricino

Finalmente, los adhesivos juegan un papel muy importante no solamente en la aglomeración de las partículas, si no, en las características y las propiedades que pueden atribuir a las superficies.

Por esto, la asociación de paneles compuestos, cataloga el desempeño de las superficies de los materiales compuestos en los siguientes ítems: resistencia a las manchas, abrasión, humedad, desgaste, impacto, deformación y resistencia microbiana.

En el caso de las superficies utilizadas en espacios interiores la resistencia a la humedad hace parte fundamental de su desempeño. Autores como Nadir Ayrilmis et al. (2009) han evaluado las características de humectabilidad midiendo el ángulo de contacto de una gota de agua destilada sobre la superficie de los laminados. Demostrando que a medida que la temperatura de secado de la superficie aumenta el ángulo de contacto también aumenta.

Otros estudios, enfocados a mejorar el desempeño de las superficies, centran sus trabajos en la impregnación de la superficie de los laminados utilizando resinas a base de fenol formaldehido, obteniendo como resultado mejorías en la estabilidad dimensional y la resistencia al impacto, dado el aumento en el módulo de elasticidad (Wang and Chui 2012). 
Otro punto importante con respecto al desempeño, es la fotodegradación causada por la propagación de los rayos UV en la superficie de los revestimientos, la cual acelera la degradación del color y la pigmentación de la madera. Estudios como los de Liu et al. (2015) han identificado la conexión entre la longitud de onda y los cambios en el color de la superficie y el cambio de la estructura química dado por la degradación causa por los rayos UV.

Otro ejemplo, es el de Patachia, Croitoru, and Friedrich (2012) quienes trataron las chapas de chapas de madera de álamo con cuatro tipos de líquidos iónicos basados en alquilimidazolio (ILs), obteniendo como resultado el incremento de la humectabilidad y de la resistencia a los rayos UV, debido a la preservación de la cristalinidad de la celulosa en altos niveles de radiación UV.

El foco de la innovación en este tipo de laminados se centra en los incompuestos antibacteriales, para aumentar la durabilidad de la superficie del material y reducir las emisiones de COVs que degradan los adhesivos y las fibras del compuesto (Chen et al. 2016).

\subsubsection{Laminados melamínicos de alta presión.}

Los laminados melamínicos de alta presión son una fina superficie decorativa. Estos laminados son adheridos a paneles de partículas, como: MDF o MDP. Representando aproximadamente el 5\% del producto final acabado. Con la finalidad de crear una cubierta de acabado al material de base ofreciendo un alto desempeño en soluciones de diseño (Composite Panel Association 2015).

Siendo aptos para distintos contextos: como cocinas, mobiliarios para ambientes húmedos, laboratorios y restaurantes (Barash, L. 2008) (Dombo, B., Stijnen, B., and Nusselder, J. 2010). En el mercado se encuentran en diversas gamas de colores y texturas sólidas que simulan la apariencia de la madera.

Según O’Carroll C (2004), 70\% de las placas de madera manufacturadas, son cubiertas con laminados melamínicos de alta presión, para fines decorativos y de protección, el resto de las placas son acabadas con chapas de madera, películas termoplásticas y pinturas.

Convencionalmente, están formados por tres capas distintas de papeles impregnados de resina, los cuales son prensados a alta temperatura y presión hasta la resina ser curada. (Barash, L. 2008; Dombo, B., Stijnen, B., and Nusselder, J. 2010).

La Figura 13 muestra un esquema representativo de un laminado de alta presión, el cual está compuesto por varias capas de papel kraft impregnado y saturado de resina melamínica, las capas de papel kraft dependen de la espesura final del laminado, una capa de papel decorativo y un overlay que funciona como capa protectora (Figueiredo et al. 2011). 
Las resinas adhesivas utilizadas en los laminadas de alta presión, son básicamente la resina fenólica y la resina melamínica.

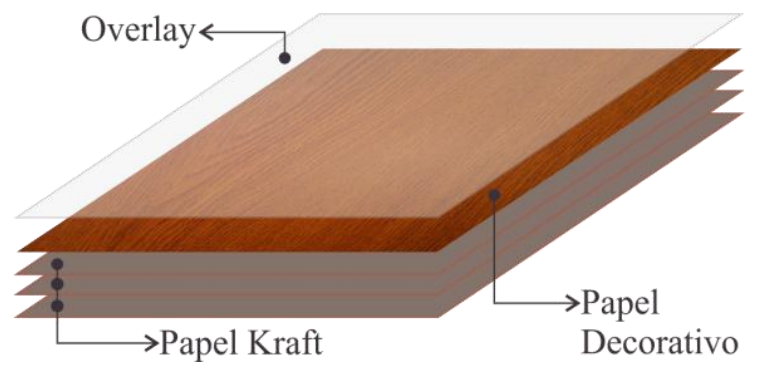

Figura 13 - Esquema representativo de la composición de un laminado de alta presión a base de papel kraft impregnado, papel decorativo impreso e impregnado y overlay $99 \%$ celulosa.

La resina fenólica es utilizada en la impregnación del papel kraft, usado en el núcleo del laminado. Esta resina, es un compuesto fenólico, del cual su materia prima es el fenol (grupo hidroxilo) que está unido directamente al formaldehído (hidrocarboneto aromático).

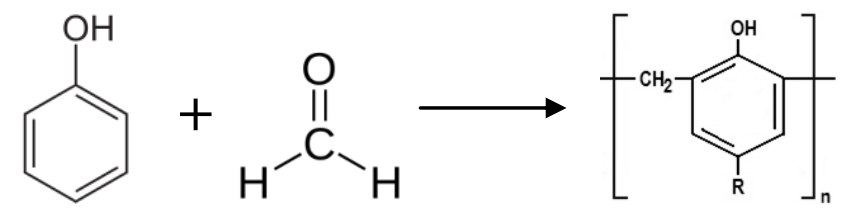

Figura 14 - Reacción química entre el fenol (grupo hidroxilo) y el formaldehído (grupo hidrocarboneto aromático). Resultado monômero de resina fenólica.

La resina melamínica es utilizada en la impregnación del papel decorativo, debido a la posibilidad de ser fabricadas en cualquier color, ya que es incolora y transparente. Esta resina está compuesta por moléculas de formaldehído y melamina (Figura 15). La cual por medio de condensación, se obtiene un material termo-rígido y duro (IUPAC 2005).<smiles>CCNc1nc(NCC(C)(C)C)nc(NC(C)(C)C)n1</smiles>

Figura 15 - Polimerización de la melamina con el formaldehido, por medio de condensación reaccionan formando un monómero de resina melamínica formaldehído

La cantidad de capas de papel kraft pueden variar, dependiendo de la aplicación del laminado. De igual forma que el gramaje y el porcentaje de impregnación de la resina. En este tipo de papel, la porosidad es altamente controlada, para así mismo poder controlar la absorción de la resina. El gramaje del papel varía entre 80 a $120 \mathrm{gr} / \mathrm{cm}^{2}$. Industrialmente, después de la impregnación del papel, la resina es secada y curada a altas temperaturas en cuestión de segundos. Después de esto, el papel impregnado queda totalmente maleable y puede ser provisionado de nuevo en grandes rollos. 
La capa intermedia del laminado es llamada: capa de papel decorativo, la cual es usualmente una hoja de papel impreso en colores sólidos o distintos diseños. El papel decorativo de color sólidos pasa a través de unos "pisadores" que lo impregnan con una resina melamínica que le proporciona mayor durabilidad, lo que es esencial para que esta capa de papel decorativo resista al desgaste, la abrasión y la ruptura. (Gokay Nemli 2016). Debido a esto el papel decorativo exige extrema pureza y es producido solamente en pequeños gramajes $\left(50-150 \mathrm{~g} / \mathrm{m}^{2}\right)$.

Por último, la capa final denominada "overlay", es una capa transparente de papel $(99 \%$ celulosa pura) que es saturada con resina melamínicas. Esta capa es la encargada de proteger el papel decorativo permitiendo la visualización del mismo. El gramaje de este papel oscila entre $18-50 \mathrm{~g} / \mathrm{cm}^{2}$. Las capas decorativas de colores sólidos no necesitan del overlay, puesto que son impregnadas con resina melamínica. La impregnación de la resina y la celulosa ("overlay") en el papel decorativo, debe poder el mismo índice de refracción del papel, lo que significa que las fibras de celulosa deben ser invisibles al ojo humano y solo los pigmento del papel decorativo deben aparecer (Gokay Nemli 2016).

En el proceso de laminación, la temperatura de prensado en fábrica oscilan entre los 120 y $135^{\circ} \mathrm{C}$. Según especificaciones de las resinas en uso. Y la presión de trabajo, es definida por la Ecuación 1

$$
\begin{gathered}
T=\frac{\text { Area material }(\text { cm }) \times \text { Presión especifica }(\text { Kgf })}{\text { Diametro del Pistón }(\text { cm })} \text { Ecuación } 1 \\
T=\frac{\text { Area material }(\text { cm }) \times \text { Presión especifica }(\text { Kgf })}{\text { Diametro del Pistón }(\mathrm{cm})}
\end{gathered}
$$

La Ecuación 1, depende del área del material, la presión específica (definida por las propiedades del material) y el diámetro del pistón de la prensa. La Ecuación 1 fue suministrada por la empresa proveedora de papel kraft impregnado que colaboró en este proyecto.

Después del proceso de prensado a alta temperatura, el material es curado dentro de la misma prensa. Para este proceso de curado la temperatura de la prensa es resfriada y llevada a temperatura ambiente ( $25 \pm 3$ aprox.). El proceso de prensado y curado es realizado en aproximadamente $40 \mathrm{~min}$.

La presión de los laminados de alta presión, está en un rango de 8,4 hasta $14 \mathrm{MPa}$. Mientras que, los laminados de baja presión son prensados a una presión entre 2,8 a 8 MPa (Cyril Harris 2005).

Dentro de las referencias bibliográficas más recientes, encontradas en la literatura, sobre el desarrollo de laminados de alta y baja presión a escala de laboratorio, donde se utilizan papeles pre-impregnados por un proveedor comercial, y se exploran diferentes índices de impregnación y gramajes de papel, siendo caracterizados por medio de ensayos físicos-mecánicos, los cuales determinan el rendimiento de los laminados proyectados experimentalmente. Algunos trabajos de la literatura son citados en la 
Tabla 1 - Referencias bibliográficas sobre conformado de laminados decorativos de alta presión en laboratorio. se puede percibir que el tema estético no es de importancia en ninguno de estos trabajos, puesto que en ninguno de los trabajos se realizan ensayos qualitativos.

En los fabricantes brasileros son adoptadas normas internacionales tales como la ISO 4586-1/2 (ISO 2004) y la NEMA - LD3 (ANSI/NEMA 2005), que responden a cuestiones técnicas tales como la espesura, dimensiones, resistencia al impacto, resistencia a manchas, resistencia al desgaste, estabilidad dimensional a alta temperatura, estabilidad dimensional a $25^{\circ} \mathrm{C}$, resistencia à alta temperatura, resistencia a la inmerso en agua hirviendo, resistencia a luz de xenón, estabilidad dimensional, resistencia a burbujas e índice de propagación de llama, esta última sigue la norma nacional ABNT NBR 94421988.

Por otro lado, las normas anti-hongos son comunes en este tipo de laminados. Aunque no todos los fabricantes adoptan la iniciativa de fabricar productos con atributos antifungos. Por lo tanto, fabricantes como Maica Laminates e Formica utilizan aditivos anti-bacteriales en la producción de sus laminados. 
Tabla 1 - Referencias bibliográficas sobre conformado de laminados decorativos de alta presión en laboratorio.

\begin{tabular}{|c|c|c|c|c|c|c|}
\hline \multirow[b]{2}{*}{ Autor } & \multirow{2}{*}{$\begin{array}{c}\text { Compañía } \\
\text { proveedora de } \\
\text { papel }\end{array}$} & \multirow{2}{*}{$\begin{array}{l}\text { Porcentaje de } \\
\text { Impregnación } \\
\text { de Resina (\%) }\end{array}$} & \multicolumn{4}{|c|}{ Factores de nivel del conformado de los laminados } \\
\hline & & & $\begin{array}{c}\text { Temperatura } \\
\text { Prensado } \\
\left({ }^{\circ} \mathbf{C}\right)\end{array}$ & $\begin{array}{c}\text { Tiempo } \\
\text { (m) }\end{array}$ & $\begin{array}{l}\text { Presión } \\
\text { (MPa) }\end{array}$ & $\begin{array}{c}\text { Temperatura. } \\
\text { Curado }\left({ }^{\circ} \mathbf{C}\right)\end{array}$ \\
\hline $\begin{array}{l}\text { (Y. Liu, } \\
\text { Shen, and } \\
\text { Zhu 2015) }\end{array}$ & $\begin{array}{c}\text { Daregolbal } \\
\text { Wood-based } \\
\text { Panels } \\
\text { Corporation } \\
\end{array}$ & $53 \%$ MUF & $170,180,190$ & $\begin{array}{c}40,50 \\
60\end{array}$ & $2 ; 2,5 ; 3,5$ & -- \\
\hline $\begin{array}{c}\text { (Ayfer } \\
\text { Dönmez } \\
\text { Çavdar et al. } \\
\text { 2013) }\end{array}$ & $\begin{array}{c}\text { Kastamonu } \\
\text { Integrated } \\
\text { Wood Industry }\end{array}$ & $\begin{array}{l}50 \% \text { Resina } \\
\text { melaminica, } \\
3.5 \% \mathrm{Al} 2 \mathrm{O} 3\end{array}$ & 150 & 8 & 2,5 & 20 \\
\hline $\begin{array}{c}\text { (Gökay } \\
\text { Nemli and } \\
\text { Usta 2004) }\end{array}$ & $\begin{array}{l}\text { Fabricado in- } \\
\text { situ }\end{array}$ & $\begin{array}{c}51 \% \text { and } 53 \% \\
\text { MUF }\end{array}$ & 190 & 25 & 2,5 & 20 \\
\hline $\begin{array}{l}\text { (Ayrilmis } \\
\text { 2012) }\end{array}$ & $\begin{array}{c}\text { Kastamonu } \\
\text { Integrated } \\
\text { Wood } \\
\text { Company }\end{array}$ & $\begin{array}{l}54 \% \text { MUF, } \\
50 \% \text { UF }\end{array}$ & 180 & 5 & 3 & $6 \%$ humedad \\
\hline $\begin{array}{l}\text { (Wang, S.- } \\
\text { Y. et al. } \\
\text { 2007) }\end{array}$ & $\begin{array}{c}\text { Jen-Chun } \\
\text { Enterprises in } \\
\text { Feng-Yuan, } \\
\text { Taiwan and } \\
\text { Tai-Lin Resin, } \\
\text { Taipei, Taiwan }\end{array}$ & $\begin{array}{c}0,20,30,50, \\
70,80,100,50 \\
\text { PF }\end{array}$ & 180 & 5 & 2,9 & -- \\
\hline $\begin{array}{l}\text { (Alpár and } \\
\text { Winkler } \\
\text { 2006) }\end{array}$ & $\begin{array}{l}\text { Proveedores } \\
\text { comerciales }\end{array}$ & $61,25 \mathrm{UF}$ & 180 & 30 & 4,5 & -- \\
\hline $\begin{array}{c}\text { (Istek and } \\
\text { Aksu 2010) }\end{array}$ & $\begin{array}{l}\text { Fabricado in- } \\
\text { situ }\end{array}$ & $\begin{array}{c}100 \% \mathrm{UF}, \\
100 \% \mathrm{MF}, \\
\text { and } 55 \%, \mathrm{UF} \\
\text { plus } 45 \% \mathrm{MF}\end{array}$ & $140-145$ & 40 & 2,5 & 120,160 \\
\hline $\begin{array}{c}\text { (Yu Liu and } \\
\text { Zhu 2014) }\end{array}$ & $\begin{array}{c}\text { Proveedores } \\
\text { comerciales en } \\
\text { China }\end{array}$ & $53,6 \% \mathrm{MF}$ & 170 & 45 & 3 & 130 \\
\hline $\begin{array}{l}\text { (Roberts and } \\
\text { Evans 2005) }\end{array}$ & $\begin{array}{c}\text { Fabricado in- } \\
\text { situ }\end{array}$ & $25 \% \mathrm{UF}$ & 182 & 30 & 10 & 125 \\
\hline $\begin{array}{l}\text { (Bardak et } \\
\text { al. 2011) }\end{array}$ & $\begin{array}{c}\text { Proveedores } \\
\text { comerciales en } \\
\text { Turquia }\end{array}$ & $55,00 \%$ UF & 185 & -- & 2,6 & 25 \\
\hline $\begin{array}{l}\text { (Figueiredo } \\
\text { et al. 2011) }\end{array}$ & $\begin{array}{c}\text { Diferentes } \\
\text { productores de } \\
\text { papel en Norte } \\
\text { America y } \\
\text { Europa }\end{array}$ & PF $62,8 \%$ & $120-150$ & 80 & 5,$5 ; 10,3$ & $\begin{array}{l}\text { "cooling } \\
\text { cycle" }\end{array}$ \\
\hline (Yang 2015) & Kapton ${ }^{\circledR}$ & $\begin{array}{c}52,58,62, \\
73 \% \\
\text { copolimeros } \\
\text { de etileno y } \\
\text { octeno }\end{array}$ & $180-190$ & -- & 3,36 & 10 \\
\hline
\end{tabular}

Estas referencias ayudaron a delimitar los parámetros de laminado para los ensayos experimentales con los diferentes substratos. A continuación la metodología utilizada en cada uno de los experimentos. 


\section{Metodología}

La metodología utilizada en esta disertación está dividida en tres partes (Figura 16), comenzando con la caracterización físico-quimia de la Hoja Caulinar del Bambú (HCB) y el Peciolo de la hoja de la Palmera (PHP).

En el segundo ítem de la metodología, se encuentra el prototipo de fabricación del revestimiento, el cual se divide en pre-tratamientos y producción del laminado.

Finalmente la caracterización del revestimiento, realizada por medio de ensayos físicoquímicos.

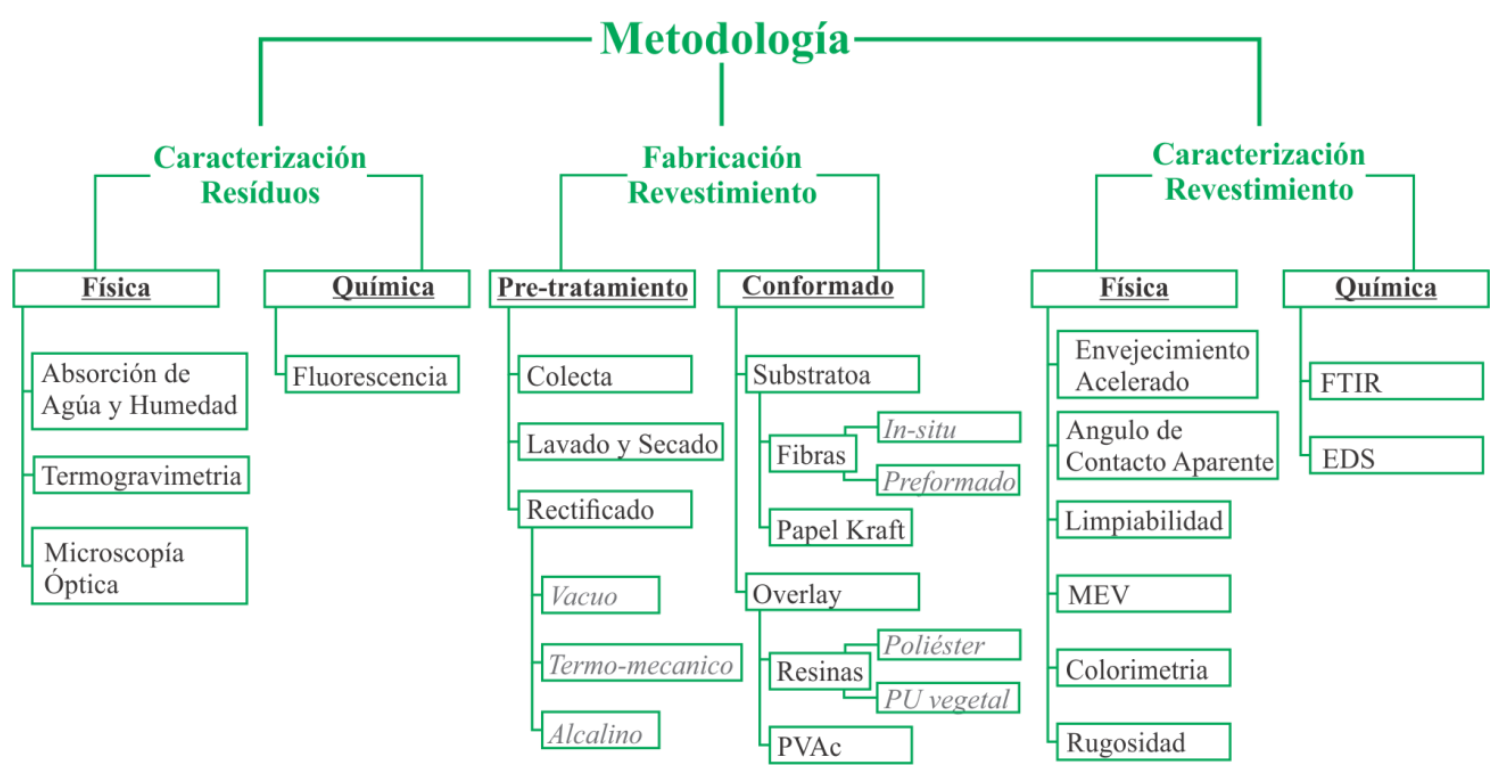

Figura 16 - Flujograma representativo de la metodología aplicada en el proyecto

\subsection{Caracterización de los residuos in-natura.}

Las hojas caulinares del bambú y los peciolos envainadores de la hoja de la palmera utilizados en todos los experimentos, fueron colectados en la Universidad de Sao Paulo, campus principal. Las hojas se lavaron con agua común del acueducto municipal para eliminar impurezas en la superficie. Se secaron a $103 \pm 2{ }^{\circ} \mathrm{C}$. Posteriormente se almacenaron en condiciones de laboratorio, durante 48 horas. Este proceso, es el inicial para todos los ensayos físicos, químicos y mecánicos descritos de aquí en adelante.

Los ensayos de caracterización física se realizaron en el laboratorio de microestructura y eco-eficiencia del departamento de ingeniería civil. Los ensayos de caracterización química se realizaron en el laboratorio caracterización tecnológica del departamento de ingeniería de minas y petróleos. Ambos laboratorios en ubicados en la Escola Politecnica, de la Universidade de São Paulo, campus principal. El proceso de fabricación y laminados de los revestimientos se llevo a cabo en el laboratorio de 
construcciones y ambiencia de la facultad de zootecnia e ingeniería de alimentos de la Universidade de São Paulo, campus Piranunsunga, SP.

\subsection{1 Índice de humedad}

Para determinar el contenido de humedad $(\mathrm{H}), 10$ cuerpos de prueba de cada residuos, fueron dimensionados en especímenes de 50x50mm según la norma brasilera NBR 14810-3. Estos fueron pesados individualmente en una balanza semi-analítica con resolución de $0,1 \mathrm{gr}$. El dato de esta masa inicial fue tomado como masa húmeda.

Después de esto, los cuerpos de prueba fueron colocados en un horno para secar. Partiendo de una temperatura ambiente $(23 \pm 2)^{\circ} \mathrm{C}$ hasta alcanzar los $(103 \pm 2)^{\circ} \mathrm{C}$.

Después de 4 horas en el horno, las muestras son pesadas nuevamente, este valor es tomado como masa seca. La determinación del contenido de humedad fue realizada según la Ecuación 2.

Ecuación 2

$$
H=\frac{M_{H}-M_{S}}{M_{H}} \times 100
$$

Donde: $\mathrm{H}=$ Contenido de Humedad $(\%), \mathrm{M}_{\mathrm{H}}=$ Masa humedad, $\mathrm{Ms}=$ Masa seca.

Con el fin de determinar la cantidad de agua por unidad de masa en las muestras secas. Ya que la humedad puede estar presente como humedad adsorbida en las superficies internas y como agua condensada capilarmente en los poros pequeños. La determinación del contenido de humedad natural en las HCB y el PHP ayuda a Este dato es importante para la interpretación de los datos en los análisis termo gravimétricos.

\subsubsection{Termogravimetría}

El análisis termo gravimétrico posibilita conocer las alteraciones termodinámicas provocadas en el material durante el proceso de quema, demostrando así como los cambios de temperatura pueden degradarlo.

El análisis fue realizado en una termo-balanza de marca Netzsch STA 409, sobre atmosfera de nitrógeno, la taza del flujo de gas en la atmosfera fue de 20mil/min, la taza de conductividad térmica del gas de arrastre fue de 60 mil y el rango de temperatura de calor fue de 30 a $600^{\circ} \mathrm{C}$. se utilizaron 3 cuerpos de prueba de cada residuos dimensionados en $1 \times 1 \mathrm{~mm}$.

\subsubsection{Fluorescencia de rayos $X$}

Para llevar a cabo el análisis químico por medio de fluorescencia de rayos $\mathrm{X}$, los cuerpos de prueba utilizados fueron calcinados, cenizas de las cuales se utilizaron 200 gr. de cada muestra, previamente trituradas. Con la finalidad de determinar la cantidad 
de material volátil presente en las muestras. La pérdida al fuego se realizada a $800^{\circ} \mathrm{C}$ durante $1 \mathrm{~h}$.

El análisis por fluorescencia fue realizado en un espectrómetro de fluorescencia de rayos X (Philips PW2400) y simultáneamente el software Venus 100 Minilab para análisis cuantitativa.

\subsubsection{Microscopia Electrónica de Barredura y EDS}

Las imágenes fueron tomadas en un microscopio electrónico de barredura con detector de EDS de marca FEI Quantas 600, ubicado en el laboratorio de caracterización tecnológica del departamento de Ingeniería de Minas y Petróleo de la Universidad de São Paulo.

En este caso, las muestras fueron fracturadas por un medio químico, con nitrógeno y alcohol para la evaluación de su división anatómica vascular. La superficie de las muestras fue recubierta con hilo de carbono.

\subsubsection{Microscopia Óptica Digital}

Las imágenes de la superficie de las HCB y el PHP fueron evaluadas cualitativamente por medio de microscopia óptica digital (HIROX KH-7700) con diferentes ampliaciones y utilizando la herramienta de barrido 3D, esta última utilizando siempre

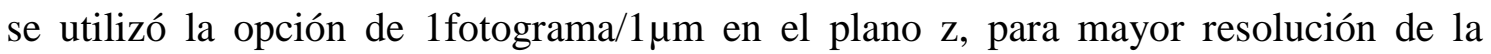
imagen.

\subsubsection{Envejecimiento acelerado}

El ensayo de envejecimiento acelerado fue realizado en una cámara QUV/se (Q-Lab) operada de acuerdo a la norma ASTMG154-06. Las 10 de cada superficie (40 cuerpos de prueba) fueron expuestas a 104 horas continuas de radiación $\left(0,95 \mathrm{~W} / \mathrm{m}^{2}\right)$, distribuidas en tres ciclos, descritos en la Tabla 2 los cuales se repitieron 8 veces.

Tabla 2 - Ciclos de envejecimiento acelerado

\begin{tabular}{ccc}
\hline Ciclo & Temperatura & Horas \\
\hline UV & 60 & 8 \\
Oscurecimiento & 30 & 1 \\
Condensación & 40 & 4 \\
\hline
\end{tabular}

La degradación de los cuerpos de prueba se midió, comparando las medidas del Angulo de contacto color, Angulo de contacto aparente, y FTIR, antes y después del envejecimiento acelerado.

\subsubsection{Colorimetría}

Para la evaluación del color se utilizó un colorímetro (BYK-Gardner-Color Guide 45/0), el cual función con el sistema CIE L*a*b* (Figura 17). 


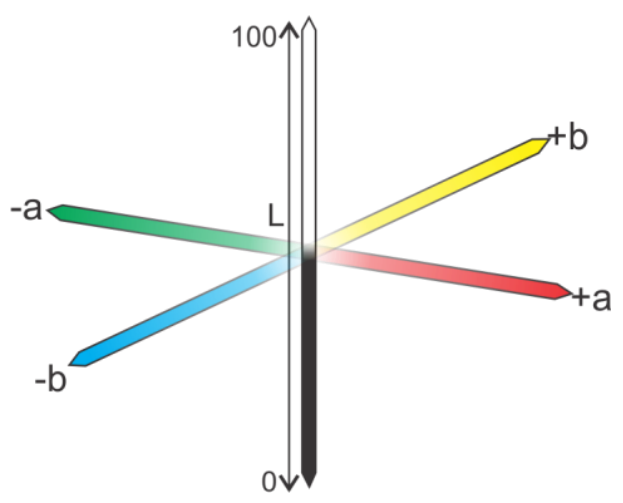

Figura 17 - Sistema de medición del color CIELab

Cada parámetro de este sistema representa una determinada variación del color: el eje L representa la luminosidad, la cual varia de 100 (blanco) a 0 (negro), el eje a y b representan las coordenadas cromáticas, de la siguiente forma: +a para rojo, -a para verde, $+\mathrm{b}$ para amarillo $\mathrm{y}-\mathrm{b}$ para azul.

Estas coordenadas de color se midieron antes después del envejecimiento acelerado de las superficies. Se realizaron cinco medidas por cada una de las muestras de $7 \times 5 \mathrm{~cm}$.

La diferencia de color $(\Delta E)$ fue determinada de acuerdo a la norma ASTMD2244-14, utilizando la siguiente formula Ecuación 3.

Ecuación 3

$$
\begin{gathered}
\Delta L=L_{i}-L_{f} ; \\
\Delta a=a_{i}-a_{f} ; \\
\Delta b=b_{i}-b_{f} \\
\Delta E=\sqrt{(\Delta L)^{2}+(\Delta a)^{2}+(\Delta b)^{2}}
\end{gathered}
$$

Donde, $\Delta L, \Delta a, \Delta b$, son los cambios entre los valores iniciales y finales de la medición (Turkoglu, Baysal, and Toker 2015).

\subsubsection{FTIR}

Para la obtención del espectro infrarrojo de absorción y emisión de la superficie de los residuos, con el fin de conocer los grupos funcionales asociados a cada superficie, se utilizado un espectrómetro de FTIR (Fourier Transform Infrared-Photoacoustic Spectroscopy) Nicollet 6700, con detector DTGS. Ubicado en el laboratorio de caracterización micro-estructural de materiales no metálicos del departamento de Ingeniería de Materiales de la Escola Politécnica de la USP.

El equipo se utilizó en el modo DRIFT (difusión de la reflectancia), el espectro fue medido en la región de 400 a $4000 \mathrm{~cm}^{-1}$ de la longitud de onda, con una resolución de $4 \mathrm{~cm}^{-1}$. Se utilizaron 5 cuerpos de pruebas de cada superficie (20 cuerpos de prueba) dimensionados en $1 \times 1 \mathrm{~mm}$. 
Se utilizaron comandos del software del equipo, como alineamiento de la línea base (FLAT) y la suavización de los ruidos (SMOOTH).

\subsection{9 Ángulo de contacto aparente}

Durante su ciclo de vida natural, antes de las hojas caer secas de los árboles, la superficie interna se encontraba en contacto directo con el tallo de la planta y la superficie externa se encuentra expuesta a la intemperie, por ende al envejecimiento natural. La humectabilidad de la superficie fue medida en ambas superficies (Externa e Interna) de la HCB y el PHP, y debido a la orientación de las fibras, la cual es diferenciada en ambos residuos, el Angulo de contacto fue medido en ambos sentidos de orientación de las fibras (Figura 18). Se utilizaron 10 cuerpos de prueba de cada residuo.

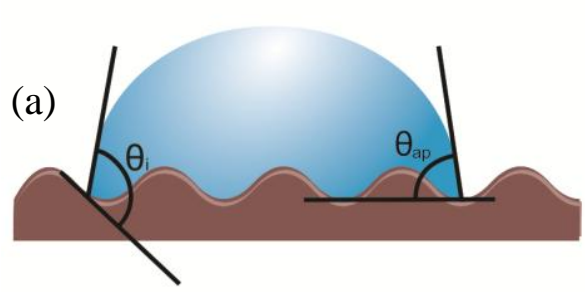

(b)

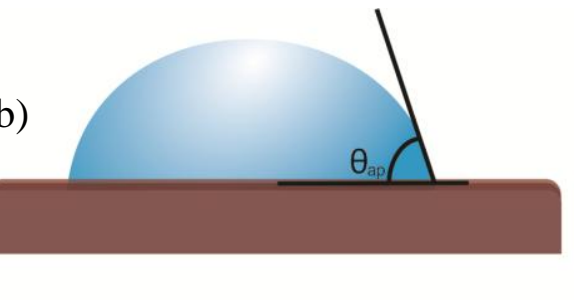

Figura 18 - Medidas del Angulo de contactos realizados en ambos sentidos de orientación de las fibras (a) perpendicular (b) paralelo.

La determinación del ángulo de contacto aparente fue realizada con un goniómetro de marca Kruss - DSA 100, utilizando el método de la gota colocada (sessile drop).

Utilizando agua deionizada con tensión superficial de $0,0072 \mathrm{~N} / \mathrm{m}$. Una gota de $10 \mu \mathrm{L}$ de volumen fue depositada en el substrato y monitoreada por un periodo de 600 segundos, este proceso se repitió 10 veces en cada superficie en los dos sentidos de orientación de las fibras. La lectura de los datos se realizó en intervalos regulares de 15 segundos. Los datos se obtuvieron automáticamente por el software del equipo (DSA1).

\subsection{Fabricación de los Revestimientos}

\subsubsection{Pre-tratamiento de los residuos}

En este ítem se realizaron varios ensayos para definir el pre-tratamiento adecuado de los residuos, antes del proceso de laminación. Este tratamiento consiste en determinar el método adecuado para preservar la apariencia estética de la superficie, tal como texturas, colores y tonalidades.

\subsubsection{Colecta}

La colecta de las hojas se hizo en los bambús y palmeras ornamentales, en las laderas del Campus Butantã, campus principal de la Ciudad Universitaria de la USP. Se recolectaron más de 100 hojas de diferentes dimensiones. Se recogieron aleatoriamente, seleccionando visualmente aquellas que su superficie aparentaba estar conservada. 
De la colecta de las hojas de la palmera solamente fueron recogidas 20 hojas, que ya se encontraban en el suelo, obteniendo el peciolo de cada una de estas. Cada peciolo excedía los $100 \mathrm{~cm}$ de largo, por lo que fue cortada en secciones de $40 \times 40 \mathrm{~cm}$ para una manipulación más cómoda en el laboratorio.

Estas dos colectas se realizaron, durante todo el año en el periodo de febrero a septiembre. Meses que presentaron mayor floración de las especies fueron abril y mayo.

\subsubsection{Lavado y secado}

Las hojas caulinares y los peciolos recogidos fueron lavados con agua de la red pública en el laboratorio y su superficie fue suavemente fue rozada con una esponja común para retirar la mayor cantidad de impurezas posible.

El secado se realizó en hornos de laboratorio partiendo de una temperatura de (23 $\left.\pm 2^{\circ} \mathrm{C}\right)$ hasta alcanzar $\left(103 \pm 2^{\circ} \mathrm{C}\right)$. Cuando el agua de la superficie fue totalmente evaporada.

Después del secado, los residuos fueron estabilizados, en condiciones de laboratorio, con $65 \pm 5 \%$ de humedad relativa y temperatura ambiente.

\subsubsection{Proceso de Rectificado}

Dado el hecho que estos residuos son una superficie de doble curvatura por naturaleza, ya que son provenientes de la envoltura a los tallos, estos tienden a crecer con en una forma cóncava envolviendo el tallo.

Por lo anterior, al utilizar estos residuos como revestimiento es necesario que adopten una forma linear, ya que serán sometidos a laminación.

Para esto es necesario que estos pierdan su memoria de forma y se adapten a una forma rectilínea.

\subsection{Tratamiento a vacuo}

Este tratamiento se realizo en el laboratorio de suelos del programa de construcción civil de la Universidad de São Paulo. Con el fin de extraer la lignina por un medio termo-mecánico.

Tres hojas caulinares después de lavadas y secas, fueron sumergidas en 2 litros de agua deionizada dentro de un autoclave a $140^{\circ} \mathrm{C}$. Después de la estabilización de la temperatura las hojas se mantuvieron durante $2 \mathrm{hrs}$ consecutivas en el autoclave.

\subsection{Tratamiento alcalino}

Las hojas se sumergieron en una solución de 2,0\% de hipoclorito de sodio y agua, durante tres horas. Buscando, modificar y extraer la lignina químicamente. Durante este tratamiento el $\mathrm{Ph}$ de la solución liquida, fue monitoreado. 


\subsection{Tratamiento termo-mecánico}

Las hojas fueron sumergidas en agua des-ionizada durante 24 horas. Después de esto una superficie metálica caliente a $60^{\circ} \mathrm{C}$, se coloca encima de la superficie de las hojas, junto con un tejido de teflón como barrera, entre la hoja y la superficie metálica.

Este proceso es repetido varias veces hasta que la hoja no destile más agua. Inmediatamente, la hoja se coloca entre dos placas cerámicas frías.

\subsubsection{Conformado del residuo con diferente substratos}

El conformado de los revestimientos se hizo utilizando tres tipos de substratos. Fibras de baja densidad, MDF y papel kraft pre-impregnado.

Para proteger la superficie visible de los revestimientos moldados, se ensayaron diferentes revestimientos de base oleosa y de base acuosa, analizando la interacción de estos sobre la superficie del residuo.

\subsubsection{Substrato de Fibras de la HCB moldadas in-situ}

El primer substrato utilizado fueron las fibras de la HCB trituradas, estas fibras son una fibra de baja densidad. El tratamiento de los residuos esta explícito en la Figura 19. Donde se muestra la recolección de las hojas, luego fueron lavadas y secadas. Las hojas enteras que recubren las fibras trituradas, se sometieron a un baño de vapor para atenuar la rigidez de la lignina y evitar el agrietamiento de la superficie en el prensado, mientras que las hojas trituradas para ser usadas en el substrato pasaron por la estufa de secado, para luego ser aglutinadas con la resina.

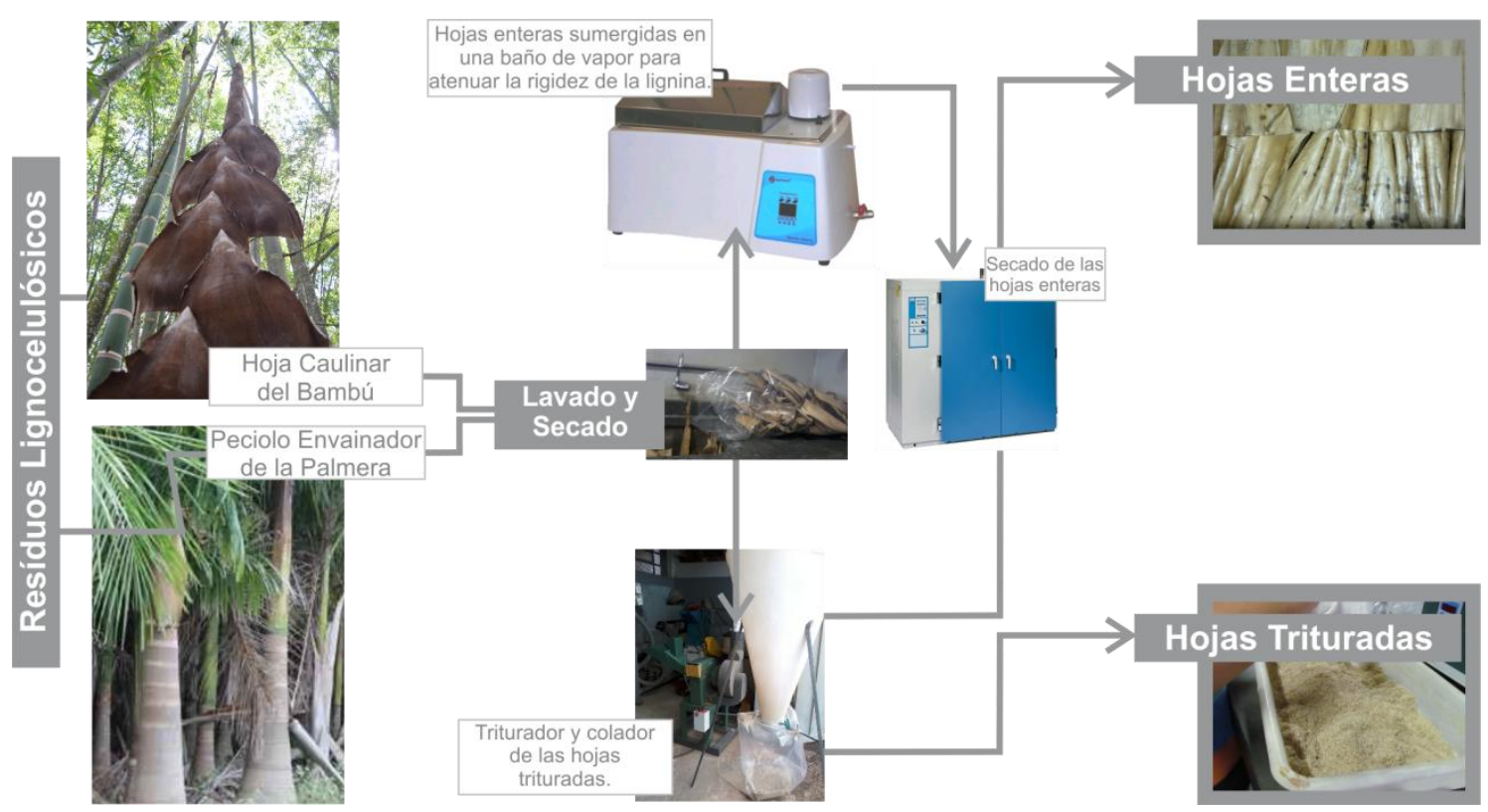

Figura 19 - Proceso de obtención de las materias primas para laminación con fibras de baja densidad.

Para la producción de estos revestimientos, se utilizaron tres capas de material. La primera compuesta por las hojas caulinares de bambú enteras para aprovechar su superficie, en la segunda capa se utilizaron hojas caulinares trituradas y por último, 
nuevamente una capa de hojas enteras. Para cada muestra los índices de resina variaron, los cuales fueron 15,20 y $25 \%$.

Los cuerpos de prueba fueron dimensionados en un área de 40x40 cm y una espesura de $0,3 \mathrm{~cm}$, para obtener un volumen de $480 \mathrm{~cm}^{3}$, una densidad de $0,25 \mathrm{gr} / \mathrm{cm}^{3}$ y una masa total de 120 gr. para cada cuerpo de prueba.

Las materias primas fueron procesadas previamente de la siguiente forma: lavado, secado, triturado y secado. Como se indica en la Figura 19. Para luego ser pesadas de acuerdo a lo valores indicados en la Tabla 3.

Tabla 3 - Dimensionamiento de los revestimientos

\begin{tabular}{cccc}
\hline CP & $\begin{array}{c}\text { Porcentaje de Resina } \\
(\boldsymbol{\%})\end{array}$ & $\begin{array}{c}\text { Peso de la resina } \\
\text { (gr.) }\end{array}$ & $\begin{array}{c}\text { Peso de las hojas } \\
\text { (gr.) }\end{array}$ \\
\hline $\mathbf{1}$ & 15 & 18 & 102 \\
$\mathbf{2}$ & 20 & 24 & 96 \\
$\mathbf{3}$ & 25 & 30 & 90 \\
\hline
\end{tabular}

Consecuentemente, las materias primas se secaron, la mescla de la resina con el catalizador, se hizo en porciones iguales $(1: 1)$.

Después de procesar los materiales, se da inicio al proceso de laminación (Figura 20) se procede a colocar una a una las capas nombras anteriormente, dentro de un molde cuadrado de madera, que se encuentra apoyado sobre una lámina de teflón, el cual es necesario para evitar que la superficie del panel a moldar se pegue a la superficie de la prensa caliente.

La mescla de la resina poliuretana a base de aceite de ricino y su catalizador fue esparcida con un dispersor sobre la superficie de la primera capa de hojas enteras, después de esto se colocó una capa de hojas trituras, que previamente había sido mesclada con la resina bi-componente y por último se colocó la última capa de hojas enteras.

La prensa fue pre-calentada a $100^{\circ} \mathrm{C}$. El prensado del panel se realizó durante $10 \mathrm{~min}$. Hasta alcanzar una temperatura de $120^{\circ} \mathrm{C}$ y $5 \mathrm{MPa}$.

El proceso de cura se realizó a temperatura ambiente durante 48 horas, antes de iniciar la caracterización del espécimen. 


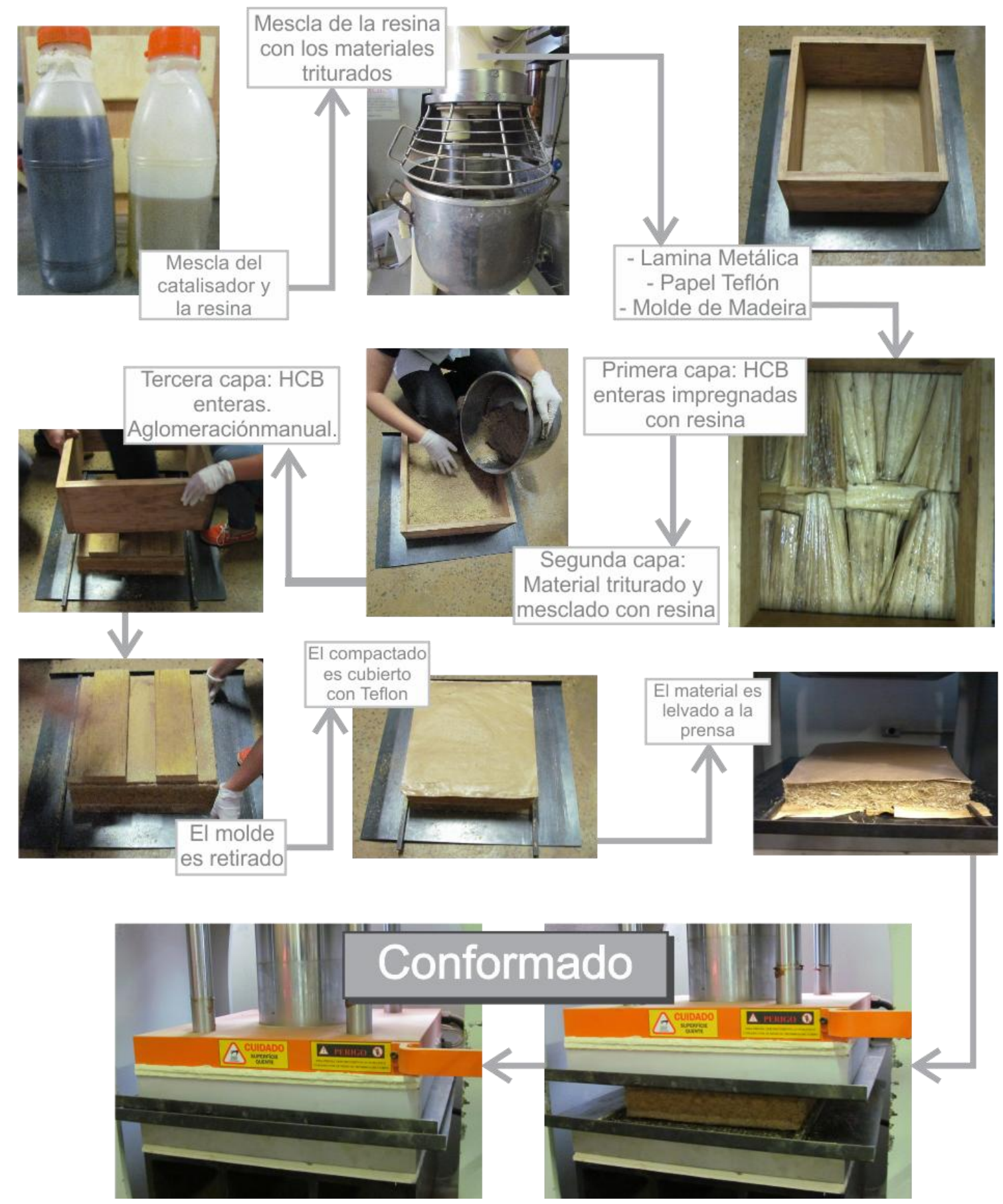

Figura 20 - Proceso de conformado paso a paso.

\subsubsection{Substrato de MDF industrial moldado a frio}

Para el conformado del revestimiento con substrato de Fibras de Densidad Media (MDF), las hojas primeramente se rectificaron por el proceso de termo-mecánico manual (explícito en la página 26).

Dos hojas caulinares fueron dimensionadas dentro del área de un trapecio de $10 \mathrm{~cm}$ de base (Figura 21). Para el substrato se utilizo una placa de MDF de 14x11 cm. 


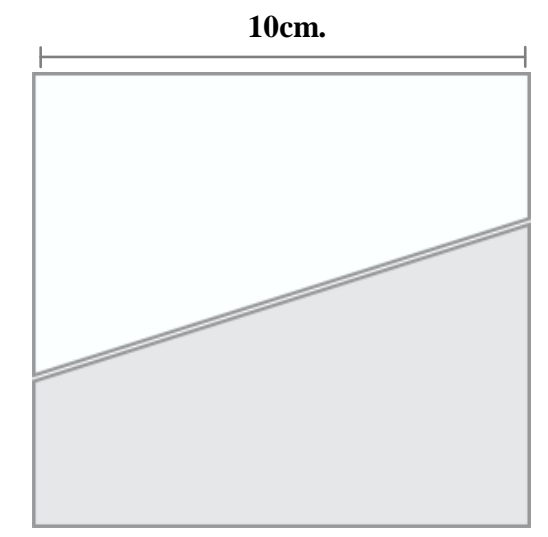

Figura 21 - Dimensionamiento de las hojas.

Las superficie del substrato y la superficie de la hoja fueron impregnada con resina poliuretana de base vegetal para obtener mayor adhesión, finalmente fueron prensadas manualmente.

\subsubsection{Substrato de papel kraft}

El conformado con papel kraft, fue realizado en dos etapas. La primera etapa de este ensayo se llevo a cabo en los laboratorios de la empresa MADEPAR, en la ciudad de Simões Filho, en el estado de la Bahia.

En este caso la superficie de las hojas se utilizó como substituto del papel decorativo utilizado en los laminados de alta presión.

Utilizando 10 hojas de papel kraft como substrato, las cuales fueron previamente impregnadas de forma industrial al 35\% con resina fenólica. Y 2 hojas de papel decorativo impregnado con resina melamínica.

Se moldaron tres tipos de cuerpos de prueba: 1) papel kraft + residuo 2) papel kraft + papel decorativo + residuo 3) papel kraft +2 papeles decorativos + residuo.

Este conjunto de materiales fue colocado previamente entre dos chapas metálicas, dispuestas a ser prensadas en una prensa hidráulica (Figura 22) con sistema de resfriamiento incorporado.

La temperatura de calentamiento fue de $120^{\circ} \mathrm{C}$ durante 20 minutos. La temperatura de resfriamiento fue de $25^{\circ} \mathrm{C}$. El proceso total de prensado fue de 45 minutos. 


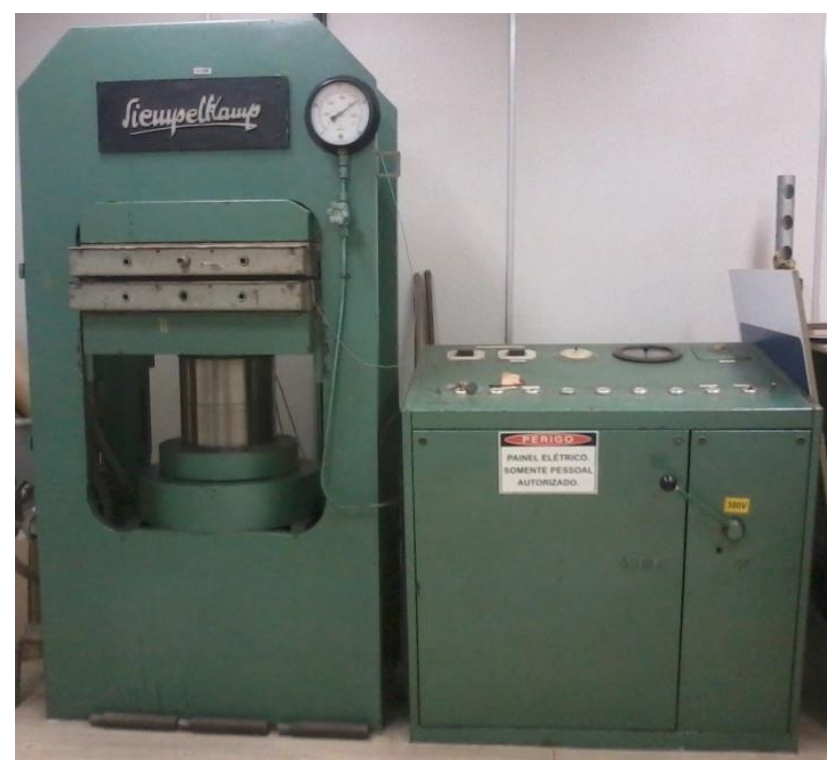

Figura 22 - Prensa Hidráulica

La segunda etapa de prensado fue realizada en el laboratorio de construcciones rurales y ambiência de la facultad de zootecnia e ingeniería de alimentos de la Universidad de São Paulo, campus Pirassununga.

En esta etapa de prensado se utilizaron las materias primas suministradas por la empresa Madepar. Dentro del material provisto por la empresa se encuentran 80 hojas (50x50cm) de papel decorativo blanco melamínico y 187 hojas de papel kraft fenólico. Previamente impregnados al $30 \%$.

Tabla 4 - Parámetros de laminación en laboratorio

\begin{tabular}{ccccc}
\hline Residuo & $\begin{array}{c}\text { Cantidad de Hojas } \\
\text { de Papel kraft } \\
\text { impregnado }\end{array}$ & $\begin{array}{c}\text { Tiempo de prensado en } \\
\text { temperatura máxima. (minutos) }\end{array}$ & Temperatura $\left({ }^{\circ} \mathbf{C}\right)$ & Presión $(\mathbf{M P a})$ \\
\hline HCB & 6 & 20 & 120 & 6,5 \\
PHP & 10 & 20 & 120 & 6,5 \\
\hline
\end{tabular}

Los parámetros de laminación explícitos en la Tabla 4 son el resultado de pruebas cualitativas realizadas anteriormente.

\subsection{Caracterización del revestimiento}

\subsubsection{Rugosidad}

Después del prensado de la superficie, la topografía de las superficies fue medida por medio de la técnica de interferométria a laser, utilizando un perfilometro óptico, marca Bruker, modelo NP-Flex.

Para la caracterización de la superficie se adoptaron los siguientes parámetros: lente objetiva $5 \mathrm{x}-$ michelson. Con paso de $x=2 \mathrm{~mm}$. y $y=2 \mathrm{~mm}$. Luz monocromática verde, velocidad de barredura igual a 10x, limite de ruido de $2 \%$, la distancia en $\mathrm{z}=3000 \mu \mathrm{m}$. para cada superficie se utilizaron 3 superficies de cada residuo (12 especímenes en 
total), cada ensayo tuvo una duración de 4,5 horas en promedio. Para cada superficie se realizaron 3 mediciones en promedio en una área de 5x5mm.

Después de la adquisición de los datos de la topografía de la superficie, los perfiles se sometieron a un filtro para la interpolación de los datos y la eliminación de los puntos no validados, utilizando los puntos alrededor del área medida. Utilizando las herramientas del software visión 64, herramienta conectada al interferómetro para lectura de datos.

Los parámetros de rugosidad evaluados para la caracterización numérica de la superficie fueron: $S_{a}$, promedio aritmético de las alturas de la superficie a partir de un plano medio; $S_{q}$, desviación típica de la distribución de las alturas de los picos y valles de la superficie definidos por la ecuación 1 y 2 respectivamente (Costa 2014).

Ecuación 4

$$
S_{a}=\frac{1}{M N} \sum_{\mathrm{j}=1}^{\mathrm{N}} \sum_{\mathrm{i}=1}^{\mathrm{M}} \mid \eta\left(X_{i} Y_{j} \mid\right.
$$

Ecuación 5

$$
S_{q}=\sqrt{\frac{1}{M N} \sum_{\mathrm{j}=1}^{\mathrm{N}} \sum_{\mathrm{i}=1}^{\mathrm{M}} \eta^{2}\left(X_{i} Y_{j}\right.}
$$

Donde, $\mathrm{M}$ y $\mathrm{N}$ equivalen al número de puntos en $\mathrm{X}$ y $\mathrm{Y}$; $\grave{\eta}$ es el conjunto de datos de la superficie.

\subsubsection{Absorción de agua}

Para determinar la capacidad de absorción de agua en masa, se utilizaron 10 cuerpos de prueba de cada residuo cortados en fragmentos de $40 \times 20 \mathrm{~mm}$ e identificados. Seguidamente, se procede a determinar y anotar los datos referentes a la masa determinada en la balanza semi-analítica, con resolución de 0,1 gr.

Las muestras fueron pesadas y este valor denominado como $\mathrm{M}_{0}$. Posteriormente, El recipiente en el cual fueron depositadas las muestras se llenó con agua destilada, de modo que los cuerpos de prueba quedaran totalmente sumergidos y el nivel de agua excedieron excediera los $25 \mathrm{~mm}$ por encima de la superficie superior del cuerpo de prueba. La temperatura del agua fue de aproximadamente $20^{\circ} \mathrm{C}$.

Posteriormente, después de 2 horas de inmersión de los cuerpos de prueba, se retiraron del recipiente, removiendo cuidadosamente el exceso de agua con papel absorbente. Subsecuentemente, se medió nuevamente el peso en la balanza. Este proceso se repitió pasadas 24 horas de inmersión. Para el cálculo de la absorción de agua, se utilizó la Ecuación 6. 


$$
A A=\frac{M_{1}-M_{0}}{M_{0}} \times 100
$$

Donde: $\mathrm{AA}=$ Absorción de agua (\%), $\mathrm{M}_{1}=$ masa después de la inmersión (gr.) $\mathrm{M}_{0}=$ masa antes de la inmersión (gr.)

Los resultados son referentes a las medidas de los valores evaluados entre cuerpos de prueba, en porcentajes con exactitud de $0,1 \%$.

\subsubsection{Limpieza e Higiene}

Las superficies prensadas se sometieron al ensayo de limpieza y resistencia al ataque químico, con substancias de uso cotidiano, las cuales representan un alto grado de resistencia al ataque químico. Entre estas: salsa de tomate, mostaza, mayonesa, café, vinagre, salsa inglesa, hipoclorito de sodio, vino.

Los agentes de limpieza fueron: agua común y jabón de limpieza abrasiva. Todo esto utilizando una esponja de uso cotidiano de cerdas de naylon y un paño húmedo.

Para esto las placas de los revestimientos ensayados se demarcaron en seis espacios. Los agentes que generan manchas permanecieron por 12 horas en contacto con la superficie para después ejecutar el proceso de limpieza (Menegazzo et al. 2006). 


\section{Resultados y Discusión}

Los resultados de los experimentos físicos, químicos y mecánicos se explican en la siguiente sección. Estos son agrupados siguiendo el índice de la metodología.

Iniciando con la caracterización físico-química de la HCB y el PHP. Con el fin, de determinar parámetros de temperatura para la fabricación.

Por otro lado, dentro de los pre-tratamientos para el rectificado de la Hoja Caulinar del Bambú (HCB) y el Peciolo de la Hoja de la Palmera (PHP), se descartó el tratamiento químico, ya que degrada rápidamente la superficie.

En cuanto al proceso de laminación, el substrato kraft, fue la técnica que mostro un mejor desempeño, en cuanto a la conservación de las características visuales de la superficie de los residuos.

Por último, los ensayos de caracterización del revestimiento, muestra que con el proceso de laminación, la ondulación en las HCB aumenta, mientras que la rugosidad disminuye; en el PHP tanto la ondulación como la rugosidad disminuyen. En el proceso de absorción de agua ambos residuos disminuyen sus valores promedios de absorción. En cuanto, a la limpieza e higiene ambas superficies se muestran susceptibles a las manchas, sin embargo la HCB se muestra más resistente a la limpieza abrasiva.

\subsection{Resultados de la caracterización Físico-química de la HCB y el PHP.}

\subsection{1 Índice de humedad natural}

El contenido de humedad es un importante parámetro de calidad de la madera, puesto que influencia fuertemente la durabilidad en cuanto a la proliferación de organismos vivos (Fridh L., Volpé S., and Eliasson L. 2014), dado el hecho que, las hojas caulinares del bambú (HCB) y el peciolo de la hoja de la palmera (PHP) pretenden ser utilizados en este proyecto como complemento en materiales compuestos, se decidió investigar el índice de humedad natural de estos.

La Figura 23 muestra los valores del contenido de humedad de HCB. Obteniendo un valor mínimo de $7,90 \%$ y máximo de $10,55 \%$, y un promedio de $9,10 \%$.

En el PHP se obtuvo un valor mínimo de 7,78\% y máximo de 13,03\%. Para un promedio de $11,39 \%$.

Lo que indica que el PHP posee un índice de humedad mayor que la HCB. 


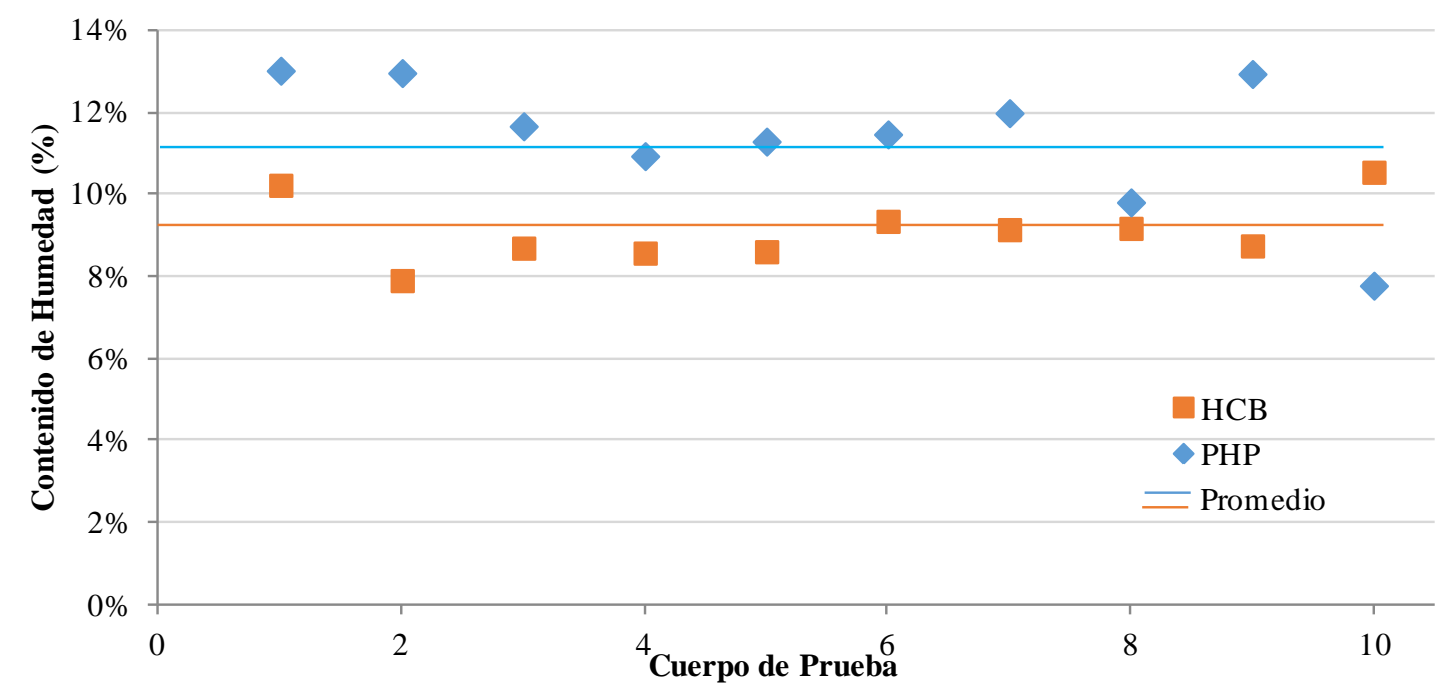

Figura 23 - Contenido de Humedad de los residuos

El concepto de humedad para productos reconstituidos es diferente en relación a los productos de madera natural, ya que los productos reconstituidos exigen contenidos de humedad bajos en sus fibras o partículas, lo cual es una requisito estipulado por el tipo de adhesivo que se usará (Silva et al. 2006).

Por otro lado, el contenido de humedad de un material varía de acuerdo a la humedad relativa del aire (Silva et al. 2006), dado esta condición es importante conocer los valores propios de humedad del material, ya que la taza de deterioración térmica de materiales celulósicos es proporcional a su contenido de humedad (Du et al. 1999). Es decir, a mayor contenido de humedad, mayor resistencia a la degradación térmica.

Dado el hecho que el proceso de transformación por medio de laminación a alta presión y temperatura, representa un aceleración en la degradación térmica. El análisis termo gravimétrico permite conocer los limites de temperatura para conservar el material, durante el proceso de laminación.

\subsubsection{Termogravimetría}

Para conocer la degradación térmica del material, se realizaron ensayos termo gravimétricos que reflejan el comportamiento termodinámico.

El análisis termo-gravimétrico (TG) muestra los cambios químicos y perdidas de masa, de acuerdo a la temperatura. Se observan periodos de estabilidad térmica y reacciones químicas exotérmicas y endotérmicas. La cinética de la curva de pérdida de masa junto con la derivada termo gravimétrica (DTG) de la misma proporcionan información acerca del proceso de degradación térmica de un material, así como los picos de la curva DTG resaltan los eventos de las transiciones de los flujos de calor y los cambios químicos transcurridos en la curva TG (Man Singh 2004).

Con el objetivo de encontrar las transiciones de flujo de calor asociadas al punto de transición vítrea de los principales compuestos orgánicos (lignina, celulosa y 
hemicelulosa) de la HCB y el PHP en estado natural, se muestra en la Figura 24, las curvas TG y DTG asociadas a estos.

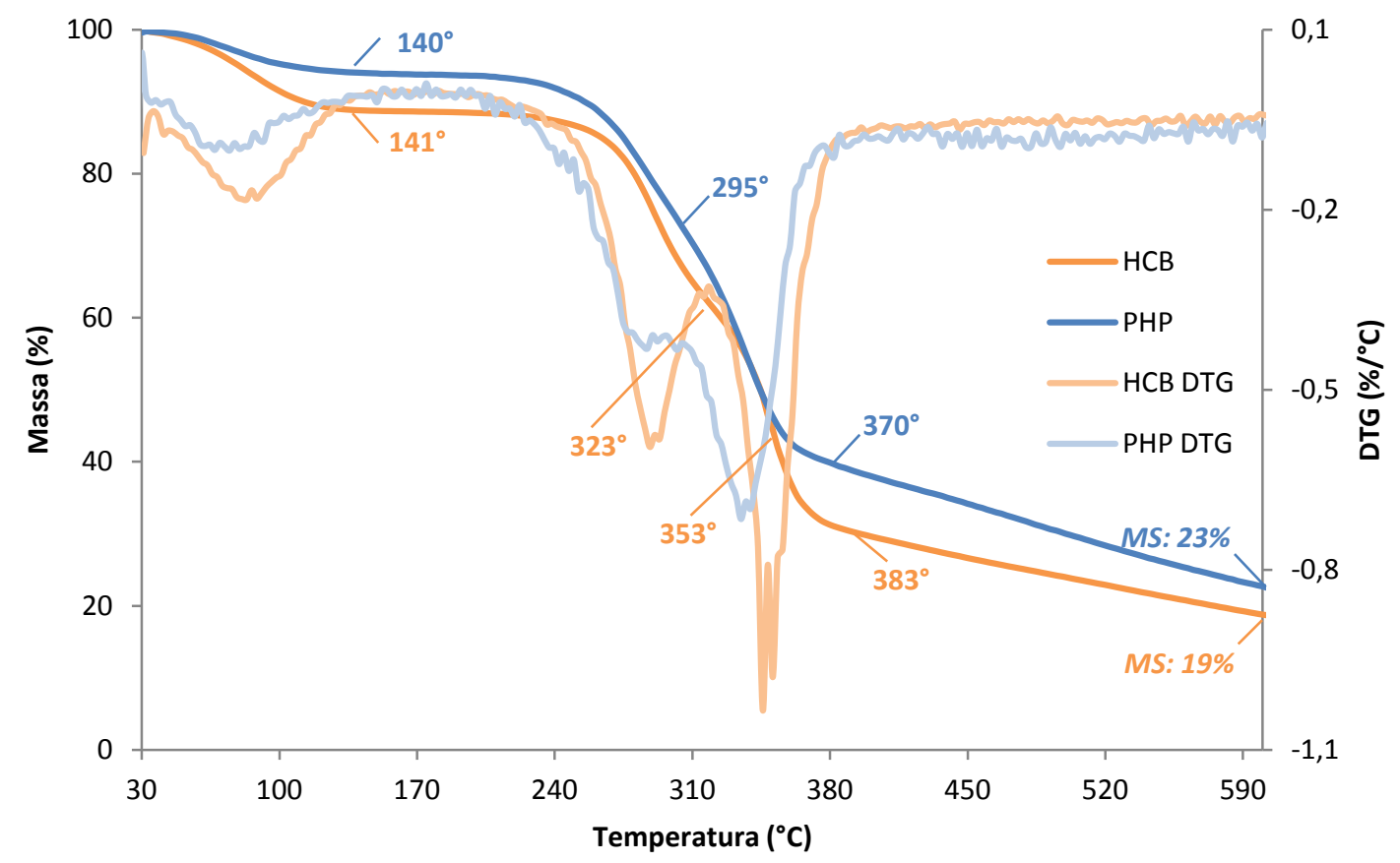

Figura 24 - Curvas TG y DTG de las HCB y la PHP naturales.

Los resultado muestran diferentes zonas de reacción. La curva DTG de la HCB, muestra en $140^{\circ} \mathrm{C}$ el final del primer pico endotérmico, donde se ha perdido $11 \%$ de la masa total, mientras que en el PHP se da esta misma reacción en $140^{\circ} \mathrm{C}$ pero perdiendo $6 \%$ de la masa total.

Después de este primer evento, se muestra una suave línea recta entre 140 y $240^{\circ} \mathrm{C}$, representando la estabilidad térmica que se da antes de iniciar la degradación de los compuestos.

El segundo evento térmico, aparece en el PHP en $295^{\circ} \mathrm{C}$ perdiendo $23 \%$ de la masa total; mientras que en la $\mathrm{HCB}$ este segundo evento aparece en $323^{\circ} \mathrm{C}$ perdiendo $40 \%$ de la masa total. Este pico es atribuido a la primera fase de degradación de la lignina (Guimarães and Tannous 2014).

La HCB presenta un pico exotérmico, que no surge en el PHP. Este pico se da en $353^{\circ} \mathrm{C}$ perdiendo $58 \%$ de la masa.

Ambos especímenes presentan su última reacción química entre $370^{\circ} \mathrm{C} \mathrm{y} 380^{\circ} \mathrm{C}$ finaliza así con un último pico exotérmico, donde la pérdida de masa es de $69 \%$ y $51 \%$ para el HCB y PHP, respectivamente.

Finalmente, en $600^{\circ} \mathrm{C}$ se obtiene una masa residual (MS) de $19 \%$ para la $\mathrm{HCB}$ y de $21 \%$ para el PHP. 
Con lo anterior, podemos verificar que compuestos tales como: lignina, celulosa y hemicelulosa comienzan a deteriorarse por las condiciones atmosféricas de temperatura; a partir de los $140^{\circ} \mathrm{C}$. Las cadenas de material orgánico por ser más cortas y volátiles se evaporan más rápido, debido a la ausencia de oxígeno, por lo que no existe combustión. (Marinho N. P. et al. 2013; Seye, Cortez, and Olivares G. 2003).

Los datos del análisis termo-gravimétrico muestran un comportamiento similar entre la HCB y el PHP teniendo una relación de calentamiento linear y en las mismas condiciones atmosféricas.

Lo que se puede concluir de este análisis termo-gravimétrico, es que para el proceso de laminación la $\mathrm{HCB}$ y el PHP deben ser manipulados en temperaturas menores a $140^{\circ} \mathrm{C}$, para evitar la degradación de sus componentes.

Para completar la información química acerca de los compuestos en las HCB y el PHP, la masa residual obtenida en el ensayo termo-gravimétrico se sometió a análisis de fluorescencia de rayos $\mathrm{X}$, los resultados son mostrados a continuación.

\subsubsection{Análisis Química y Microestructural}

La Tabla 5 muestra los valores cuantitativos del análisis químico usando la técnica de fluorescencia de rayos $\mathrm{x}$, con el fin de conocer los componentes químicos inorgánicos que hacen parte de la estructura atómica de las HCB y el PHP. Este permitió determinar que estas están constituidas por $96,7 \%$ y $99,9 \%$ de carbono orgánico en la HCB y el PHP, respectivamente.

Tabla 5 - Valores cuantitativos resultantes del ensayo por fluorescencia de rayos $\mathbf{x}$.

\begin{tabular}{|c|c|c|}
\hline Muestras & HCB & PHP \\
\hline $\mathrm{SiO}_{2}$ & 32,72 & 46,3 \\
\hline $\mathbf{K}_{2} \mathbf{O}$ & 22,32 & 3,92 \\
\hline $\mathrm{CaO}$ & 4,89 & 36,1 \\
\hline $\mathrm{Fe}_{2} \mathrm{O}_{3}$ & 16,82 & 1,93 \\
\hline $\mathrm{SO}_{3}$ & 4,89 & 2,89 \\
\hline MgO & 1,83 & 2,82 \\
\hline $\mathrm{Na}_{2} \mathrm{O}$ & 0,31 & 2,83 \\
\hline $\mathbf{A l}_{2} \mathbf{O}_{3}$ & 1,22 & 0,72 \\
\hline $\mathbf{P}_{2} \mathbf{O}_{5}$ & 0,61 & 1,81 \\
\hline $\mathrm{TiO}_{2}$ & 0,31 & 0,1 \\
\hline $\mathrm{Cr}_{2} \mathrm{O}_{3}$ & 0,61 & 0,13 \\
\hline MnO & 0,31 & 0,25 \\
\hline $\mathrm{NiO}$ & $<<$ & $<<$ \\
\hline $\mathrm{CuO}$ & $<<$ & $<<$ \\
\hline Cl & 0,43 & $\mathrm{Nd}$ \\
\hline ZnO & $<<$ & $\mathrm{Nd}$ \\
\hline $\mathbf{R} \mathbf{b}_{2} \mathbf{O}$ & $\mathrm{Nd}$ & $<<$ \\
\hline SrO & $\mathrm{Nd}$ & $<<$ \\
\hline Br & $<<$ & $\mathrm{Nd}$ \\
\hline $\mathrm{Nb}_{2} \mathrm{O}_{5}$ & -- & $<<$ \\
\hline Perda ao Fogo & 96,7 & 99,9 \\
\hline
\end{tabular}




$$
<<=(\text { menor que } 0,01 \%) ; \mathrm{Nd}=\text { elemento no detectado. }
$$

El $3,27 \%$ y el $1 \%$ de las cenizas restantes de la calcinación de la HCB y el PHP, muestra que los minerales principales que componen la estructura de las hojas son: Dióxido de silicio (33 y 46\%), oxido de potasio (22 y 4\%), oxido de Calcio (5 y 36\%), oxido de ferro (17 y $2 \%$ ) y oxido sulfúrico (5 y $3 \%$ ), respectivamente.

Estudios en la literatura muestran este tipo de material lignocelulósicos como fuente de minerales para producir aditivos y geo-polímeros (Castro, B. 2008). Es importante tener en cuenta que al calcinar estos residuos, más del $90 \%$ de su composición irá a fijarse en la atmosfera como gas contaminante, afectando directamente la concentración de $\mathrm{CO}_{2}$, por ende aumentando el efecto de gas invernadero (Hinkle 1994).

Por lo anterior, se ha resuelto utilizar las HCB y el PHP íntegras y sin calcinar. Por consiguiente, se ha analizado morfológicamente la estructura interna y la superficie de las mismas. Para conocer la distribución de los minerales encontrados en el análisis químico (Tabla 5).

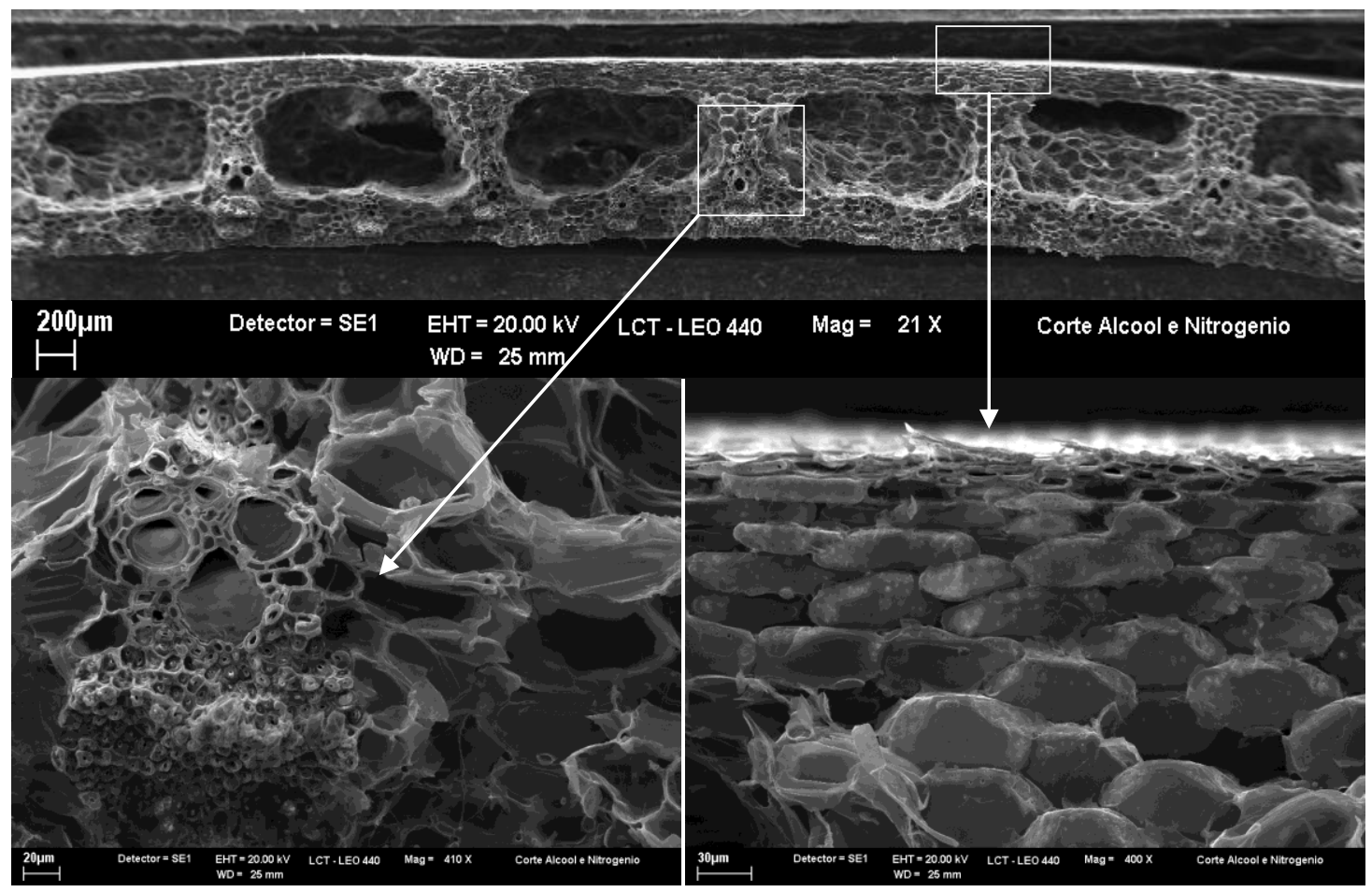

Figura 25 - Sección Transversal de la HCB, mostrando la anatomía compuesta por fibras y macro-fibras.

Del punto de vista anatómico, las paredes del bambú se dividen en: epidermis (capa externa), dermis (próximo a la capa externa), tejido base (capa intermediaria) formado por haces vasculares y la pared de cavidad (pared de la medula). La constitución de estos es de $50 \%$ tejido parenquimatoso, $40 \%$ fibras de celulosa y $10 \%$ de tejidos, vasos y tubos perforados (Marinho 2012 ; Ghavami and Marinho 2005).

La Figura 25 muestra la sección transversal de la HCB, la cual se asemeja a la microestructura del tallo del bambú, mostrada por Ghavami and Marinho 2005. En este caso 
podemos apreciar grandes macro-poros, compuestos por una organizada estructura de micro-fibras.

La microestructura de las hojas caulinares del bambú y los principales componentes de su morfología, como las macro-fibras, los haces vasculares, conjunto de haces vasculares, epidermis y el tejido parenquimatico conforman la estructura anatómica interna que se percibe en la sección transversal del tallo del bambú, la cual es envuelta por un tejido parenquimatico fundamental constituido por cordones de esclerenquimaticos que forman los haces vasculares (Bittencourt 2008).

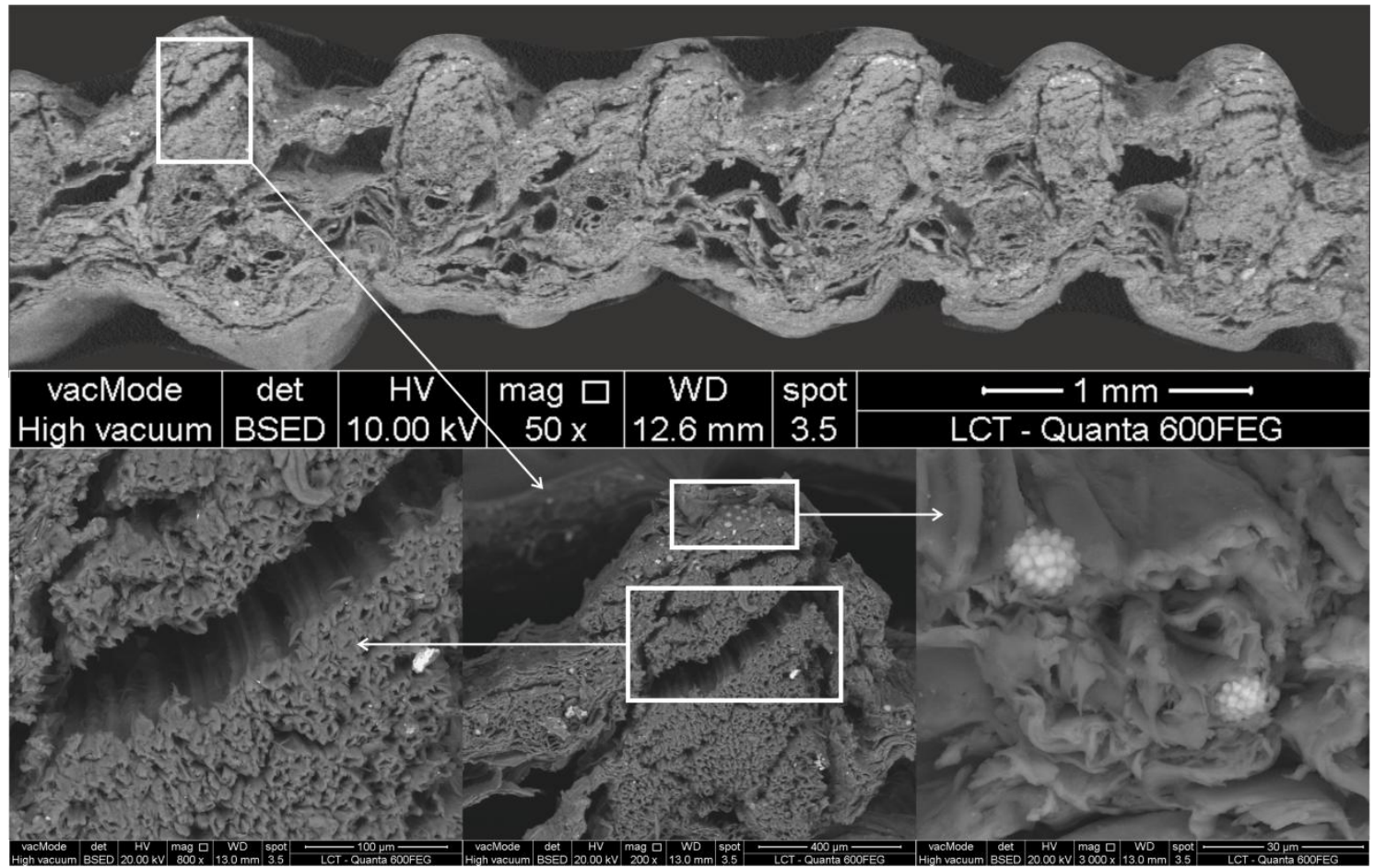

Figura 26 - Sección Transversal del PHP, mostrando la anatomía compuesta por fibras y macro-fibras

La anatomía del PHP, en sección transversal, muestra que sus paredes laterales son mas gruesas que las paredes de la HCB, estas paredes se caracterizan por la deposición de lignina y hemicelulosa. Estos vasos tienen un papel importante para conducir agua y minerales a la planta (Rudall, 2007). Los haces vasculares observadas en la (Figura 26), están envueltos por el esclerénquima. Las células del esclerénquima son a menudo lignificadas, por lo general pierden su contenido de lignina en la madurez (Mauseth, 2003).

En este estudio, se puede percibir la presencia de fibras debido a su estructura característica. Las paredes de las células tienen la propiedad esclerénquimatica que le da elasticidad (Rudall, 2007) y soporte mecánico a los haces vasculares (Trigiano; Gray, 2005).

Figura 26 (derecha, abajo) muestra inclusiones en el parénquima, que se caracteriza por la acumulación de oxalato de calcio. El oxalato de calcio es un bio-mineral común en las plantas, que se producen en forma de cristales de diferentes formas se pueden 
encontrar en algunos tejidos órganos o plantas y con frecuencia se forman en células especializadas en forma de cristales llamados vacuolas idioblastos (Franceschi, 2001). Estas inclusiones son conocidas como drusas. Algunos autores afirman que las drusas pueden representar formas de almacenamiento de calcio y ácido oxálico y algunas evidencias sugieren que la presencia de drusas se relaciona con la reabsorción de calcio de los períodos de agotamiento de calcio por la planta (Horner, Kausch; Wagner, 1981) (Nunes S. 2008).

Comparando a la estructura microestrutural del PHP esta se muestra menos porosa que la HCB. Mientras que los perfiles de las paredes parenquimáticas que se muestran en los extremos de las micrografías, tienden a ser más ondulados en el PHP que en la HCB. Por esto, cada una de sus superficies fue analizada por medio de microscopia óptica.
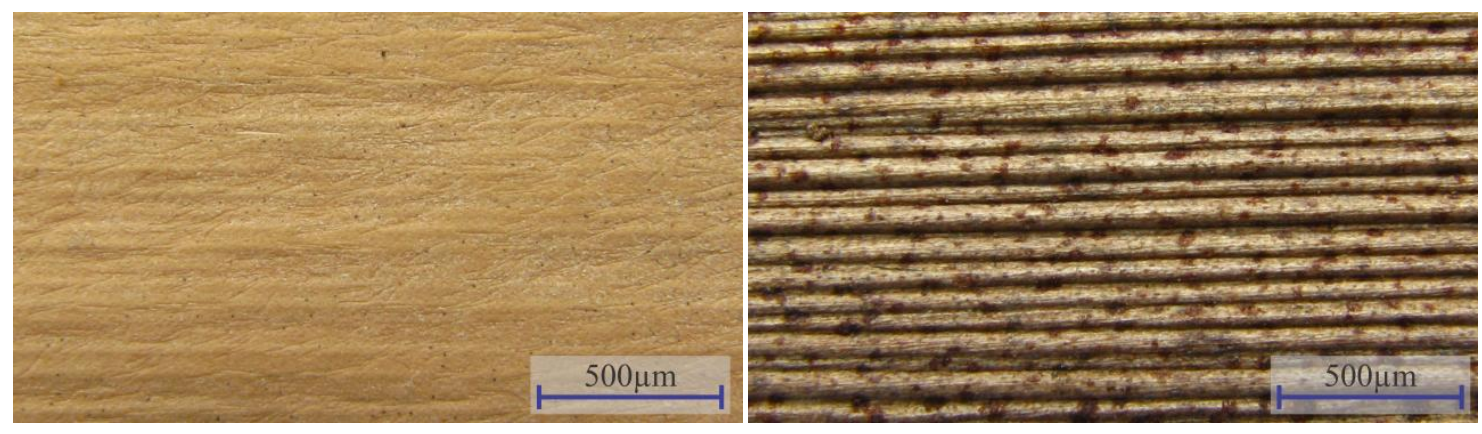

Figura 27 - Superficies Externas: HCB (izquierda) y PHP (derecha)

La Figura 27 muestra ambas superficies externas. En la HCB se aprecian fibras aleatorias de aproximadamente $100 \mu \mathrm{m}$, las cuales se denominan como pubescencia. Autores como (Molina-Montenegro M.A. 2008) afirman que la presencia de esta se debe a (1) la alta radiación incidente, (2) la economía hídrica y (3) la difusión de gases. En la superficie del PHP se observa la ausencia de esta pubescencia, pero las fibras longitudinales son bastante marcantes sobre la superficie a diferencia de la $\mathrm{HCB}$, donde apenas son apreciables.
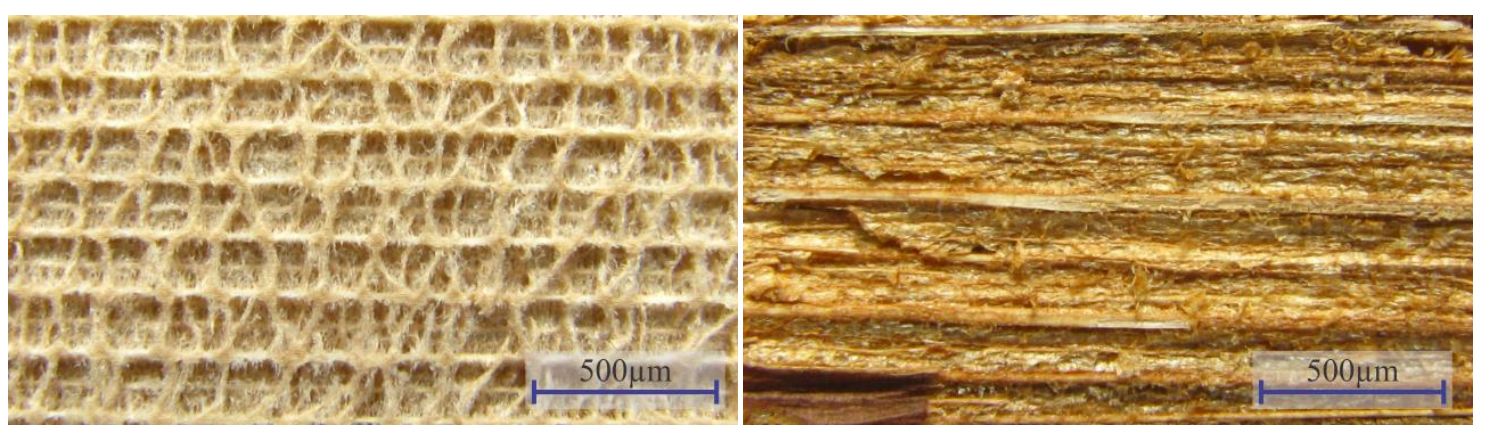

Figura 28 - Superficies Interna: HCB (izquierda) y PHP (derecha)

Las HCB y el PHP forman una compleja estructura de un material compuestos, a causa de su función natural, la cual consiste en proteger el tallo del bambú durante su crecimiento. A esto se debe la compleja estrutura fibrovascular, que se aprecia en la Figura 28 ya que es la encarga del transporte de nutrientes para el desarrollo del tallo. 

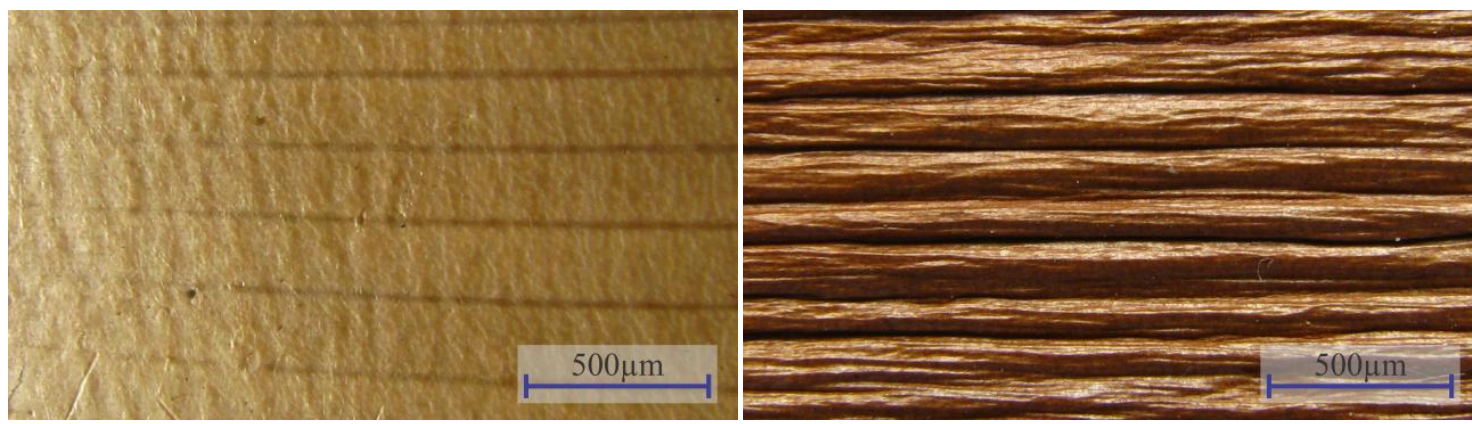

Figura 29 - Superficies Internas: HCB (izquierda) y PHP (derecha)

La superficie externa debe repeler cualquier tipo de cuerpo extraño y proteger los canales fibro-vasculares, mientras que la superficie interna (Figura 29) debe permitir el paso de los nutrientes hacia y desde los canales fibro-vasculares.

\subsubsection{Cambio de color por envejecimiento acelerado (QUV)}

El color es un importante aspecto perceptivo en las superficies decorativas y dado el hecho que la pretensión es utilizar las superficies nombras anteriormente, estas se sometieron al ensayo de envejecimiento acelerado por medio de la emisión de rayos ultravioleta y humedad controlada. La Tabla 6 Tabla 6 - Imágenes representativas de las superficies antes y después del envejecimiento acelerado.muestra imágenes representativas de cada superficie antes y después del proceso de envejecimiento acelerado.

Tabla 6 - Imágenes representativas de las superficies antes y después del envejecimiento acelerado.
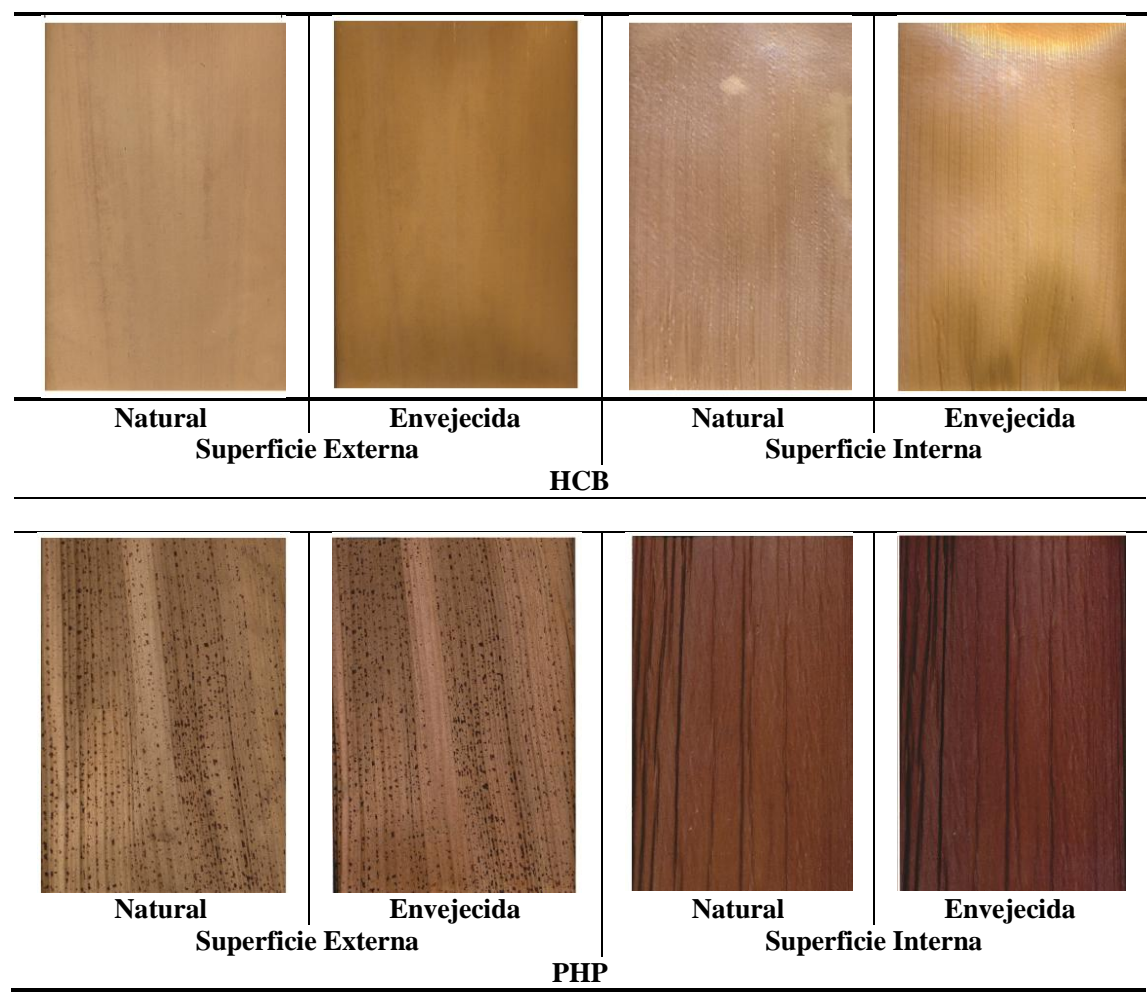

Figure 30 - Imágenes representativas de las superficies antes y después del envejecimiento. 
Visualmente la superficie externa de la HCB se tornó más oscura con el envejecimiento acelerado, mientras que, la superficie interna se torna más brillante. El aspecto amarillo de ambas superficies parece haber disminuido.

Por otro lado, las superficies del PHP aparente haber tenido un cambio sutil en el color, comparada con la HCB. Aunque, la apariencia rojiza y la tonalidad oscura del PHP parece haber aumentado.

En la Tabla 7 se muestran los resultados de las medidas con base al método CIELab, según las coordenadas de $L, b$ y $a$ (Figura 17).

El envejecimiento acelerado aumento la tonalidad amarilla (vector hacia $+b$ ) de todas las superficies, a excepción de la superficie externa del PHP. La cual en su ciclo de vida natural ya había sido expuesta a los rayos UV y a la intemperie. Los cambios de color en la tonalidad amarilla de las muestras de control es el reflejo de cambios ocurridos en la estructura química de la lignina (Turkoglu, Baysal, and Toker 2015).

La tonalidad rojiza aumento (vector hacia $+a$ ) para todas las superficies. Sin embargo, este efecto fue más acentuado en ambas superficies del PHP.

Según los resultados del sistema CIELab, el envejecimiento acelerado no disminuyó la luminosidad (valores en $L$ ) en la superficie externa del HCB y las superficies internas del PHP, indicando que las superficies fueron altamente degradadas. El oscurecimiento de las superficies se ha asociado a la despolimerización de la lignina (E. Baysal et al. 2014), (A. Temiz et al. 2005).

Tabla 7 - Valores promedios de cambios de color. Valores entre paréntesis representan la desviación estándar.

\begin{tabular}{|c|c|c|c|c|c|c|}
\hline & \multicolumn{3}{|c|}{ Natural } & \multicolumn{3}{c|}{ Envejecidas } \\
\hline \multirow{2}{*}{ Bamboo External } & $\boldsymbol{L}$ & $\boldsymbol{b}$ & $\boldsymbol{a}$ & $\boldsymbol{L}$ & $\boldsymbol{b}$ & $\boldsymbol{a}$ \\
& 61,86 & 22,08 & 6,48 & 54,83 & 30,41 & 11,03 \\
& $(1,94)$ & $(1,72)$ & $(0,63)$ & $(1,88)$ & $(2,07)$ & $(1,32)$ \\
\hline \multirow{2}{*}{ Bamboo Internal } & 58,42 & 18,77 & 8,38 & 59,84 & 28,51 & 9,91 \\
& $(7,01)$ & $(2,71)$ & $(1,21)$ & $(5,08)$ & $(4,57)$ & $(1,65)$ \\
\hline \multirow{2}{*}{ Palm External } & 46,84 & 16,09 & 6,02 & 47,98 & 12,24 & 6,64 \\
& $(4,50)$ & $(2,98)$ & $(1,17)$ & $(3,98)$ & $(2,12)$ & $(1,27)$ \\
\hline \multirow{2}{*}{ Palm Internal } & 32,66 & 15,58 & 15,00 & 32,40 & 17,11 & 15,51 \\
& $(2,83)$ & $(5,21)$ & $(2,56)$ & $(1,23)$ & $(4,32)$ & $(3,07)$ \\
\hline
\end{tabular}

La Figura 31 muestra el cambio total del color $(\Delta E)$, donde se percibe que las superficies del PHP tienen una mayor estabilidad del color cuando se expuestas a una combinación de radiación y humedad en el sistema CUV UV de envejecimiento acelerado. 


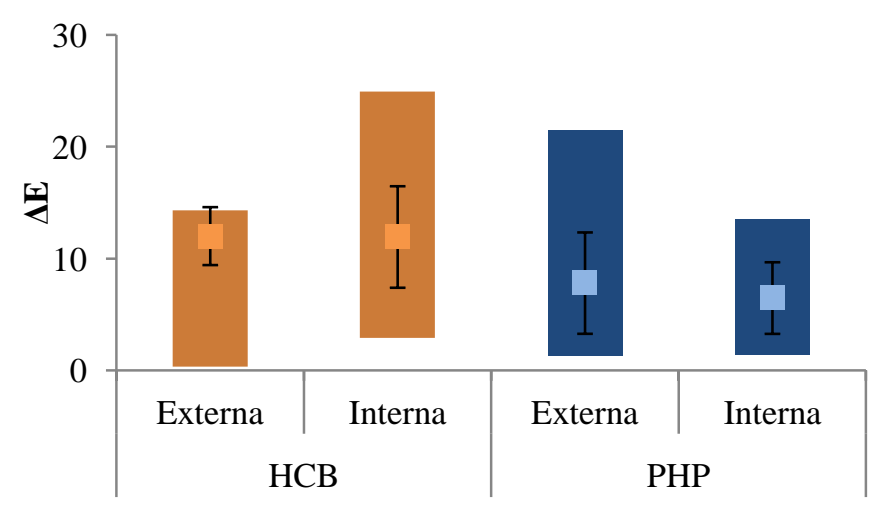

Figura 31 - Cambio total del color en cada superficie

La resistencia a la degradación por causa de las ondas UV están asociadas a la presencia de grupos funcionales ralentizaron la fotodegradación, es este caso retardando la formación de grupos carbonilos (Müller et al. 2003).

\subsubsection{Química de la superficie: análisis por medio de FTIR}

La química de la superficie esta compuesta básicamente de celulosa, lignina, hemicelulosa y extractivos (E. Baysal et al. 2014) y se espera que sea una superficie heterogénea (A. Temiz et al. 2005; Müller et al. 2003; Jian-Guo Dai et al. 2010).

Las ondas encontradas entre 2000 y $4000 \mathrm{~cm}^{-1}$ son el espectro referente a las partículas de agua, a causa de la humedad natural en los cuerpos de prueba (John Wiley 2004), esta se repite en todos los espectros, por esto los siguientes gráficos solo se muestran en la región entre 400 y $2000 \mathrm{~cm}^{-1}$, ya que es en esta región es donde aparecen los grupos funcionales referentes a los compuestos de la superficie.
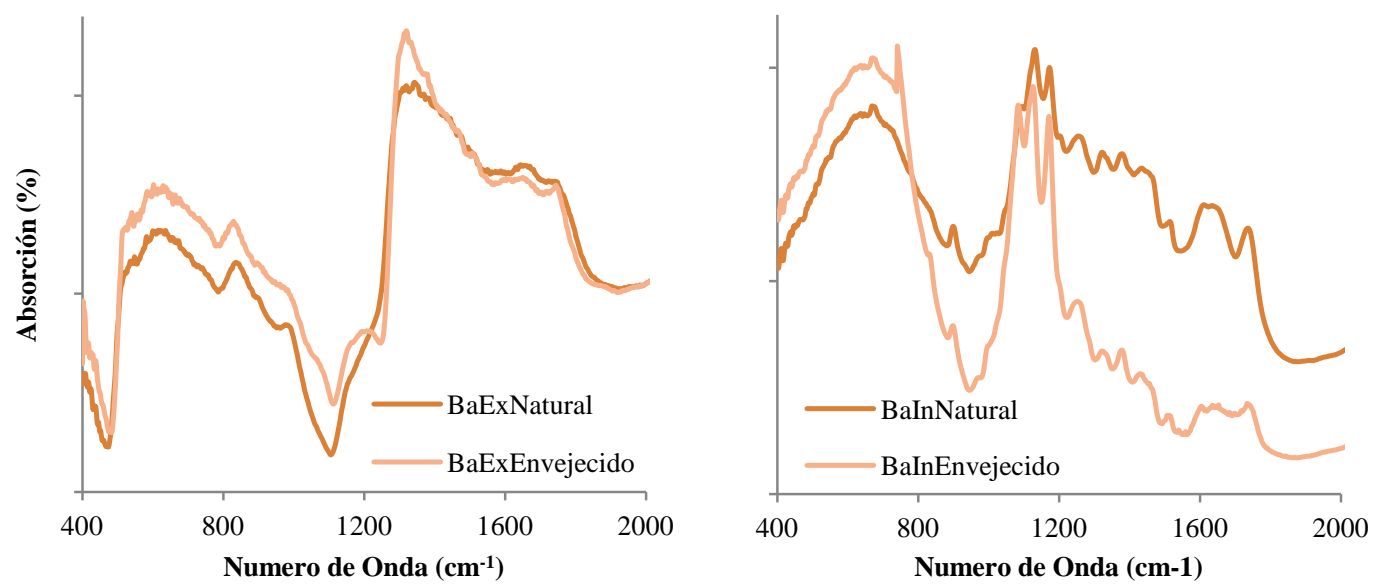

Figura 32 - Espectros en la región infrarroja entre 400 y $2000 \mathrm{~cm}^{-1}$ en la superficie externa (izquierda) y superficie interna (derecha) de la HCB antes y después del envejecimiento acelerado.

La Figura 32 muestra la evidente diferencia en la composición química de las superficies de la $\mathrm{HCB}$, asociadas a la reacción al estímulo de los rayos UV. En la superficie externa de la HCB después del envejecimiento acelerado, se observa un 
aumento en la cantidad de grupos carbonilos $\left(1508-1735 \mathrm{~cm}^{-1}\right)$. En la superficie interna de la HCB solo aparece un nuevo pico $1421 \mathrm{~cm}^{-1}$. Este hecho explica que la decadencia del brillo de la superficie está asociada a la desintegración del contenido de la lignina (Turkoglu, Baysal, and Toker 2015).

Los espectros en la superficie externa e interna del PHP después del envejecimiento acelerado muestran una menor intensidad que en las superficies naturales (Figura 33). En la superficie externa del PHP existe un pico pronunciado en 1720 y $1737 \mathrm{~cm}^{-1}$, asignado a los carbonilos grupo xilano $(\mathrm{C}=\mathrm{O})$, el cual puede estar asociado a la hidrofobicidad de la superficie (Sreekala et al. 2000). Aunque no existen relevantes cambios químicos después del envejecimiento, la absorción dada entre $1500 \mathrm{~cm}^{-1} \mathrm{y}$ $1800 \mathrm{~cm}^{-1}$, es asignada a las vibraciones del grupo acetilo o ácido carboxílico $(\mathrm{C}=\mathrm{O})$, las cuales disminuyen su absorción después de la irradiación la luz UV, en todas las muestras, lo que indica una disminución en los carboxílicos derivados principalmente de lignina (Colom et al. 2003).
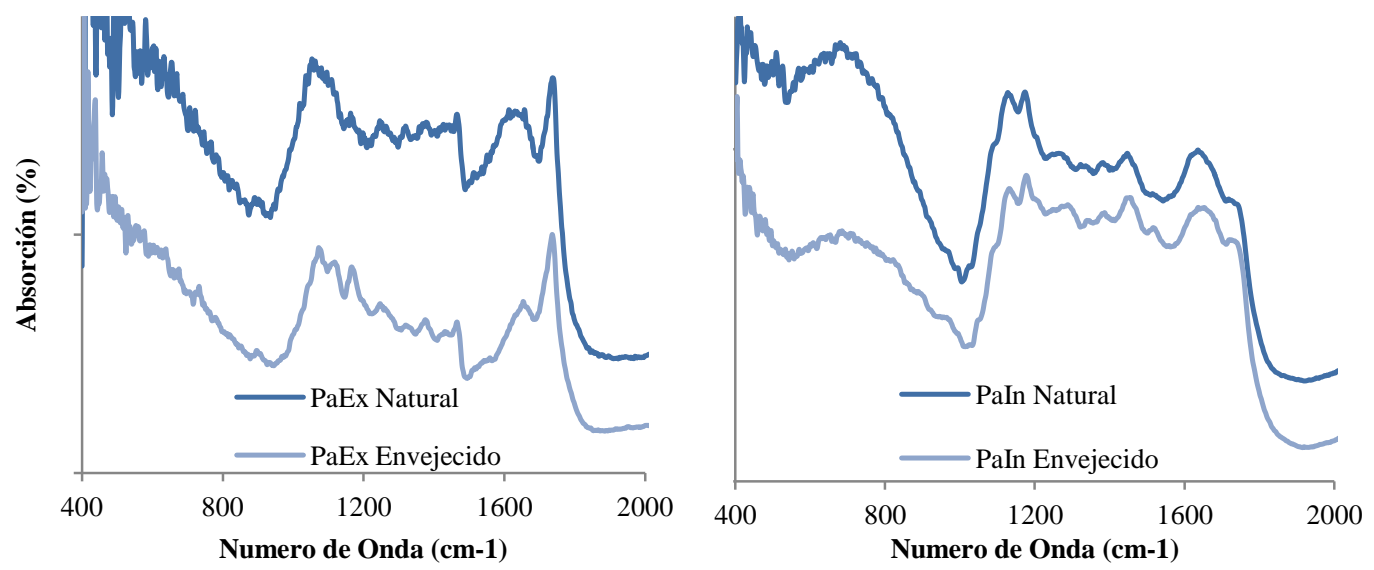

Figura 33 - Espectros en la región infrarroja entre 400 y $2000 \mathrm{~cm}^{-1}$ en la superficie externa (izquierda) y superficie interna (derecha) de la HCB antes y después del envejecimiento acelerado.

$\mathrm{La}$ 
Tabla 8 muestra los picos característicos de las superficies. El grupo $\mathrm{O}-\mathrm{H}$ de los alcoholes primarios y secundarios se muestra ausente en la superficie externa de la $\mathrm{HCB}$, mientras que el $\mathrm{CH}_{2}$ y $\mathrm{C}=\mathrm{C}$ alkenos desaparecen después del envejecimiento, pero aparecen $\mathrm{C}=\mathrm{C}$ aromáticos y $\mathrm{C}=\mathrm{O}$ de las carbonilas, ya el grupo funcional $\mathrm{C}-\mathrm{H}$ de la celulosa y hemicelulosa desaparece después del envejecimiento acelerado en la superficie interna de la HCB. 
Tabla 8 - picos característicos de las superficies de ambos residuos antes y después de los efectos del envejecimiento acelerado

\begin{tabular}{|c|c|c|c|c|c|c|c|c|}
\hline \multicolumn{4}{|c|}{ HCB } & \multicolumn{4}{|c|}{ PHP } & \multirow{3}{*}{ Grupo Funcional } \\
\hline \multicolumn{2}{|c|}{ Externa } & \multicolumn{2}{|c|}{ Interna } & \multicolumn{2}{|c|}{ Externa } & \multicolumn{2}{|c|}{ Interna } & \\
\hline Nat & Envej. & Nat & Envej. & Nat & Envej. & Nat & Envej. & \\
\hline-- & -- & 1130 & 1130 & 1162 & 1162 & 1172 & 1172 & $\mathrm{O}-\mathrm{H}$ alcoholes (primaries y secuncdarios) y eteres alifaticos \\
\hline-- & 1209 & -- & -- & 1245 & 1245 & 1265 & 1265 & $\mathrm{O}-\mathrm{H}$ Fenolico \\
\hline 1328 & 1311 & 1321 & -- & 1373 & 1373 & 1378 & 1378 & $\mathrm{C}-\mathrm{H}$ celulosa y hemicellulose \\
\hline 1436 & -- & -- & 1421 & 1465 & 1465 & 1446 & 1446 & $\mathrm{CH}_{2}$ celulosa, lignin \\
\hline-- & 1508 & 1511 & 1511 & 1511 & 1511 & -- & 1519 & $\mathrm{C}=\mathrm{C}$ aromatico \\
\hline 1654 & -- & 1645 & 1645 & 1629 & 1629 & 1633 & 1633 & $\mathrm{C}=\mathrm{C}$ alkenos \\
\hline-- & 1735 & 1735 & 1735 & 1737 & 1737 & 1720 & 1720 & $\mathrm{C}=\mathrm{O}$ Carbonilas xylan (hemicelulose) \\
\hline
\end{tabular}

\subsubsection{Angulo de Contacto Aparente.}

La Figura 34 muestra la vista superior de una gota de $10 \mu \mathrm{ml}$ depositada sobre la superficie. La Figura 35 muestra la vista lateral usada para estimar el Angulo de contacto aparente.
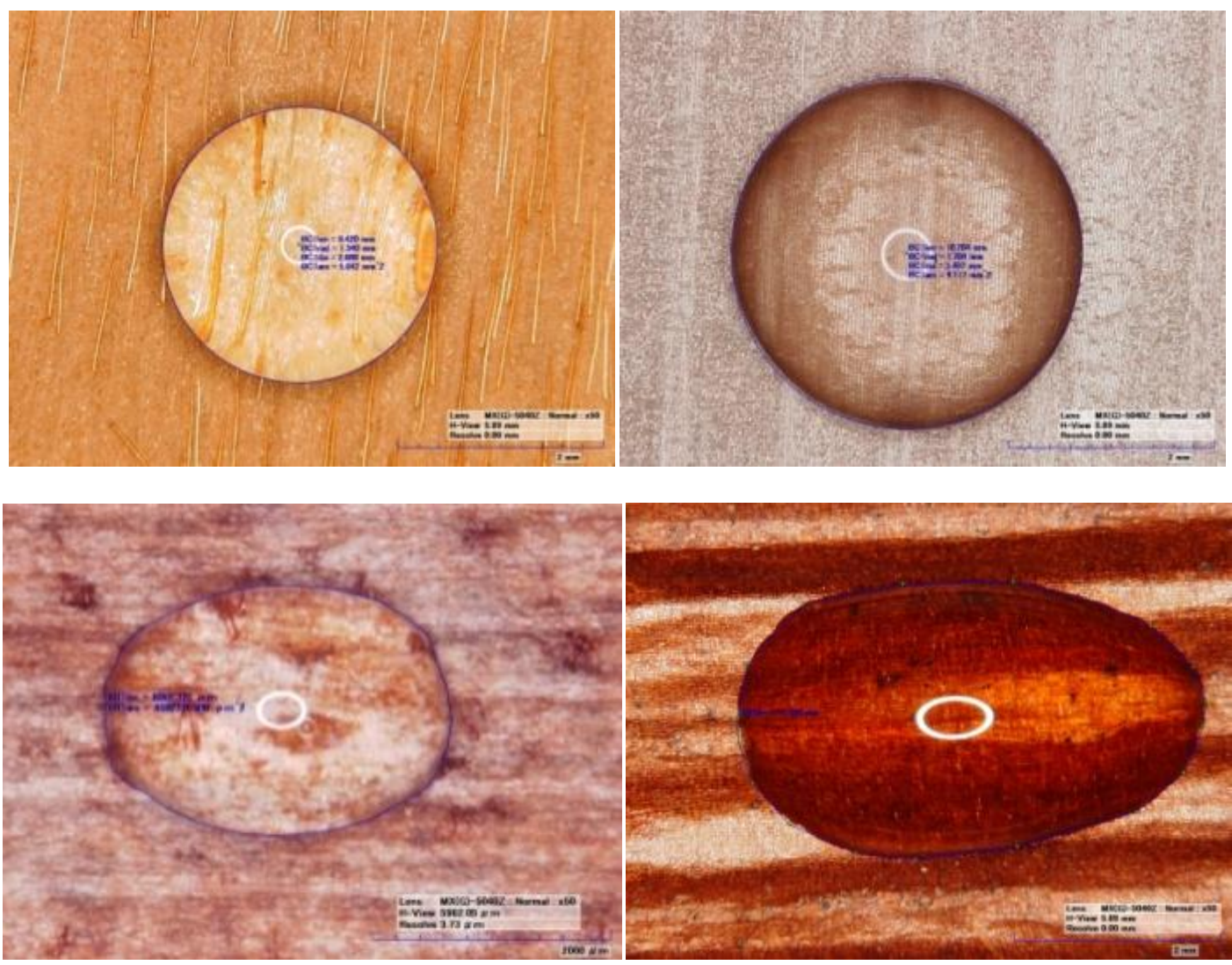

Figura 34 - Vista superior de una gota de agua sobre la superficie natural de la HCB y el PHP. 

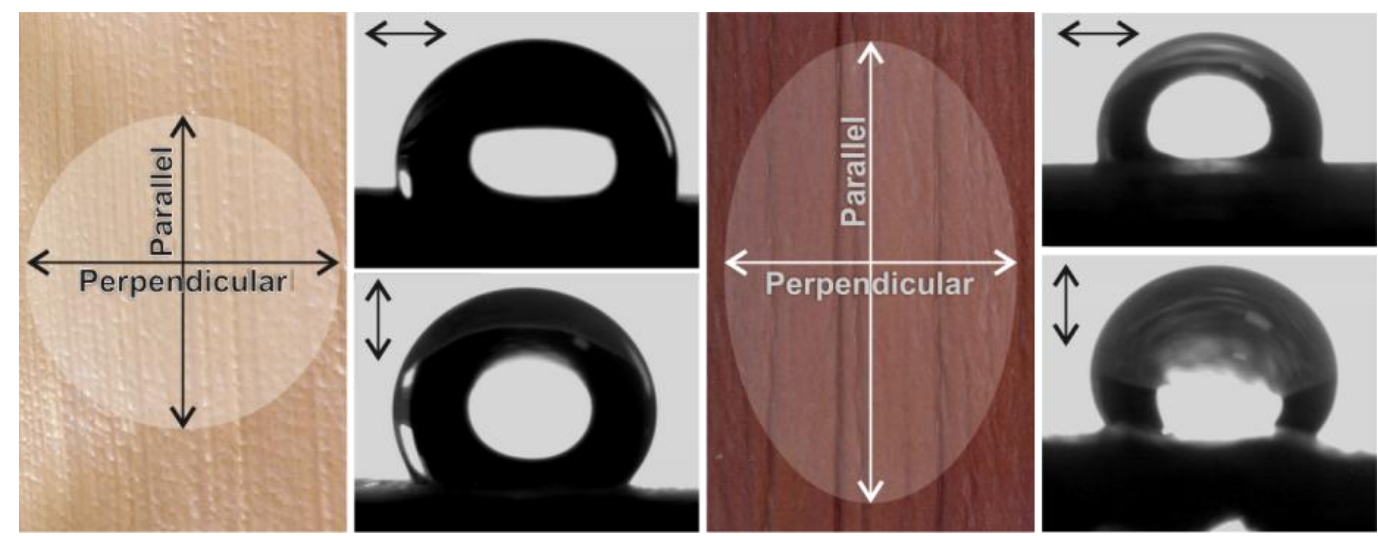

Figura 35 - Vista esquemática que muestra el despliegue de la gota de agua sobre siguiendo la organización de las fibras (paralela o perpendicular).

La gota sobre las dos superficies del PHP tiende a adoptar una configuración geométrica elipsoidal, mientras que la gota sobre la superficie de la HCB tiende a ser perfectamente redonda.

La relación de aspecto de las gotas sobre la $\mathrm{HCB}$ se encuentran alrededor de 1, en ambas superficies, mientras que la relación de aspecto en la superficie externa del PHP es 1,3 y en la superficie interna es 1,4. Estos resultados son coherentes con la textura observada en las imagines de microscopia óptica.

La Figura 36 muestra la secuencia de la interacción de una gota de agua de $3 \pm 0,5 \mu 1$ con la superficie externa de la $\mathrm{HCB}$ in natura durante 10 minutos. En ambos gráficos y debido a la progresión de la gota sobre la muestra, es posible observar que la superficie externa es hidrófoba, es decir, el Angulo de contacto es mayor a $90^{\circ}$.
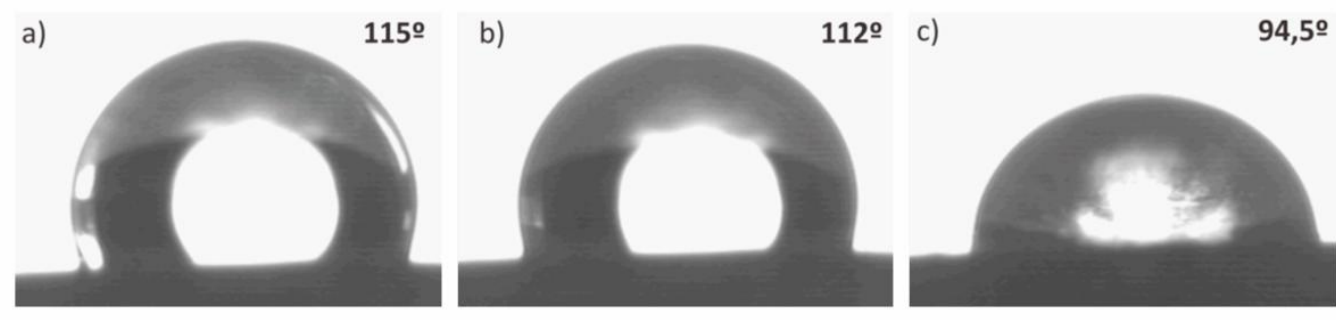

Figura 36 - Interacción del agua con la superficie externa de la HCB a) 15 segundos b) 5 minutos c) 10 minutos después de la aplicación.
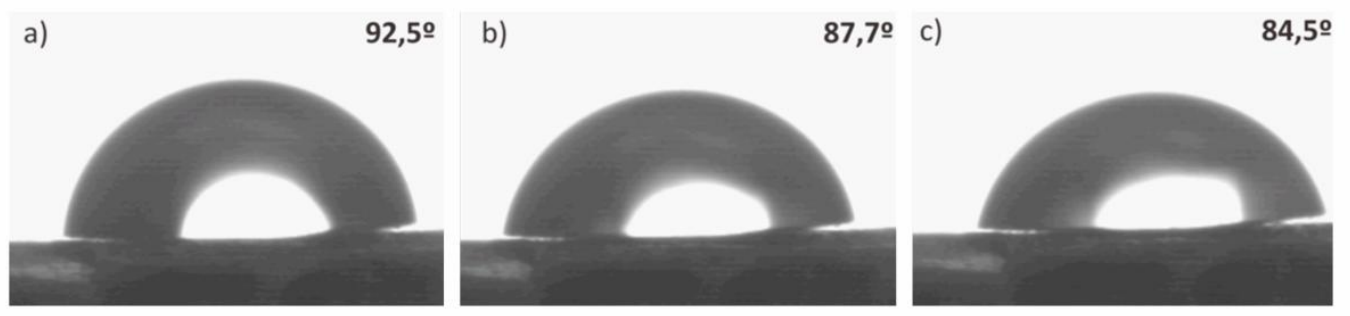

Figura 37 - interacción del agua con la superficie interna de la HCB

a) 15 segundos b) 5 minutos c) 10 minutos después de la aplicación. 
Mientras que la Figura 37 muestra que la superficie interna de la HCB tiende a ser hidrófila. Aunque su Angulo de contacto comienza mayor a $90^{\circ}$ este disminuye considerablemente para catalogar la superficie hidrófila.

La Tabla 9 resume los resultados del Angulo de contacto. La geometría redonda de la gota en las $\mathrm{HCB}$, presenta un promedio de $92^{\circ}$ (superficie interna) y $114^{\circ}$ (superficie externa) cuando el ángulo es medido paralelo a las fibras. La medida perpendicular a las fibras arroja valores de $97^{\circ}$ (superficie interna) y $122^{\circ}$ (superficie externa). Por lo anterior, se puede afirmar que la proporción entre el ángulo de contacto aparente es mayor que la proporción de la relación de aspecto medida en las gotas.

Para el PHP, el ángulo de contacto aparente es mayor cuando es medido perpendicular a las fibras, ya que refleja la energía de disipación necesaria para desbordar los picos de la superficie. Valores promedio de $116^{\circ}$ contra $90^{\circ}$ (superficie externa) y $93^{\circ}$ contra $68^{\circ}$ (superficie interna). Donde nuevamente, se puede afirmar que la proporción entre el ángulo de contacto aparente es mayor que la proporción de la relación de aspecto medida en las gotas.

Tabla 9 - Promedio del ángulo de contacto aparente en las superficies.

\begin{tabular}{|c|c|c|c|}
\hline \multicolumn{2}{|c|}{ HCB } & Perpendicular & Paralelo \\
\cline { 2 - 4 } & Superficie Externa & 122 & 114 \\
\hline \multirow{2}{*}{ PHP } & Superficie Interna & 97 & 92 \\
\cline { 2 - 4 } & Superficie Interna & 116 & 90 \\
\hline
\end{tabular}

En general, las superficies externas presentan ángulos de contactos mayores que las superficies internas, siendo estas altamente hidrófobas. Esto es coherente con el hecho natural que las hojas caulinares deban de repeler substancias que impidan el bloqueo de la luz solar, ya que impediría su proceso fotosintético, por ende el desarrollo de la planta(Rúgolo and Rodriguez 2002) (C. J. Chen et al. 2015). La diferencia de ángulos de contacto entre superficies del mismo residuo probablemente sea un efecto relativo a la composición química y la rugosidad de las superficies.

La Figura 38 muestra la oscilación de los valores en las mediciones del ángulo de contacto, cuando medio en diferente sentido de las fibras: perpendicular (//) y paralelo (-) con sus valores respectivos durante los 10 minutos de ensayo. En la superficie externa de la $\mathrm{HCB}$ los valores oscilan entre $96^{\circ}$ y $112^{\circ}$, los cuales se mantienen estables en $103^{\circ}$ en promedio. Mientras que en las superficies del PHP de contacto de la superficie interna de la HCB. Estos valores oscilan entre $86^{\circ}$ y $95^{\circ}$, en ángulo promedio es de $87^{\circ}$. 


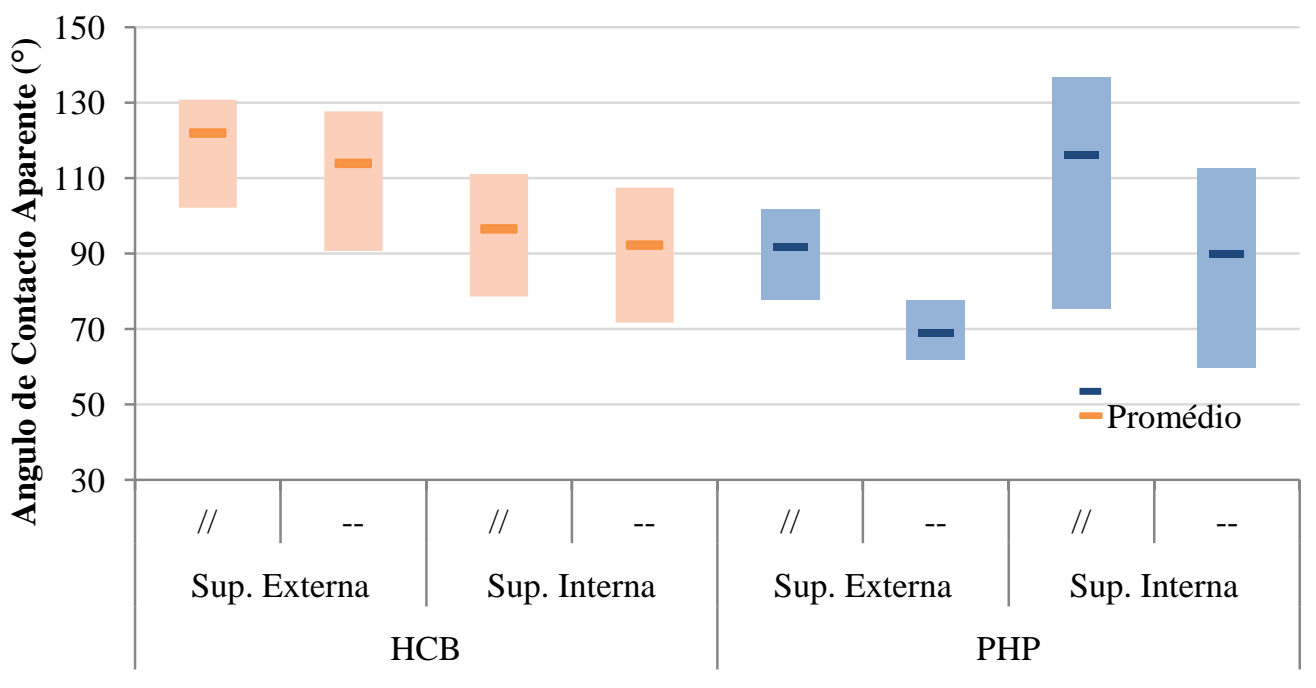

Figura 38 - Angulo de contacto de la superficie externa y de la superficie interna de la HCB y el PHP.

Gran parte de los laminados para revestimientos encontrados en el mercado son a base de celulosa, los cuales según referencias de la literatura (Sampaio 2013), presentan valores de ángulo de contacto menores a $86^{\circ}$.

La variación en la humectabilidad de cada adhesivo es principalmente controlada por la composición química de la superficie interna de la $\mathrm{HCB}$, ya que es más rugoso que la externa.

La Figura 39 muestra los resultados de los valores de Angulo de contacto los cuales, disminuyen considerablemente, por causa de los efectos del envejecimiento acelerado, sobre la superficie.
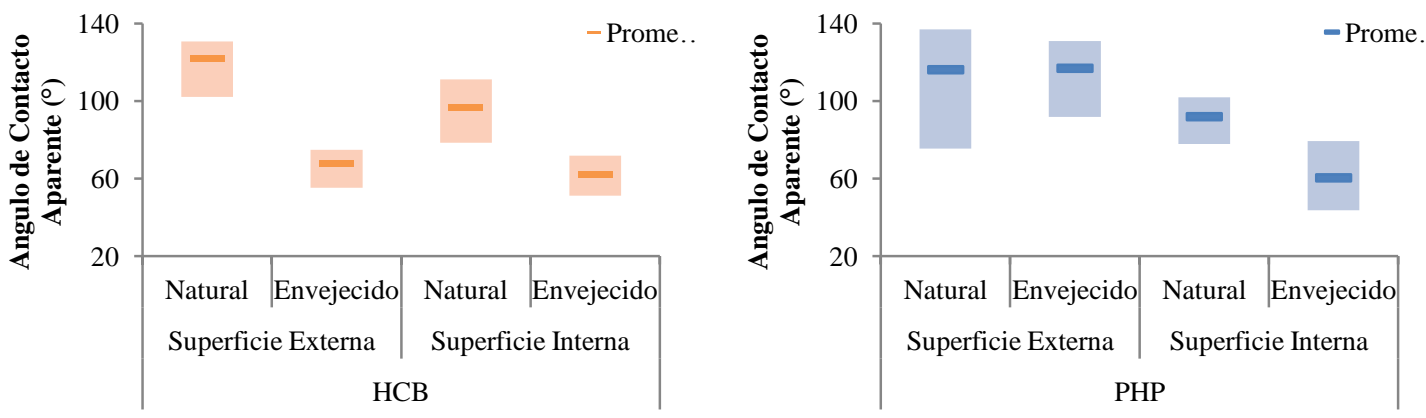

Figura 39 - Angulo de contacto aparente de las superficies sobre la vista perpendicular, en las muestras naturales y envejecidas de cada superficie.

Con lo anterior podemos afirmar que los cambios químicos afectan la humectabilidad de la superficie. Cambios químicos que se reflejaron en los resultados del FTIR. 


\subsection{Prototipo de fabricación del revestimiento: Pre- tratamientos}

El principal objetivo de este trabajo es utilizar residuos lignocelulósicos de grande área superficial en revestimientos decorativos arquitectónicos. Por esto, es necesario definir parámetros antes del proceso de laminado, para evitar daños como grietas y fisuras en la superficie de la HCB y el PHP.

En los pre-tratamientos de los residuos fueron determinados algunos parámetros para la colecta, el lavado y el secado de los mismos. Para la rectificación de las hojas, los tratamientos químicos fueron descartados. El tratamiento termo-mecánico fue el que mostró un mejor desempeño, en cuanto a la preservación de la superficie de la hoja.

\subsubsection{Colecta, lavado y secado}

Otoño es la mejor época del año para la recolección de los especímenes, dada las bajas precipitaciones. Esta estación se caracteriza por la caída de la temperatura y por el color amarillento que provoca en las hojas de los árboles, las cuales caen de los arboles como parte de su proceso natural.

Se puede afirmar que esta estación del año es apropiada para la recolección de los especímenes, dado que el clima no es muy seco ni muy húmedo en estas fechas. Es recomendable que la recolección se haga antes de los meses lluviosos.

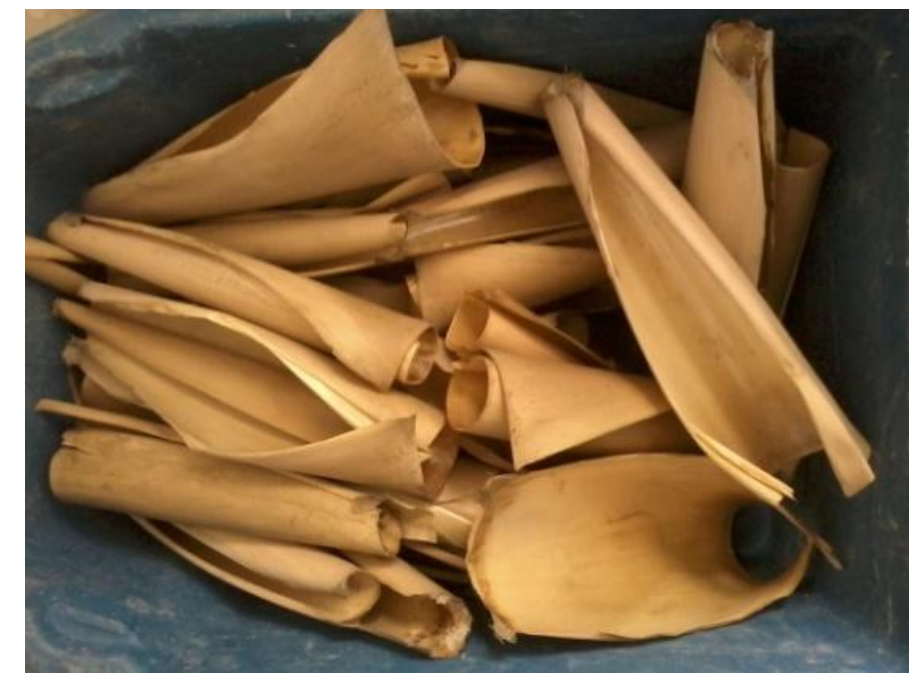

Figura 40 - Primera etapa de recolección de las HCB

Es importante que el monitoreo sea constante en el plantío, para realizar la recolección constante de las hojas.

Las hojas deben permanecer el menor tiempo posible en el suelo, para impedir la proliferación de microorganismos. Su forma cóncava (Figura 40) permite la acumulación de agua, que maximiza la supervivencia de plagas como zancudos y demás insectos voladores. 
La proliferación de microorganismos en las superficies de las hojas causa manchas, dadas por la lluvia y las aguas que entran en contacto con la tierra.

El lavado de las hojas se hizo con agua común del acueducto y un trapo húmedo, para retirar el exceso de impurezas.

Cuando las hojas entran en contacto con el agua tienden a doblarse y enrollarse en sí mismas, por esto las hojas no deben ser sumergidas totalmente en agua. Debe limpiarse, solamente su superficie.

Al mismo tiempo que las hojas están siendo lavadas, la vaina de la hoja comienza a desprenderse, como se muestra en la Figura 41. Obteniendo así, el primer residuo sólidos de la producción de los laminados.

La vaina de las hojas tiene casi la misma apariencia de las hojas caulinares, la diferencia consiste en que la vaina es mucho más flexible. La diferencia en la textura, espesura y flexibilidad de la vaina, permite inducir que en esta parte de la hoja la lignina está menos concentrada.

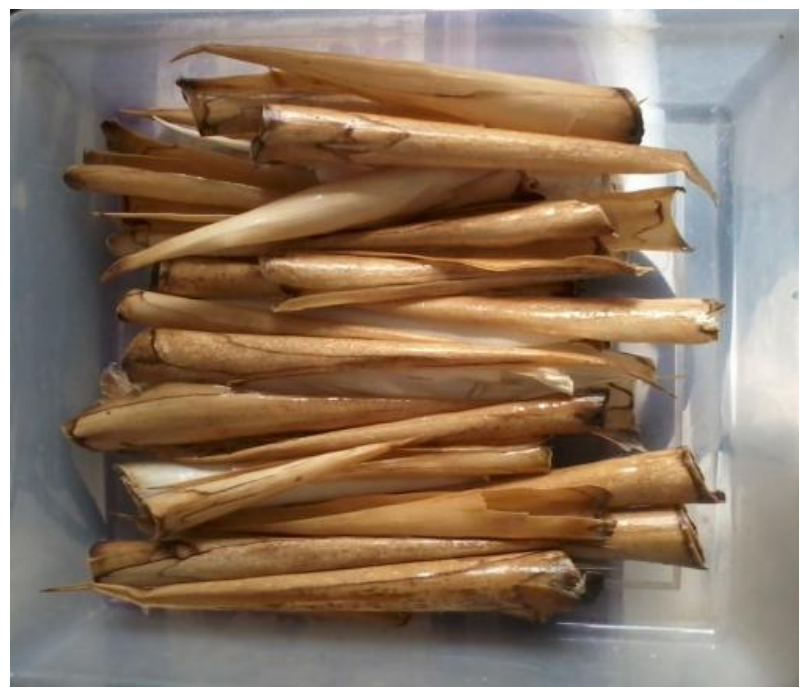

Figura 41 - Residuos de la colecta, vaina de la hoja después del lavado.

Es importante recomendar que durante la temperatura máxima de secado, las hojas no se manipulen, ya que la superficie en este punto de temperatura es extremadamente frágil y puede dañar la hoja.

La temperatura de secado dio un buen resultado debido a que la hoja completamente seca.

\subsubsection{Rectificación de las hojas}

Los procesos de rectificación de las hojas ensayados son divididos en dos tipos: rectificado termo-mecánico (vacuo), rectificado químico y termo-mecánico manual. De estos dos tratamientos el análisis fue cualitativo. 
El tratamiento termo-mecánico manual fue el tratamiento que género mejores resultados, fue el tratamiento termo-mecánico manual, ya que fie el tratamiento que menos daños superficiales causó.

\subsubsection{Tratamiento a vacuo}

Después del tratamiento a vacuo en el autoclave del laboratorio de suelos del programa de construcción civil de la universidad de São Paulo, la superficie de las hojas termino totalmente destruida. Dado el hecho que las fibras de celulosa se desprendieron, por causa de la evaporación de la lignina.

Este ensayo se realizó con el ánimo de ablandar la lignina termo-mecánicamente, pero resulto en la extracción total de la misma. Ocasionando así, el desfibrilamiento completo del material. El agua deionizada que había sido colocada en el liofilizador, se tornó amarilla, debido a los gases emitidos por la evaporación de la lignina

\subsubsection{Tratamiento alcalino}

Las hojas se sumergieron totalmente en una solución de Hipoclorito de Sódio $(\mathrm{NaClO})$ al 2,0\%. Durante tres horas. Intentando modificar la Lignina, con la finalidad de las hojas perder su rigidez.

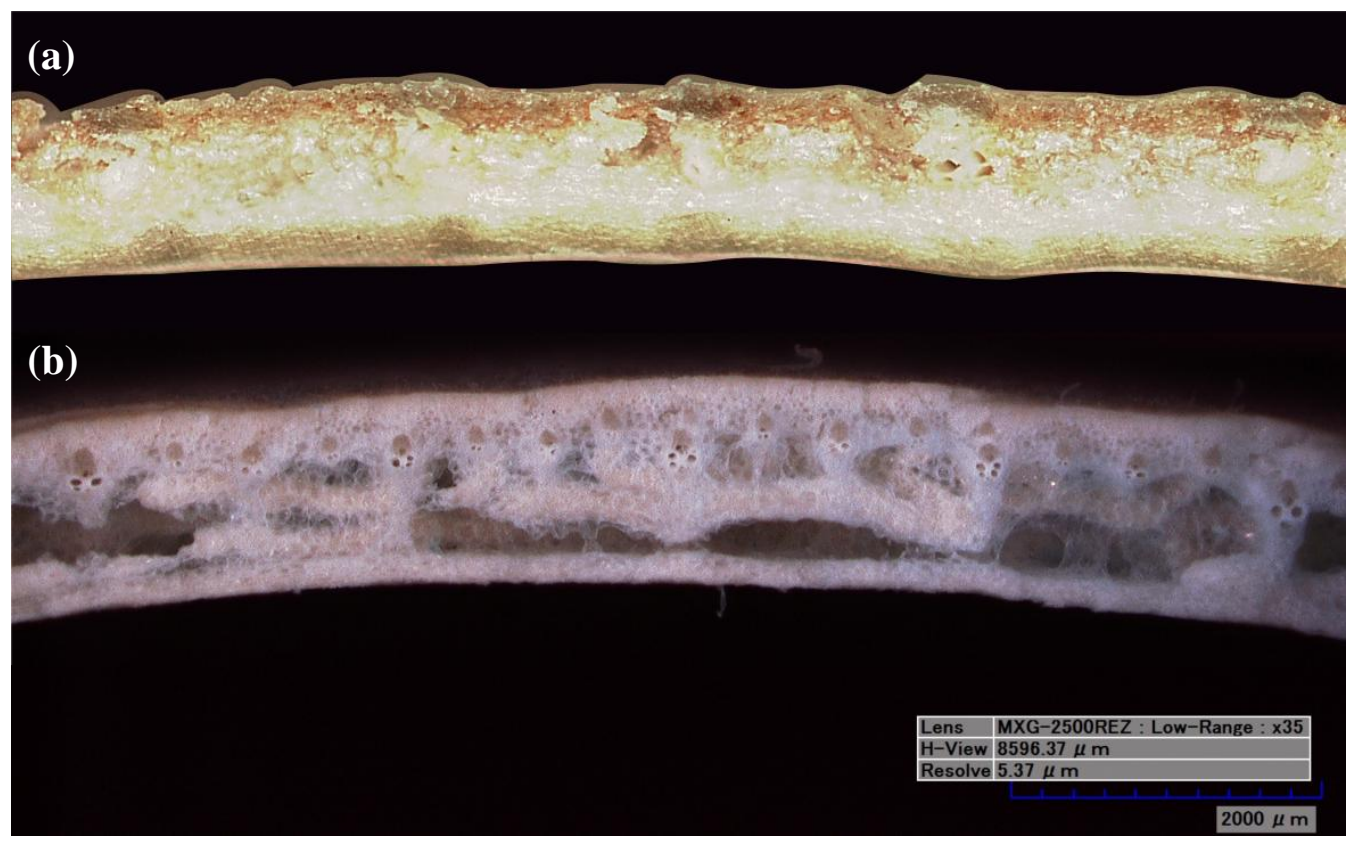

Figura 42 - Microscopia transversal de la HCB antes (a) y después (b) del tratamiuento con NaClO

Este tratamiento se realizó, infundido en el proceso de blanqueamiento de la pulpa celulósica, en el cual comúnmente se utiliza una solución de $\mathrm{NaClO}$, para remover los restos de lignina que quedan de la pulpación mecánica (Silva, et al. 2013; Albinante, Vasques, and Yuan 2013; Martin et al. 2009). Este tratamiento solubiliza la hemicelulosa y la lignina. Cristalizando la celulosa, como se observa en la (Figura 42). 
El NaClO blanqueo parcialmente la superficie de las hojas (Figura 43). Después de este tratamiento, las fibras se debilitaron, tornándose frágiles, al punto que no fue posible manipular el material.

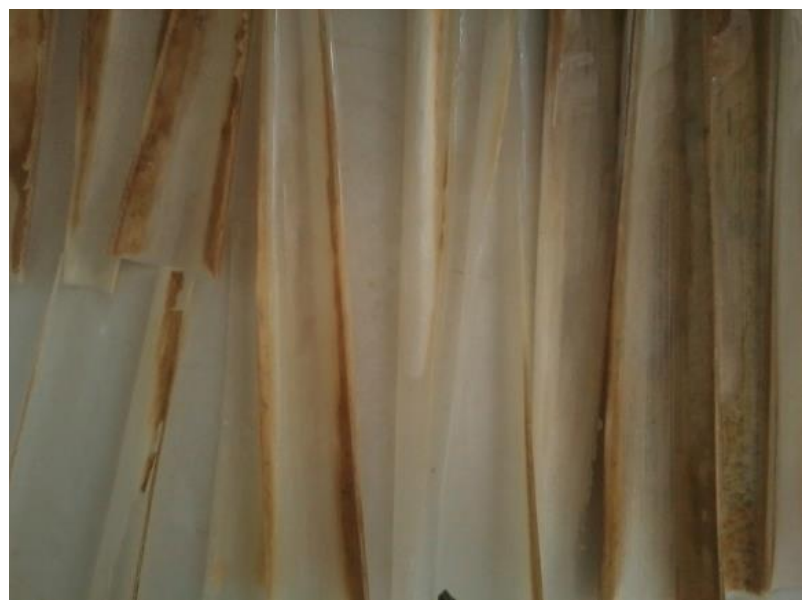

Figura 43 - Superficie de los cuerpos de Prueba después del tratamiento con NaClO

Las mediciones del $\mathrm{Ph}$ se hicieron para conocer la estabilidad de la solución química que estaba siendo utilizada.

Al inicio del experimento el $\mathrm{Ph}$ de la solución química fue de 11, tres horas después de la inmersión de las hojas, bajo para 9,5. Por esto, podemos afirmar que la alcalinidad de la solución disminuyo.

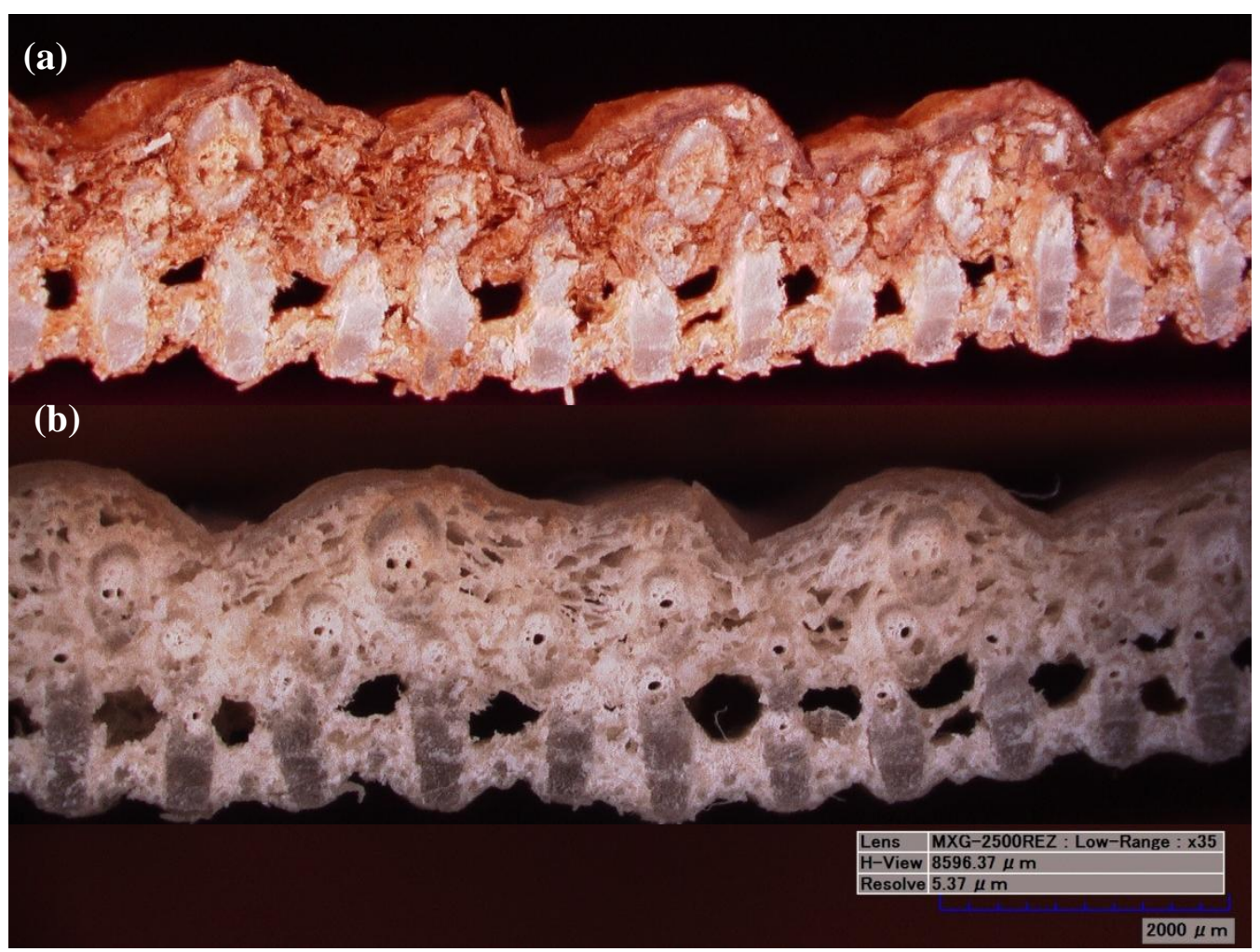

Figura 44 - Microscopia transversal de la PHP antes (a) y después (b) del tratamiento con NaClO

En las fibras del PHP alcalinizadas (Figura 44) se observa el mismo comportamiento de la HCB. Vale la pena resaltar que estas dos últimas micrografías muestran las relevantes 
diferencias en la rugosidad y ondulación de ambas superficies, lo que incentiva a realizar un análisis topográfico antes y después del proceso de laminación.

\subsubsection{Tratamiento termo-mecanico manual}

El tratamiento termo-mecanico manual se realizó con la ayuda de una placa metálica acoplada a una resistencia eléctrica y a un termostato. La temperatura máxima alcanzada por la superficie metálica fue $70^{\circ} \mathrm{C}$. La presión ejercida sobre esta fue manual, por lo que no se tienen datos exactos de presión.

Para este tratamiento, las hojas se saturaron totalmente en agua, con la finalidad de optimizar la transferencia de calor entre el agua y la lignina, así se consiguió solubilizar una pequeña parte de la lignina, permitiendo que la lignina residual se termo-formara.

El proceso de termo-formación que se dio en las hojas, fue debido a que la lignina alcanzó su punto de transición vítrea debido a la temperatura.

La lignina siendo un polímero amorfo posee un punto de transición vítrea que varia considerablemente $\left(135 \mathrm{y} 190^{\circ} \mathrm{C}\right)$, siendo influenciado por la humedad. O sea, con mayor humedad, el punto de transición vítrea de la lignina decrece.

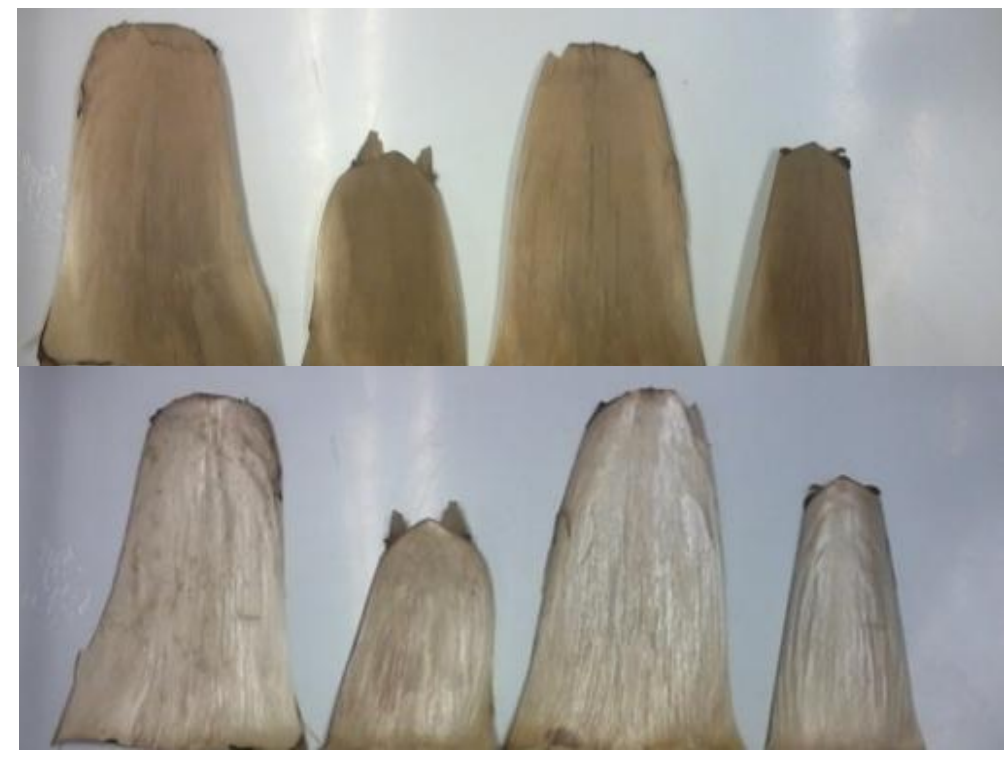

Figura 45 - Superficie externa (arriba) y superficie interna de la HCB después de la rectificación manual.

Este tratamiento ofrece un mayor control sobre la forma final de la hoja y no causa daños a la superficie. Se observó que es necesario utilizar una barrera de protección entre la superficie de la hoja y la superficie metálica, para imitar el manchamiento de la superficie. En la Figura 45 se puede observar que las características visuales de las hojas conservan su superficie natural. Por esto, este tratamiento fue el más apropiado y viable para la rectificación de la superficie.

En las superficies del PHP no fue posible realizar el proceso de rectificado térmico manualmente, por causa de la rigidez de las mismas. Rigidez que solamente en la prensa hidráulica fue posible oprimir. 


\subsection{Producción de laminados}

Los substratos de fibras de HCB y MDF solamente fueron ensayados en las hojas caulinares de bambú.

\subsubsection{Substrato de fibras de la $\mathrm{HCB}$}

En la etapa de fabricación de los revestimientos con fibras de baja densidad se utilizó una resina bi-componente a base de aceite de ricino, la cual es una opción viable para la mitigación de Compuestos Organicos Volatiles (COVs).

Dado el hecho que la aspersión de la resina se hizo solamente en las fibras trituradas, esta no funcionó como adhesivo sobre la superficie de las hojas, dejando así partes de la superficie que no se adhirieron al substrato, que en este caso son las fibras de la hoja trituradas.

Los porcentajes de resina influencian directamente la modificación de la estructura vascular de la hoja, llenando los poros y tornando la superficie más resistente.

En este proceso el espesor del revestimiento fue de $5 \mathrm{~mm}$. Ya que, es la distancia mínima de los separadores utilizados en la prensa hidráulica.

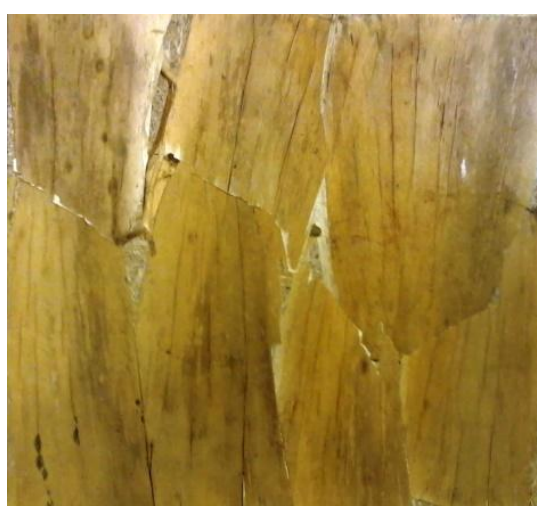

(a)

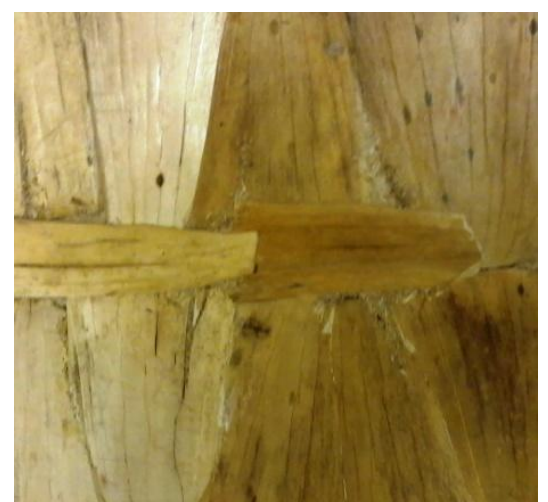

(b)

Figura 46 - Resultado final: Panel de fibras de baja densidad, con núcleo de fibras de HCB. (a) Superficie externa da HCB (b) Superficie externa da HCB

En la Figura 46 se muestra el resultado del panel de fibras de baja densidad. El resultado final muestra que hojas tienden a despegarse del núcleo fibroso.

\subsubsection{Substrato de MDF}

El conformado de los revestimientos con substratos de densidad media fue hecho a frio. La única fuente térmica utilizada fue en el pre-tratamiento de rectificación de las hojas.

Se utilizo una placa de MDF comercial de $3 \mathrm{~mm}$ como substrato. Las hojas fueron impregnadas totalmente con la resina bi-componente a base de aceite de resino, en sus 
dos superficies. En este caso los porcentajes de resina y catalizador fueron de 70 y $30 \%$, respectivamente.

Se dio un bajo porcentaje de catalizador para intentar conservar la translucidez de la resina sobre la superficie de la hoja.

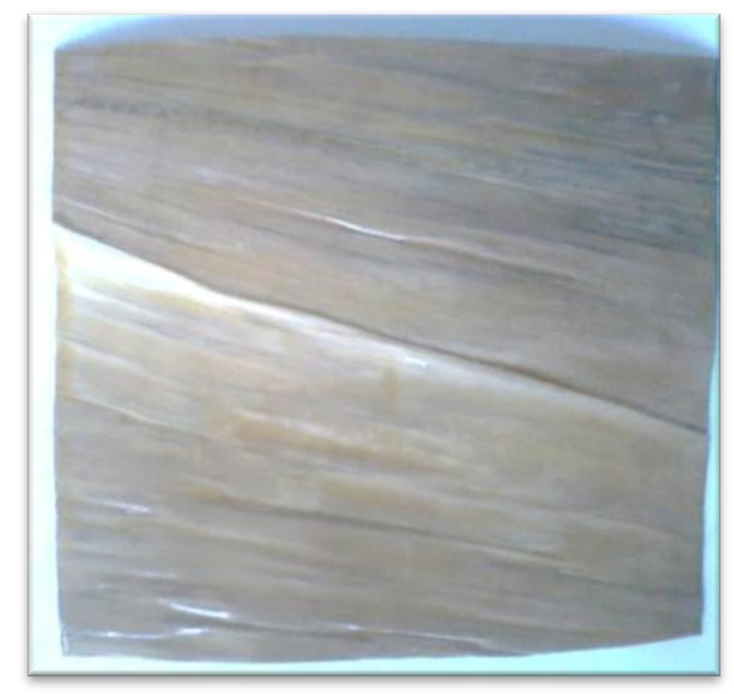

Figura 47 - Revestimiento de HCB utilizando MDF como substrato.

En la Figura 47, la adhesión de la resina en las superficies se mostró eficiente, pero la tendencia alabeada de la superficie es mayor que en los ensayos utilizando la prensa hidráulica en altas temperaturas.

\subsubsection{Substrato de Papel Kraft Pre-impregnado}

La impregnación con fenol-formaldehído ha sido muy utilizada para la mejoría de propiedades, como la resistencia mecánica, la estabilidad dimensional y la durabilidad, en cuanto a ataques químicos se refiere. Ya que, los radicales libres generados por el fenol en su proceso de cura, cuando son de nuevo expuestos a altas temperaturas y alta humedad relativa en el ambiente, los grupos metiles son convertidos en cadenas oligomericas que serán liberadas al entorno (Hoong et al., 2010).

En el primer conformado realizado en el laboratorio de la empresa Madepar, como fue dicho anteriormente (pagina 29) se utilizaron diez hojas de papel kraft impregnado al $32 \%$ con resina fenolica las HCB.

El resultado del primer conformado, en el cual la HCB se colocó directamente sobre el papel kraft. En la Figura 48 se aprecia del lado izquierdo la superficie externa y del lado derecho la superficie interna de la HCB. Denotando la sobreposición de la resina sobre la superficie de la HCB.

Después del proceso de cura del material se aprecia un curvamiento del material, a lo largo de las fibras. 


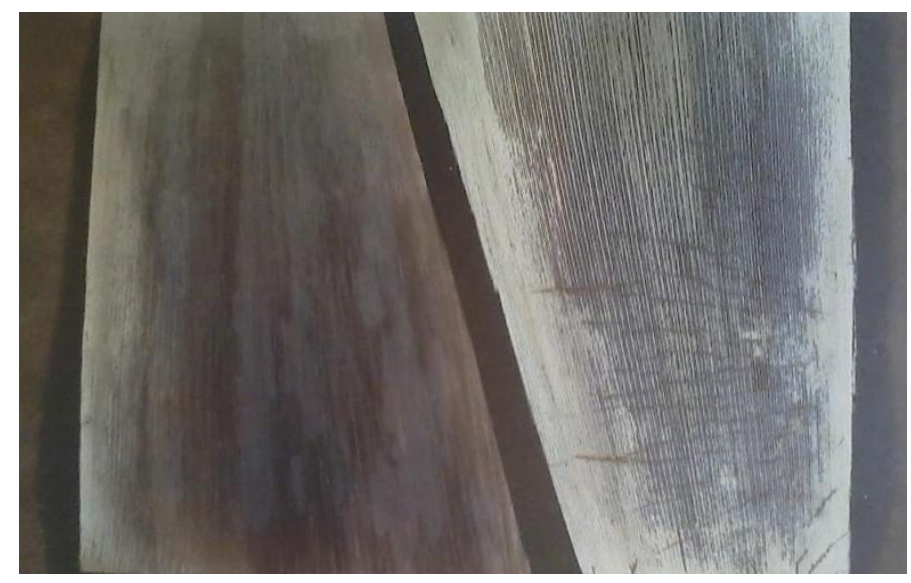

Figura 48 - HCB con substrato de papel Kraft sin barrera

Después de este primer intento de conformado, no fue posible conservar la superficie de la, por esto, se ha recurrido a utilizar una barrera entre el substrato del papel kraft y la HCB.

Esta barrera consiste en una lámina de papel decorativo impregnado con resina melamínica. En este caso fue utilizado papel decorativo blanco. La Figura 49 muestra el cuerpo de prueba usando esta barrera, del lado izquierdo la superficie externa y del lado derecho la superficie interna de la HCB.

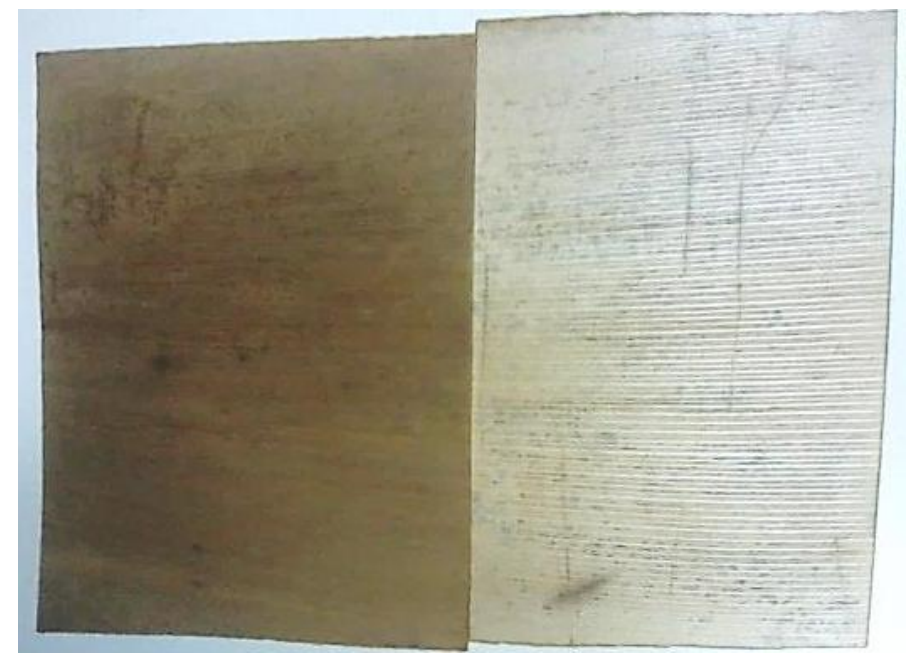

Figura 49 - HCB con substrato kraft y una barrera

Utilizando solamente una barrera de papel (Figura 49), se observa una leve sobre posición de la resina sobre la superficie. Esta sobre posición es aún más notable sobre la superficie interna de la HCB.

Por ultimo, los cuerpos de prueba moldados con dos barreras sobre el substrato kraft, impidieron el flujo de resina hasta la superficie y mantuvieron la adhesión de las HCB sobre el substrato (Figura 50) Aunque utilizando las dos barreras de papel melamínico no percibimos resina en la superficie de la $\mathrm{HCB}$, se observa el aparecimiento de manchas oscuras sobre la superficie, probablemente porque el residuo utilizado todavía conservaba humedad. 


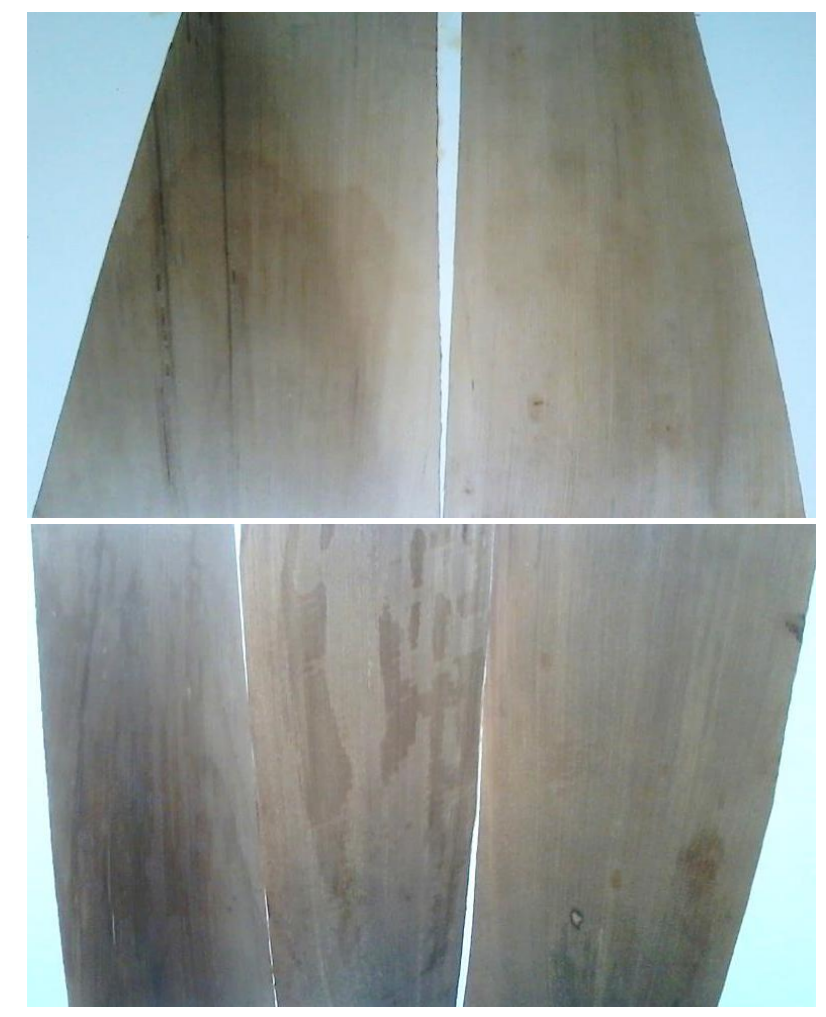

Figura 50- HCB con substrato kraft y dos barreras, superficie interna visible (arriba) superficie externa visible (abajo).

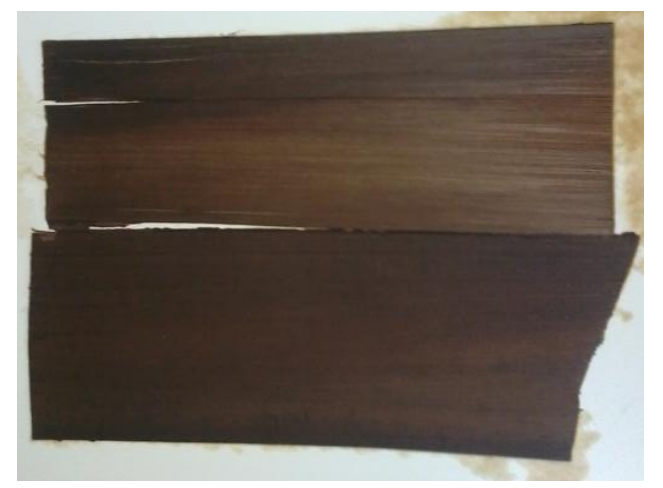

Figura 51 - laminado a base de papel kraft utilizando ambas superficies del PHP

Finalmente, el PHP fue prensado con el mismo procedimiento utilizado en las HCB. (Figura 51). Se observa que la barrera de papel decorativo aparecen manchas color marrón, estas manchas pueden haber sido ocasionadas por la lignina contenida en el material.El PHP conserva su textura, aún después del proceso de laminado. Esto crea una percepción natural en el revestimiento.El uso del substrato de papel kraft, tuvo un desempeño satisfactorio a la hora de laminar el residuo utilizado, dado que las aracterísticas visuales, como la textura y el color lograron ser conservadas después del conformado. 
Las ventajas de este método de laminación son principalmente económicas, ya que es método económicamente viable, que proporciona diferencia al producto, generando ventajas competitivas para el productor de laminados decorativos.

La desventeja es que este método necesariamente requiere que los laminados sean curados mientras durante el proceso de prensado, por esto en los procesos industriales para agilisar la producción, estos son sometidos a un proceso de resfriamiento acelerado.

\subsection{Caracterización de Laminados}

\subsubsection{Topografía de la superficie}

Como fue mostrado en el análisis químico y micro-estructural (capitulo 4.1.3) de la caracterización de los residuos, las HCB y el PHP son una compleja estructura de un material compuesto, formado por extensas cadenas de macro-tubos, las cuales son aglomeradas en el proceso de laminación. Por esto las siguientes imágenes muestran los efectos de la laminación en cada una de las superficies estudiadas.

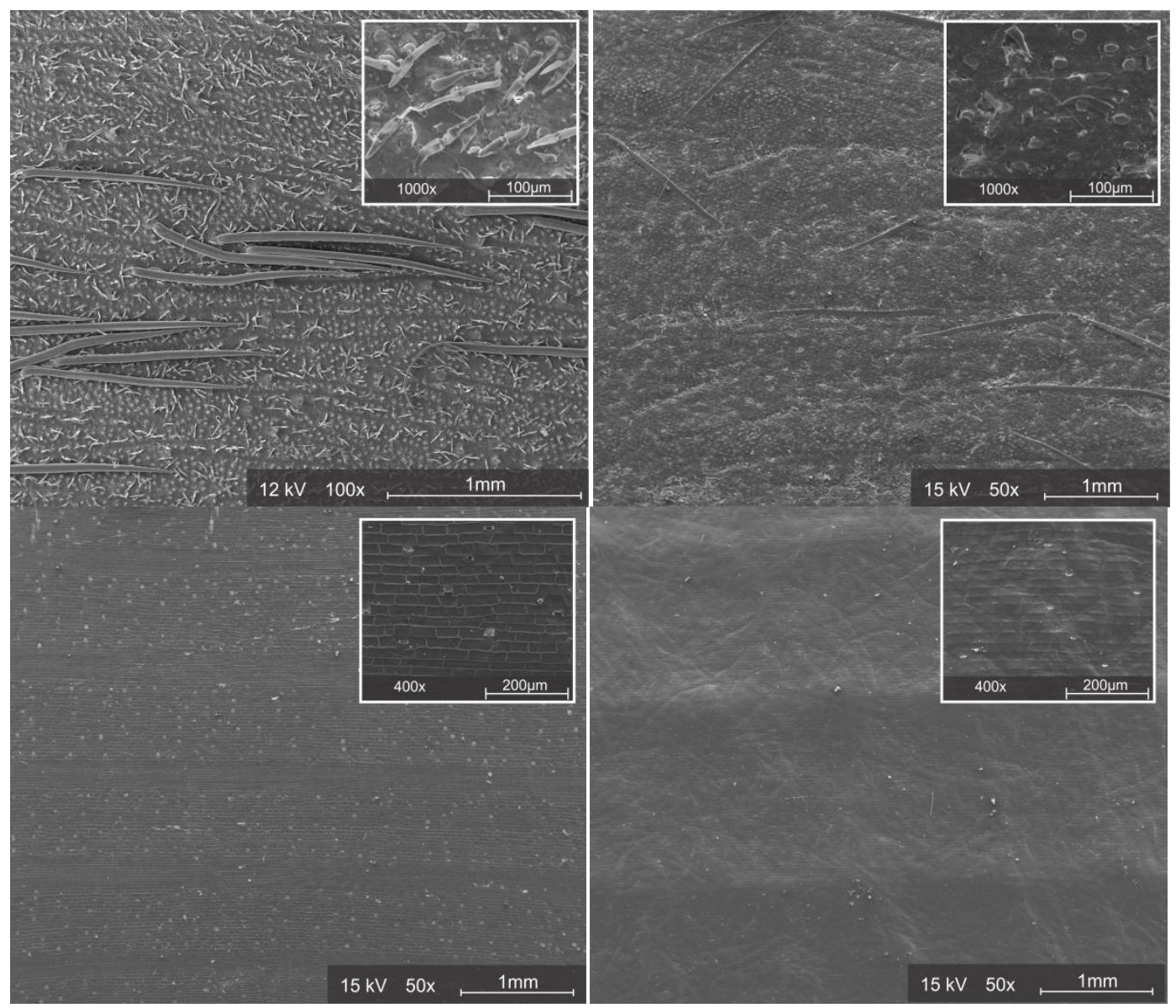

Figura 52 - Superficies de la HCB. Arriba: Superficie externa natural (izquierda) laminada (derecha). Abajo: Superficie externa natural (izquierda) laminada (derecha). 
La Figura 52 muestra las superficies de la HCB antes y después del proceso de laminación. En las superficies externas se observa que la pubescencia es menos relevante en el laminado y que las macro-saliencias de la superficie natural dejan huella en el laminado. La superficie interna muestra una estructura organizada y lisa que es separada por fibras cada $0,5 \mathrm{~mm}$ aproximadamente. Esta organización rugosa, recuerda la formación del tallo del bambú, el cual es separado por nudos. En el laminado se observa que las fibras que separan esta estructura organización estas fibras se vuelven mas relevantes, creando mayores ondulaciones en la superficies.

El análisis de EDS muestra que las superficies externas naturales de la $\mathrm{HCB}$, tienen altos índices de silicio, los cuales disminuyen con la laminación. Mientras que en las superficies internas no se encuentran señales de silicio, sin embargo la presencia de potasio y azufre, los cuales desaparecen en el proceso de laminado.
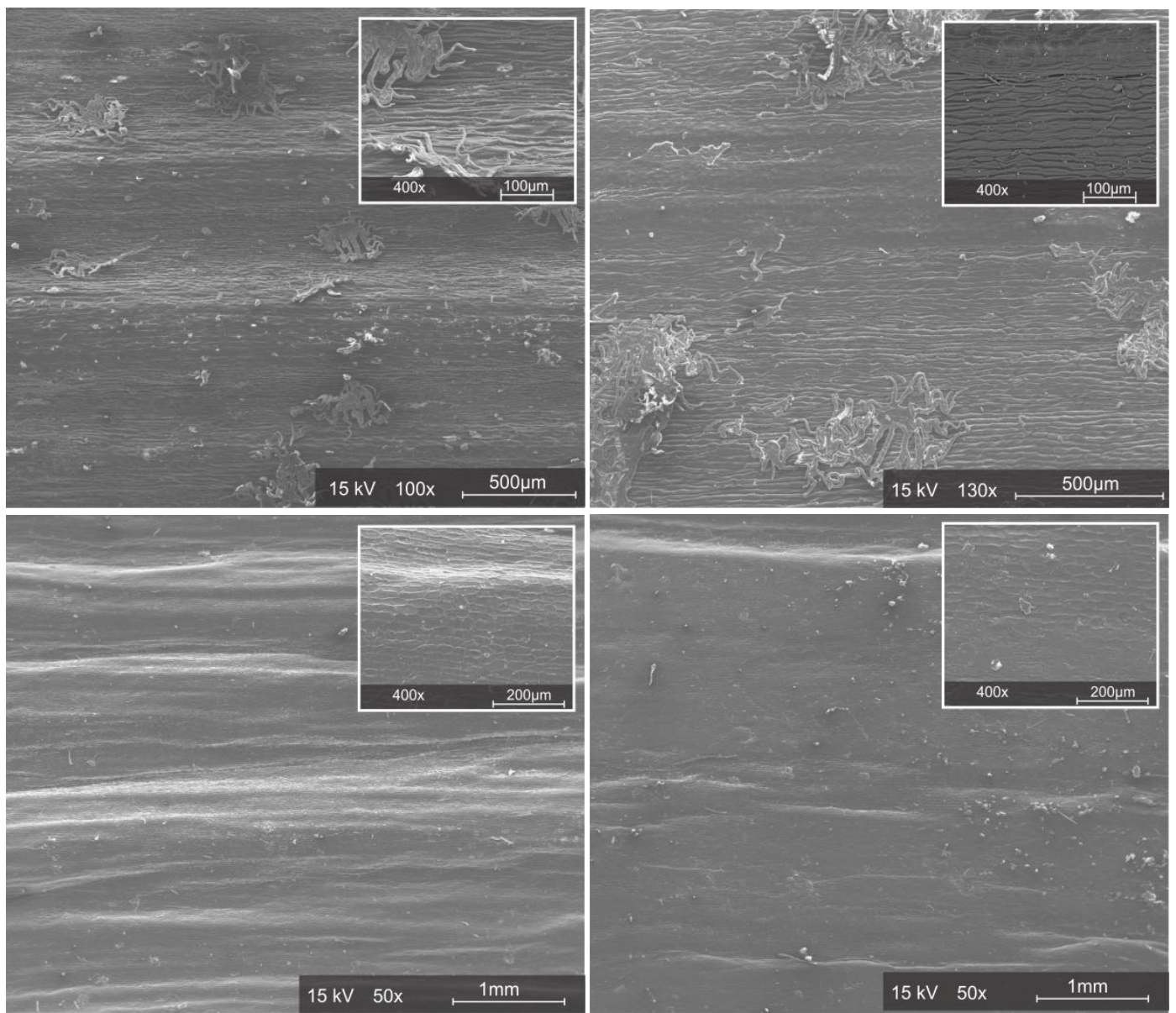

Figura 53 - Superficies del PHP. Arriba: Superficie externa natural (izquierda) laminada (derecha). Abajo: Superficie externa natural (izquierda) laminada (derecha).

La microscopia que se muestra en la Figura 53, no permite ver las ondulaciones características de las superficies del PHP, pero se observa que la capa de esta, posee ondulación y a su vez micro-rugosidades organizadas de diferentes formas. En la superficie externa la rugosidad es bastante sobresaliente en forma de "ladrillos encadenados", como acontece en la superficie interna del HCB, mientras que en la superficie interna esta rugosidad no sobre sale tanto. 
El análisis de EDS en las superficies del PHP, muestra señales de sodio, calcio, silicio, potasio en las superficies externas, las cuales disminuyen su intensidad después del proceso de laminado. En las superficies internas, se muestran señales calcio, potasio y azufre; las cuales disminuyen considerablemente después de la laminación, dando nuevas señales de silicio y cloro, considerablemente altas.

\subsubsection{Rugosidad}

Las hojas caulinares utilizadas en esta investigación son un material compuesto natural, que posee una compleja estructura fibrosa, la cual genera en su superficie ciertas ondulaciones y rugosidades, como se observó en las micrografías. Imágenes de perfil de los residuos muestran que las superficies de la HCB son más planas que las superficies del PHP.

La Figura 54 presenta un modelo 3D de la superficie de las HCB antes y después del proceso de laminación, producida con un perfilómetro óptico. La superficie externa de referencia de la $\mathrm{HCB}$ es una superficie atípica, debido a la posición aleatoria de las macro-fibras, por otro lado, la superficie interna de referencia, se muestra como una superficie lisa en relación a la superficie externa.

Para las superficies laminadas de la $\mathrm{HCB}$ el modelo 3D no muestra señales de las macro-fibras, pero se muestra una región mas pronunciada en las ondulaciones, como se exhibe en el perfil de rugosidad en la Figura 55. Después de la laminación de las HCB su estructura fibrosa interna crea ondulaciones sobre la superficie de las mismas, por causa de la compactación del compuesto, lo que ha causado una termoformación de la superficie adhiriéndose a las estructura fibrovascular.
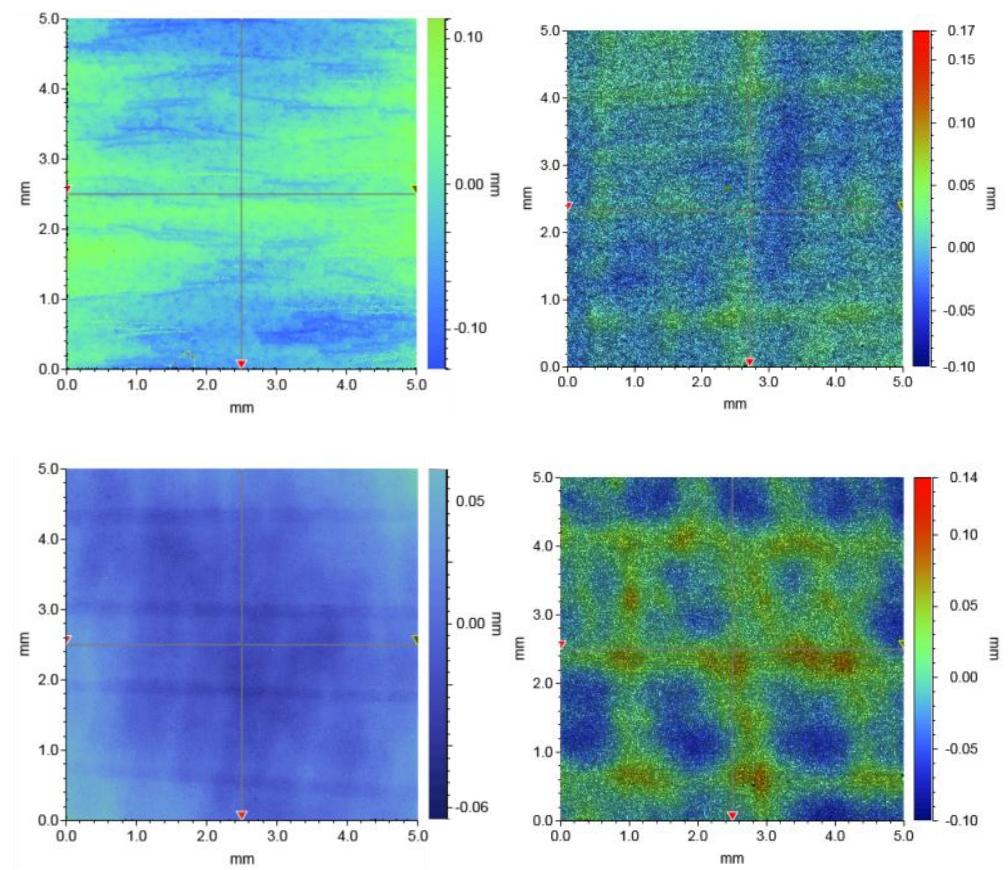

Figura 54 - Topografía de la superficie medidas por interferométria óptica en diferentes magnitudes sobre un área de 5x5mm. 
El perfil de rugosidad en las HCB naturales es atípico, dada la exposición natural y la misma organización aleatoria de las macro-saliencia en la superficie.

En los perfiles de la HCB laminada, se comienza a percibir patrones de rugosidad y ondulación, porque la laminación con temperatura permite que las capas que cubren las superficies se termoformen envolviendo completamente las fibras vasculares.

Por esto se puede identificar que las ondulaciones que se crearon en la superficie interna después de la laminación, las cuales se repiten cada $1 \mathrm{~mm}$. de la misma forma como se percibe en las imágenes microscópicas.
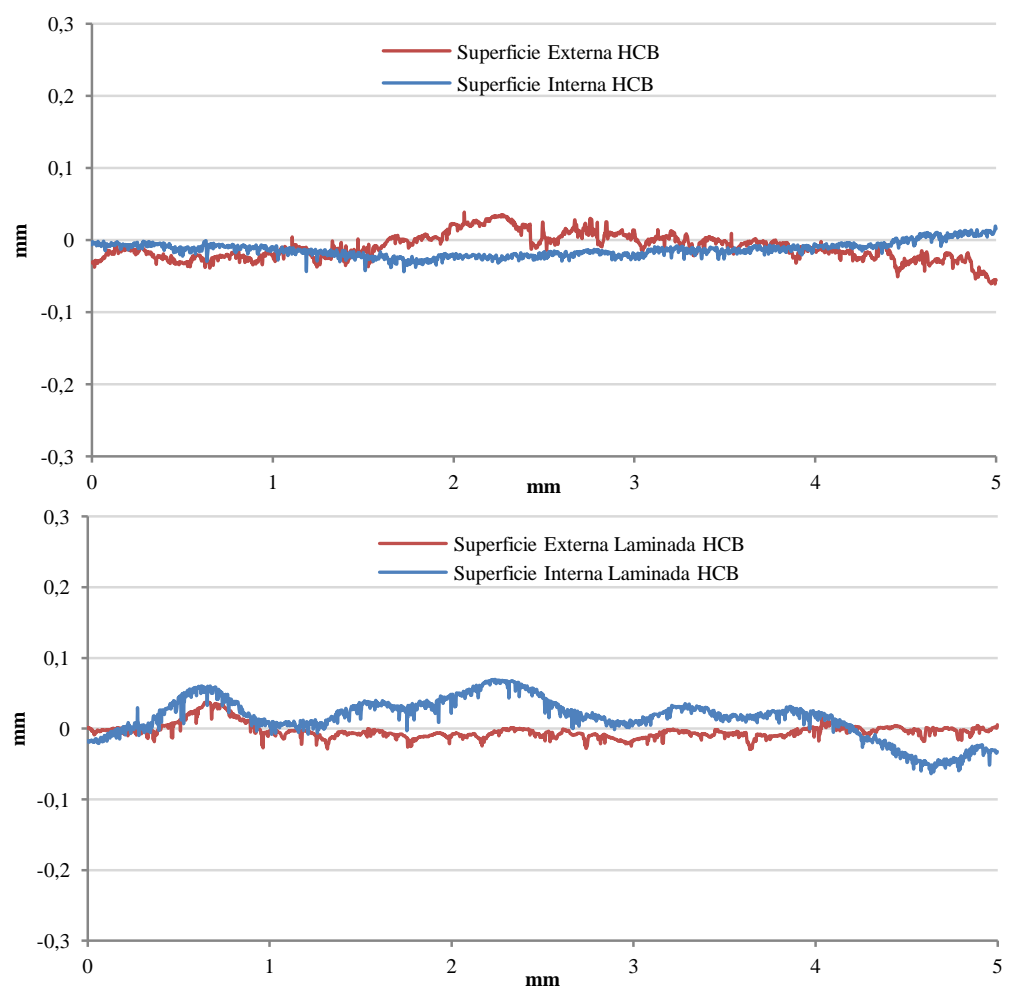

Figura 55 - Perfil representativo de rugosidad (y) de las superficies de la HCB antes y después de la laminación. Superficie natural (arriba), superficie laminadas (abajo)

La Figura 56 muestra que la superficie externa natural del PHP posee picos máximos que representan la fibras de la estructura interna, las cuales le dan un aspecto ondulado a las mismas; esta ondulación es sensible al tacto humano, estas fibras tienen un ancho de aproximadamente $500 \mu \mathrm{m}$ en la superficie externa del PHP, y un inter-espaciado que varía entre 150 y $300 \mu \mathrm{m}$. Mientras que en la superficie interna natural el ancho de las fibras es de aproximadamente $1 \mathrm{~mm}$ micras, variando su inter-espaciado entre 50 y 150 micras. 

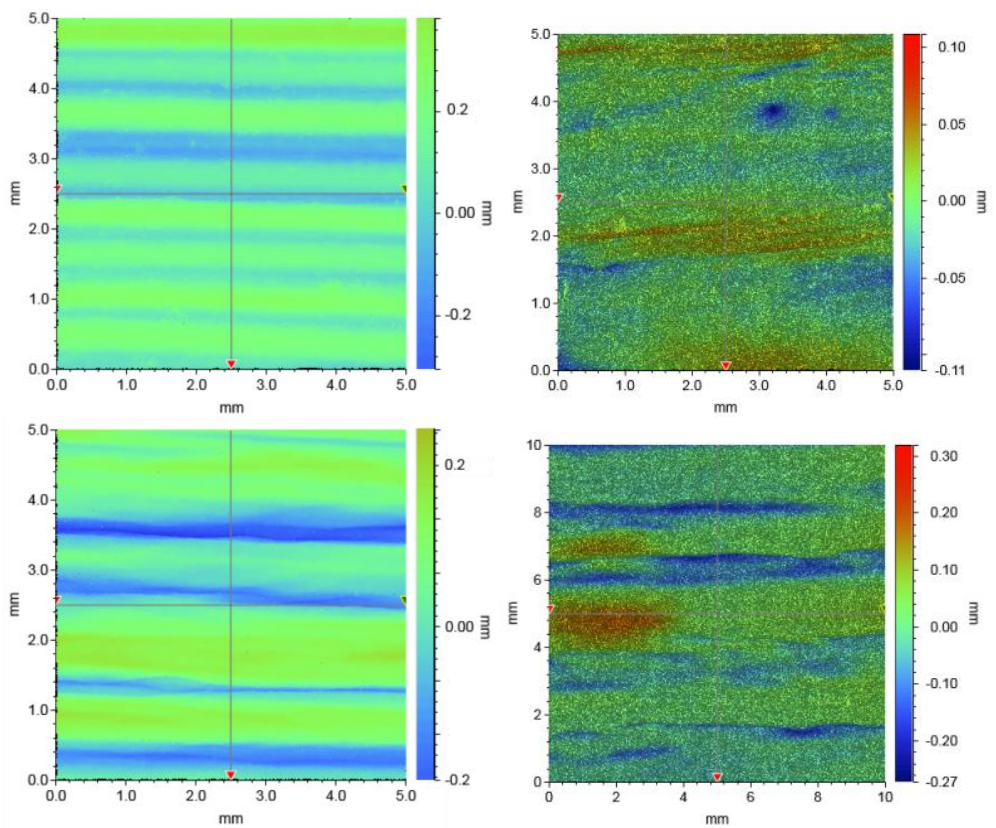

Figura 56 - Topografía de la superficie medidas por interferométria óptica en diferentes magnitudes sobre un área de $5 \times 5 \mathrm{~mm}$.

En los perfiles de rugosidad del PHP (Figura 57) se percibe que con la laminación este inter-espaciado se pierde, perdiendo así la ondulación y dejando ambas superficies del PHP mas lisas.
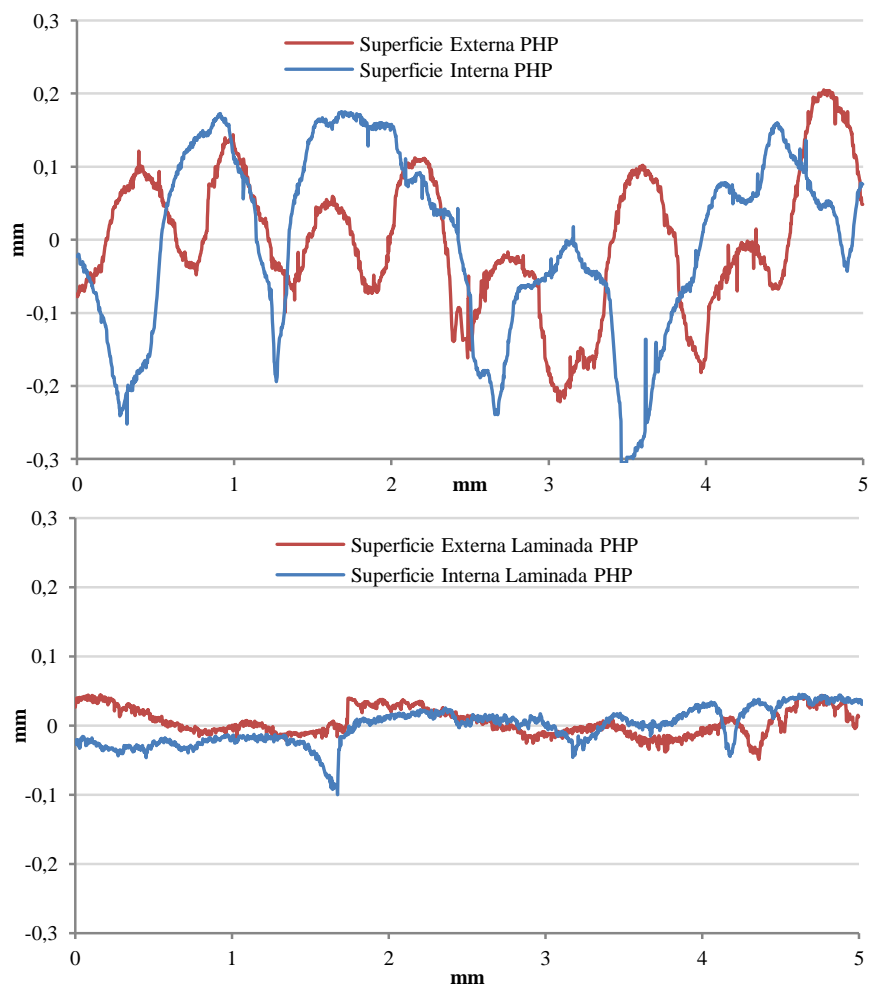

Figura 57 - Perfil representativo de rugosidad (y) de las superficies del PHP antes y después de la laminación. Superficies naturales (arriba), superficies laminadas (abajo).

La Tabla 10 representa un sumario de los valores medios y los cuadrados de la rugosidad de las superficies, concluyendo que la única superficie en la cual se aumenta la rugosidad después del laminado es la superficie interna de la HCB, debido al aumento 
en su ondulación. Mientras que la rugosidad y la ondulación en las demás superficies disminuye considerablemente después de la laminación.

Tabla 10 - Medidas de Rugosidad promedio de cada Superficie

\begin{tabular}{|c|c|c|c|c|c|c|c|}
\hline \multicolumn{2}{|c}{ Superficie } & \multicolumn{3}{|c|}{ Referencia } & \multicolumn{3}{c|}{ Laminada } \\
\cline { 3 - 8 } \multicolumn{2}{|c|}{} & Sa (mm) & $\begin{array}{c}\text { Sq } \\
(\mathbf{m m})\end{array}$ & DS (\%) & Sa (mm) & Sq (mm) & DS (\%) \\
\hline \multirow{2}{*}{ HCB } & Externa & 0,017 & 0,020 & 1,14 & 0,008 & 0,010 & 0,72 \\
\cline { 2 - 8 } & Interna & 0,015 & 0,016 & 0,75 & 0,027 & 0,032 & 1,73 \\
\hline \multirow{2}{*}{ PHP } & Externa & 0,076 & 0,093 & 5,41 & 0,016 & 0,20 & 1,22 \\
\cline { 2 - 8 } & Interna & 0,106 & 0,125 & 6,70 & 0,029 & 0,43 & 3,18 \\
\hline
\end{tabular}

Dada la características anatómicas, particularmente por la elevada porosidad y los altos porcentajes de celulosa y hemicelulosa, que se caracterizan por ser compuestos higroscópicos (Melo et al. 2015), se ha realizaron ensayos para conocer el comportamiento humectante de estos residuos, tanto en su estructura interna como en sus superficies. Los resultados expresos a continuación.

\subsubsection{Comportamiento humectante}

En la tentativa de conocer los efectos de la laminación, en el comportamiento humectable de las superficies, el ángulo de contacto de las superficies fue medido. De forma general, la variación disminuye en todas las medidas, y el ángulo de contacto aparente disminuye considerablemente en todas las superficies, dejándolas más hidrófilas.

La Figura 58 muestra que el Angulo de contacto en las superficies de la HCB. En la superficie externa disminuye $121,9^{\circ}$ a $102,1^{\circ}$ y en la superficie interna disminuye de $96,5^{\circ}$ a 71,4 en promedio. Lo que quiere decir que las superficies laminadas tienden a ser hidrófilas después de la laminación.

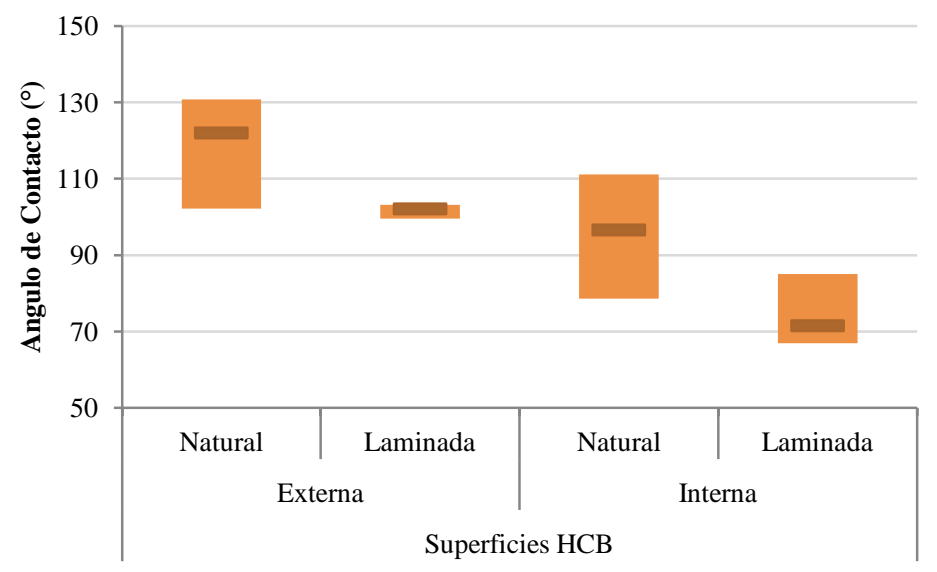

Figura 58 - Angulo de contacto aparente de las superficies de la HCB antes y después del proceso de laminación

La Figura 59 muestra que en las superficies del PHP, los valores promedios de Angulo de contacto en disminuyen de $91,8^{\circ}$ para $91,3^{\circ}$ en la superficie externa y en la superficie interna disminuye desde $116,1^{\circ}$ hasta $96,5^{\circ}$. 


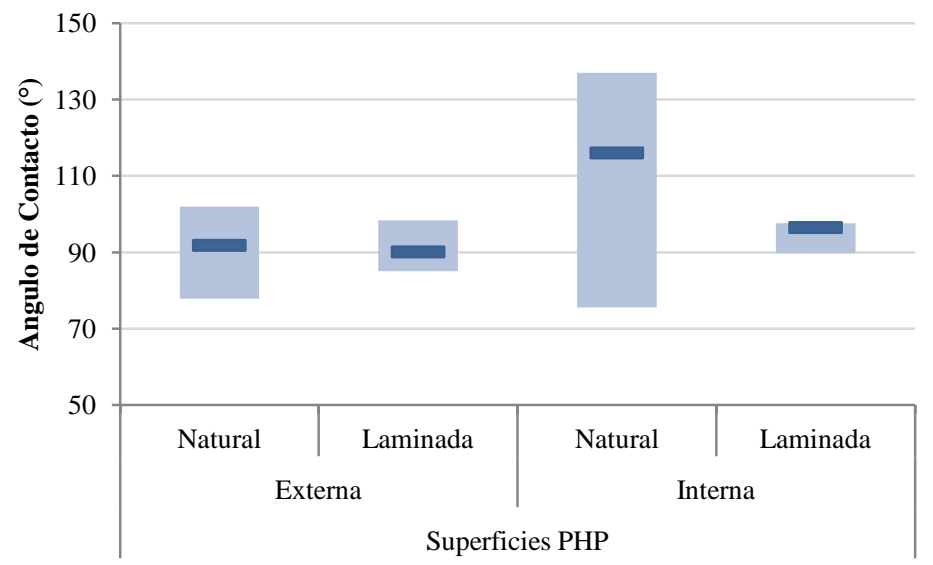

Figura 59 - Angulo de contacto aparente de las superficies de la PHP antes y después del proceso de laminación

En la Figura 60 se observan la capacidad de absorción de agua de los dos residuos. En las HCB, después de dos horas de inmersión total se obtuvieron valores de 53,01\% y 53,17, mínimo y máximo, respectivamente. Después de 24 horas de inmersión percibimos que los valores mínimos y máximos, cambiaron para 54,81\% y 70,53\% aproximadamente. El valor promedio en 2 horas fue de 54,81\% y en 24 horas $61,36 \%$.
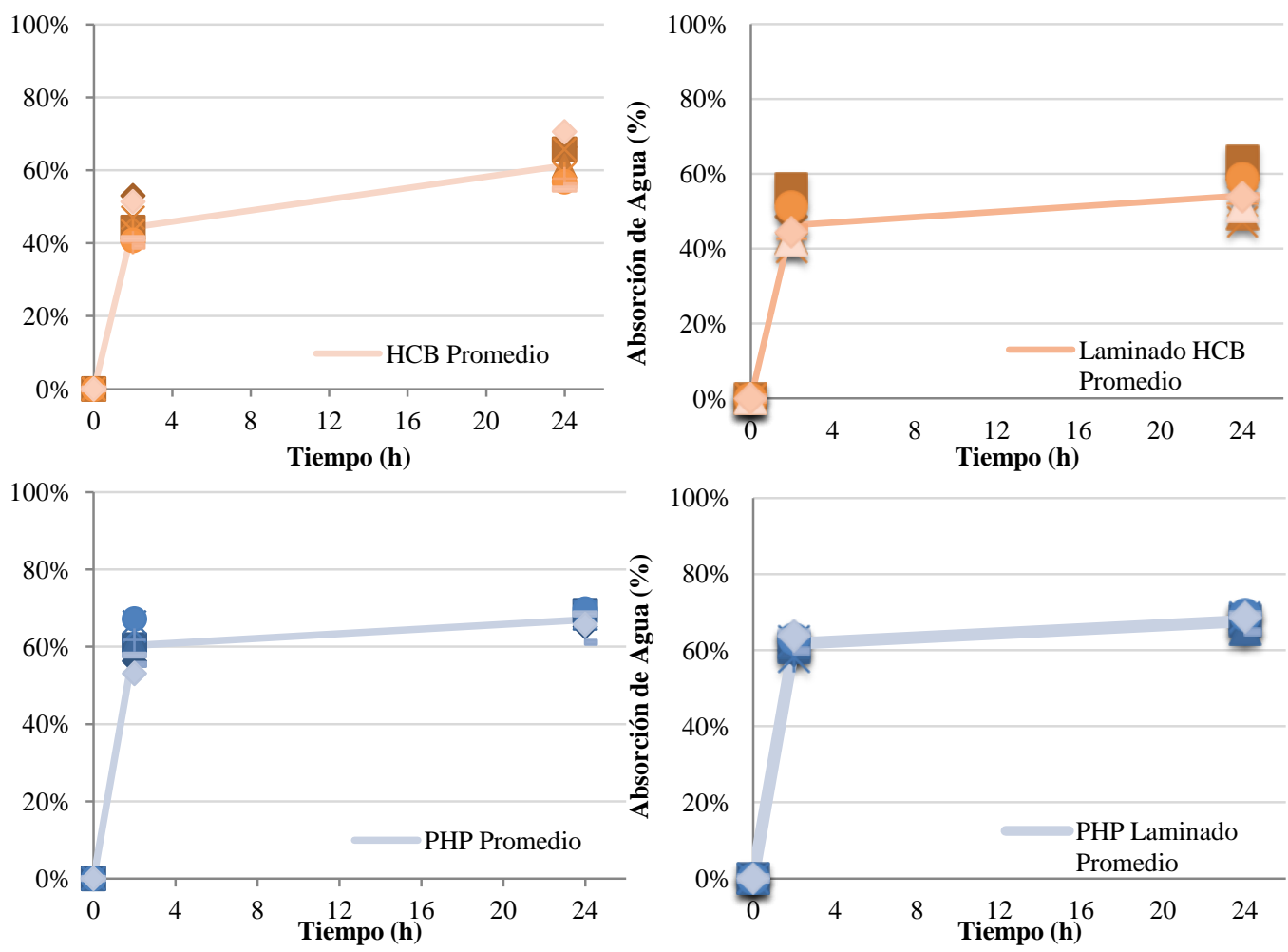

Figura 60 - Absorción de agua en HCB (Arriba) y del PHP (Abajo). Natural (izquierda) Laminado (Derecha)

Mientras que en el peciolo de la hoja de la palmera, después de dos horas de inmersión total se obtuvieron valores de 3,17\% y 53,01, mínimo y máximo, respectivamente. Después de 24 horas de inmersión percibimos que los valores mínimos y máximos, 
cambiaron para 54,81\% y 70,53\% aproximadamente. El valor promedio en 2 horas fue de $54,81 \%$ y en 24 horas $61,36 \%$.

Dado el hecho que los valores promedios de absorción de agua aumentaron xx\% después de 24 horas, se puede inferir un alto nivel de porosidad mayor en .

Aunque la absorción de agua sea bastante elevada, en comparación con los laminados industriales a base de minerales, es importante recalcar que la capacidad de absorción de agua es un parámetro importante para definir el tipo de aglomerante que se va utilizar en la adhesión del substrato y la superficie del residuo.

Según, (Vital, B.R. and Wilson, J.B. 1980) la absorción de agua disminuye con el aumento de la densidad del material. Pero, esta disminución es mucho menor cuando las condiciones de humedad en el ambiente son altas.

\subsubsection{Durabilidad}

La durabilidad se analizó desde el punto de vista del ensayo de envejecimiento acelerado y por depósito de suciedad típicas de ambientes domésticos.

\subsubsection{Limpieza e Higiene}

Algunos revestimientos de tipología mate, como lo son las maderas y en este caso, como lo son las superficies de la HCB y el PHP, generalmente presentan una mayor dificultad de limpieza durante el uso (Menegazzo et al. 2006). Las superficies mate tienen a ser más rugosas que las brillantes, es decir, las superficies brillantes son mas lisas.

Por esto, en nos referimos a las superficie interna de la HCB como una superficie brillante, y el resto de las superficies (HCB externa y PHP ambas) como superficies opacas.

La Tabla 11 muestra los resultados de la resistencia al ataque químico de los productos utilizados.

Tabla 11 - Reacción de agentes manchadores sobre la superficie

\begin{tabular}{|l|l|l|l|l|}
\hline \multicolumn{1}{|c|}{$\begin{array}{c}\text { Agentes } \\
\text { Manchadores }\end{array}$} & $\begin{array}{c}\text { Superficie } \\
\text { Externa }\end{array}$ & $\begin{array}{c}\text { Superficie } \\
\text { Interna }\end{array}$ & \multicolumn{1}{c|}{$\begin{array}{c}\text { Superficie } \\
\text { Externa }\end{array}$} & $\begin{array}{c}\text { Superficie } \\
\text { Interna }\end{array}$ \\
\hline Salsa de Tomate & Mancha & Mancha & No Mancha & Mancha \\
\hline Mostaza & Mancha & Mancha & Mancha & No Mancha \\
\hline Mayonesa & Mancha & Mancha & Mancha & Mancha \\
\hline Café & Mancha & Mancha & No Mancha & No Mancha \\
\hline Vinagre & No Mancha & Mancha & No Mancha & Mancha \\
\hline Salsa inglesa & No Mancha & Mancha & No Mancha & Mancha \\
\hline Hipoclorito de Sodio & Mancha & Mancha & Mancha & Mancha \\
\hline Vino & Mancha & Mancha & Mancha & Mancha \\
\hline
\end{tabular}


En la Figura 61 - Superficies de la HCB durante el proceso de manchado y después del procedimiento de limpieza. Superficie externa (arriba) y superficie interna (abajo). se percibe que la superficie externa de la HCB no se ve afectada por el vinagre, ni la salsa inglesa, los cuales tienen tonalidades de color opuestas, pero su ph es diferente. En la superficie interna podemos percibir que todos los agentes químicos causan manchas. Ambas superficies de la HCB se muestran resistentes al efecto abrasivo de la limpieza.
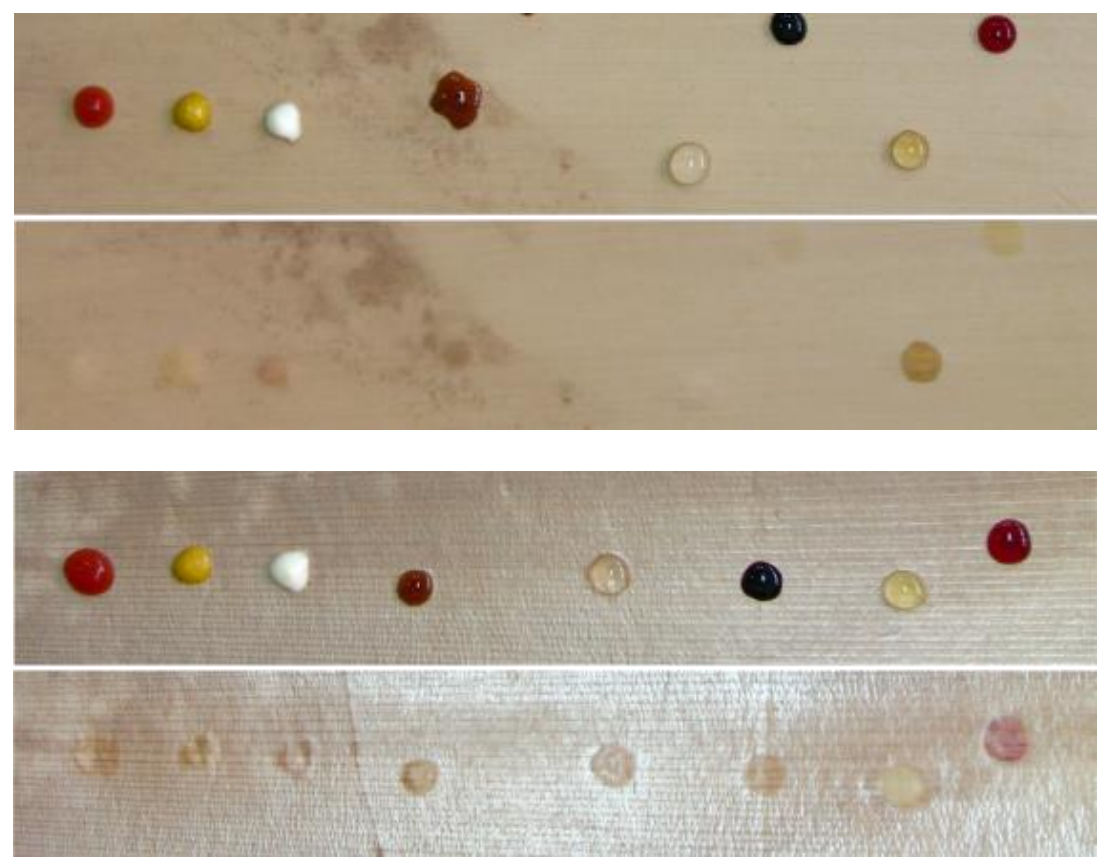

Figura 61 - Superficies de la HCB durante el proceso de manchado y después del procedimiento de limpieza. Superficie externa (arriba) y superficie interna (abajo).
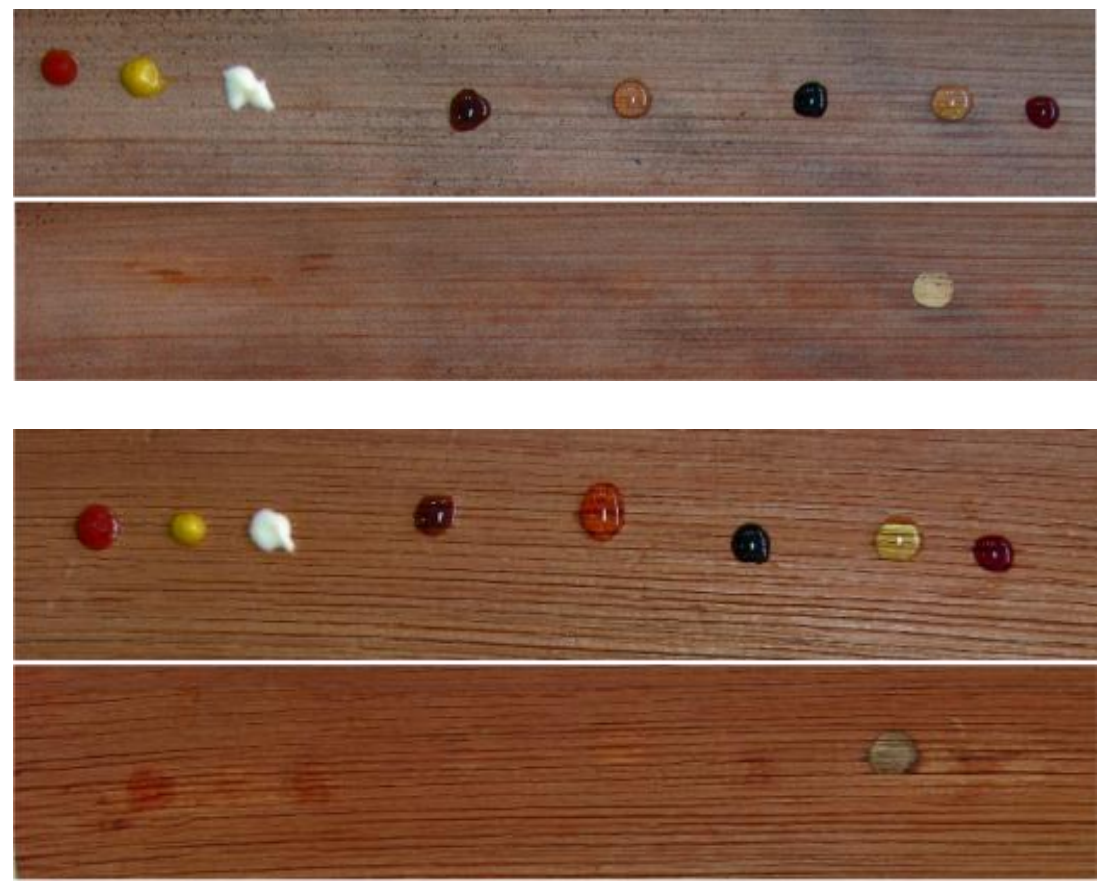

Figura 62 - Superficies del PHP durante el proceso de manchado y después del procedimiento de limpieza. Superficie externa (arriba) y superficie interna (abajo). 
En la Figura 62 Figura 62 - Superficies del PHP durante el proceso de manchado y después del procedimiento de limpieza. Superficie externa (arriba) y superficie interna podemos percibir que ambas superficies del PHP son más resistentes al ataque químico, comparadas con las superficies de la HCB. Aunque, la superficie externa la superficie externa agentes como el kétchup, el café, el vinagre y la salsa inglesa no causen manchas, podemos percibir que el efecto abrasivo de la esponja deja rastro sobre la superficie. Ya en la superficie interna, solo dos agentes no dejan manchas visibles, que son la mostaza y el café. Esta última se muestra más resistente al efecto abrasivo de la limpieza. 


\section{Conclusiones}

Las hojas caulinares del Bambú (HCB) y el Peciolo envainador de la palmera (PHP), tienen un grande potencial para ser utilizados en la producción de laminados decorativos de alta presión. Los cuales podrán ser usados en revestimientos de interiores, aunque el PHP se mostró más resistente a la foto-degradación, se sugiere para futuros trabajos el uso de un overlay o capa protectora de la superficie.

El reconocimiento de las características físico-químicas de ambos residuos, permitió identificar que las superficies internas tienden a ser mas hidrófilas que las superficies externas. Por esto para, para el uso en laminados se recomienda el uso de las superficies externas. Además, por la estabilidad de color que estas presentan ante los rayos UV. Esta resistencia se debe a la presencia de grupos funcionales $\mathrm{OH}$, que ralentizan la fotodegradación retardando la formación de grupos carbonilos.

La tendencia hidrófila en la superficie interna está relacionada, al transporte de nutrientes desde el medio ambiente externo hasta la planta. Y la tendencia es hidrófobo debido a la necesidad de repeler cuerpos extraños. Por otra parte, dado el hecho de que las superficies externas están continuamente expuestas a la luz del sol y el envejecimiento natural, el envejecimiento acelerado en las superficies interna causa cambios notables, sobretodo en el comportamiento humectante. Sin embargo, para un mayor rendimiento de los revestimientos en aplicaciones exteriores son necesarias mejoras en las superficies.

Lo que corresponde al desempeño visual de las superficies, se percibe que con el proceso de laminación de alta presión, se conserva la apariencia visual de las superficies sin afectar el color, la textura, los colores y los matices. Se sabe que el mantenimiento de los revestimientos de madera en uso exterior es crucial para el rendimiento y la durabilidad durante el envejecimiento. Por esto, el color es otra propiedad importante de la superficie aparente, es una característica visual básica para los revestimientos. Debido a esto las superficies del PHP tienen un mejor comportamiento, comparadas con la superficie de la HCB.

La topología de la superficie es tanto áspera como anisotrópica. Debido a que cada residuo es un material compuesto, combinado por dos superficies que cubren una matriz de fibras, que le dan la ondulación a la superficie, y la rugosidad es debido a la presencia de micro-saliencies. Debido a la composición química, - celulosa, lignina, hemicelulosa y extractivos -, se crea una superficie heterogénea. La influencia de la topografía sobre la humectabilidad fue analizada, de lo cual se afirma que el comportamiento humectable refleja el trabajo inherente de las plantas. 


\section{Bibliografía}

ABNT NBR 9442. 1988. Indice de Propagação de Chamas.

Abu-Sharkh, B.F., and H. Hamid. 2004. "Polymer Degradation and Stability." Degradation Study of Date Palm Fibre/polypropylene Composites in Natural and Artificial Weathering: Mechanical and Thermal Analysis 85 (3): 967-73. doi:10.1016/j.polymdegradstab.2003.10.022.

Albinante, S. R., E. B. Vasques P., and L. L. Yuan V. 2013. "Química Nova." A Review on Chemical Treatment of Natural Fiber for Mixing with Polyolefins 36. doi:10.1590/S0100-40422013000100021.

Alonso, D. M., S. G. Wettstein, and J. A. Dumesic. 2012. "Chemical Society Reviews." Bimetallic Catalysts for Upgrading of Biomass to Fuels and Chemicals 41: 8075-98. doi:DOI: 10.1039/C2CS35188A.

Alpár, Tibor, and András Winkler. 2006. "Recycling of Impregnated Décor Paper in Particleboard." Acta Silv. Lign. Hung. 2: 113-16.

Alvarez-Castillo, A., R. Salgado-Delgado, E. García-Hernández, M.M. DomínguezDomínguez, J.M. Granandos-Baeza, A. Aguirre-Cruz, Roselis CarmonaGarcía, et al. 2012. "Revista Iberoamericana de Polímeros." Aprovechamiento integral de los materiales lignocelulósicos. 13 (4): 11.

ANSI/NEMA. 2005. High-Pressure Decorative Laminates (HPDL). http://www.nema.org/Standards/Pages/High-Pressure-DecorativeLaminates.aspx.

APG III. 2009. "Botanical Journal of Linnean Society." An Update of the Angiosperm Phylogeny Group Classification for the Orders and Families of Flowering Plants: APG III - 2009 - Botanical Journal of the Linnean Society - Wiley Online Library 161: 105-21.

Ashby, M. F., and K. Johnson. 2014. Materials and Design.

A. Temiz, U. C. Yildiz, I. Aydin, M. Eikenes, G. Alfredsen, and G. Çolakoglu. 2005. "Applied Surface Science." Surface Roughness and Color Characteristics of Wood Treated with Preservatives after Accelerated Weathering Test 250 (1-4): $35-42$.

Ayfer Dönmez Çavdar, Hüsnü Yel, Hülya Kalaycıg־ lu, and Salim Hiziroglu. 2013. "Effect of Waste Melamine Impregnated Paper on Properties of Oriented Strand Board." Materials and Design 51: 751-55. doi:10.1016/j.matdes.2013.04.052.

Ayrilmis, Nadir. 2012. "Enhancement of Dimensional Stability and Mechanical Properties of Light MDF by Adding Melamine Resin Impregnated Paper Waste." International Journal of Adhesion and Adhesives 33: 45-49. doi:10.1016/j.ijadhadh.2011.11.001.

Barash, L. 2008. "Proceedings of the European Laminates Conference and Workshop." In Laminates, Decorative Surfaces, 35-54.

Bardak, Selahattin, Bünyamin Sarı, Gökay Nemli, Hüseyin Kırc1, and Mehmet Baharoğlu. 2011. "International Journal of Adhesion and Adhesives." The Effect of Decor Paper Properties and Adhesive Type on Some Properties of Particleboard 31 (6): 412-15. doi:10.1016/j.ijadhadh.2011.02.008.

Barreto, Antônio. 2008. "Modificações químicas em fibras lignocelulósicas para obtenção e aplicação em biocompósitos de matriz fenólica derivada de LCC e na biossorção de metais." Dissertation. http://www.repositorio.ufc.br/handle/riufc/1111. 
Bendahou, A., A. Dufresne, H. Kaddami, and Y. Habibi. 2007. "Carbohydrate Polymers." Isolation and Structural Characterization of Hemicelluloses from Palm of Phoenix Dactylifera L. 68 (3): 601-8. doi:10.1016/j.carbpol.2006.10.016.

Bittencourt, Paulo Rodrigo Stival. 2008. "Náilon 6 e 6,6 em Blendas com Lignina Kraft Modificada por Ácido Fórmico: Caracterização e Efeito de Radiação UV." Tese de doutorado, Maringá: Universidade Estadual de Maringá. http://www.pqu.uem.br/arquivos/documentos/do029c.pdf.

Braz Mendes, Carlos Eduardo. 2014. "Caracterização de Biomassa Lignocelulósica Para Uso Em Processos Térmicos de Geração de Energia.” Disertação de Mestrado, Universidade Estadual Paulista. http://repositorio.unesp.br/handle/11449/115659.

Castro, B., Izabella. 2008. "Geopolímeros à base de resíduos agrícolas e agroindustriais." Tese de Doutorado, Rio de Janeiro, Brasil: Instituto Militar de Engenharia.

http://www.ime.eb.br/arquivos/teses/se4/cm/Izabella_Castro_Bigno.pdf.

Castro, Heizir F. de. 2009. "Processos Químicos Industriais II - PAPEL E CELULOSE."

Chávez-Sifontes, Marvin, and Marcelo E. Domine. 2013. "Avances En Ciencias E Ingeniería." Lignina, Estructura Y Aplicaciones: Métodos de Despolimerización Para La Obtención de Derivados Aromáticos de Interés Industrial 4: 15-46.

Chen, Zi-xiang, Qiong Lei, Rui-lin He, Zhong-feng Zhang, and Ahmed Jalal Khan Chowdhury. 2016. "Saudi Journal of Biological Sciences." Review on Antibacterial Biocomposites of Structural Laminated Veneer Lumber 23 (1): 142-47. doi:10.1016/j.sjbs.2015.09.025.

C. J. Chen, Y. Zhang, J. J. Jia, M. X. Wang, and G. H. Wang. 2015. "Kem. Ind." Morphology Research of Windmill Palm (Trachycarpus Fortunei) Material 64 (9): 467-72. doi:10.15255/KUI.2015.016.

Colom, X, F Carrillo, F Nogués, and P Garriga. 2003. "Polymer Degradation and Stability." Structural Analysis of Photodegraded Wood by Means of FTIR Spectroscopy 80 (3): 543-49. doi:10.1016/S0141-3910(03)00051-X.

Composite Panel Association. 2015. "Surface \& Panel Buyers Guide: Your Guide to the World of Composite Panels and Decorative Surfaces." http://www.decorativesurfaces.org/userfiles/filemanager/5509738554f2f/.

2016. "Composite Panel Association." Accessed January 14. http://www.decorativesurfaces.org/products/decorativesurfaces/veneer.html/details/.

Conrad, Jim. $2012 . \quad 101$ Yucatan Trees. http://www.backyardnature.net/j/books/101trees.pdf.

Costa, E.B. 2014. "Análise de parâmetros influentes na aderência de matrizes cimentícias." Tese de Doutorado, São Paulo, Brasil: Universidade de São Paulo. https://www.google.com.br/url?sa=t\&rct=j\&q=\&esrc=s\&source=web\&cd=1\&ca $\mathrm{d}=$ rja\&uact=8\&ved=0ahUKEwirxaDE7fLKAhXLFJAKHbh4BSEQFggcMAA \&url=http $\% 3 \mathrm{~A} \% 2 \mathrm{~F} \% 2 \mathrm{Fwww} . t e s e s . u s p . b r \% 2 \mathrm{Fteses} \% 2 \mathrm{Fdisponiveis} \% 2 \mathrm{~F} 3 \% 2 \mathrm{~F} 3$ $146 \% 2$ Ftde-16102014162945\%2Fpublico\%2FTese_Eliane_Costa_Password_Removed.pdf\&usg=AF QjCNE8cxDEJjg5jhgtmFvcEpYc2yT0g\&sig2=Dzj5V8n50KhBp4OnvKyZAA\&bvm=bv .114195076,d.Y2I. 
Cyril Harris. 2005. "High-Pressure and Low-Pressure Laminated." Dictionary of Architecture and Construction.

Dias, M. R. A. C. 2009. "Percepção dos materiais pelos usuários: modelo de avaliação Permatus." Tese de Doutorado, Florianopolis, SC, Brasil: UFSC. http://btd.egc.ufsc.br/wp-content/uploads/2010/06/Maria-Alvares.pdf.

Dombo, B., Stijnen, B., and Nusselder, J. 2010. "Proceedings of the European Laminates Conference and Workshop." In Structured Troubleshooting: A Roadmap for Analysis of Laminate Performance, 59-68.

Du, Y., M. Zahn, B.C. LesieutreY. Du M. Zahn, B.C. Lesieutre, A.V. Mamishev, and S. R. Lindgren. 1999. "Electrical Insulatio Magazine." Moisture Equilibrium in Transformer Paper-Oil Systems 15 (1): 11-20.

E. Baysal, E. Dizman Tomak, M. Ozbey, and E. Altin. 2014. "Coloration Technology." Surface Properties of Impregnated and Varnished Scots Pine Wood after Accelerated Weathering 130 (2): 140-46.

Eric Adler. 1977. "Lignin Chemistry - Past, Present and Future.” 11: 169-218.

European Environment Agency. 2010. "Chapter 4: Natural Resources and Waste." In The European Enviroment - State and Outlook 2010. http://www.eea.europa.eu/soer/synthesis/synthesis/chapter4.xhtml.

Figueiredo, Andreia B., Dmitry V. Evtuguin, Jorge Monteiro, Elvira F. Cardoso, Pedro C. Mena, and Paulo Cruz. 2011. "Structure-Surface Property Relationships of Kraft Papers: Implication on Impregnation with Phenol-Formaldehyde Resin." Industrial \& Engineering Chemistry 50 (5): 2883-90. doi:10.1021/ie101912h.

Fiorelli, J, Curtolo, D.D., Barrero, N.G., Savastano, H., de Jesus Agnolon Pallone, E.M., and Johnson, R. 2012. "Industrial Crops and Products." Particulate Composite Based on Coconut Fiber and Castor Oil Polyurethane Adhesive: An EcoEfficient Product 40 (1): 69-75.

Fiorelli, J., C. A. Gomide, F. R. Lahr, M. F. Nascimento, D. Sartori, J. Ballesteros, S. Bueno, and U. L. Belini. 2014. "Cellulose." Physico-Chemical and Anatomical Characterization of Residual Lignocellulosic Fibers. doi:10.1007/s10570-0140398-9.

Food and agriculture organization. 2015. "Food and Agricultural Commodities Production." FAOSTAT. http://faostat.fao.org/site/339/default.aspx.

Fridh L., Volpé S., and Eliasson L. 2014. "International Journal of Forest Engineering." An Accurate and Fast Method for Moisture Content Determination 25 (3): 22228.

Fukushima, Romualdo Shigueo, Artur Jordão de Magalhães Rosa, César Gonçalves de Lima, and José Aparecido da Cunha. 1999. "Comparação Entre Dois Métodos Analiticos Para Determinação Da Lignina de Algumas Gramíneas Forrageiras.” http://www.readcube.com/articles/10.1590/S0100204X1999000600014?locale $=$ en.

Gatani, Mariana Pilar, Juliano Fiorelli, Juan Carlos Medina, Ricardo Arguello, Agustin Ruiz, Maria Fátima do Nascimento, and Holmer Savastano Jr. 2013. "Viabilidade Técnica de Produção E Propriedades de Painéis de Partículas de Casca de Amendoim." http://www.scielo.br/pdf/rmat/v18n2/04.pdf.

Ghavami, Khosrow, and Albanise B. Marinho. 2005a. "Propriedades físicas e mecânicas do colmo inteiro do bambu da espécie Guadua angustifolia," 19 edition. Http://dx.doi.org/10.1590/S1415-43662005000100016. http://www.scielo.br/scielo.php?pid=S141543662005000100016\&script=sci_arttext. 
2005b. "Revista Brasileira de Engenharia Agrícola E Ambiental." Physical and Mechanical Properties of the Whole Culm of Bamboo of the Guadua Angustifolia Species 9. doi:10.1590/S1415-43662005000100016.

Gomes, Thiago S., Leila L. Y. Visconte, and Elen B. A. V. Pacheco. 2013. "Polímeros." Polímeros - Mechanical and Thermal Behavior of Composites Based on High Density Polyethylene and Banana Tree Fiber 23 (2). doi:10.4322/S010414282013005000010.

Guimarães, H.R., and K. Tannous. 2014. "Blucher Chemical Engineering Proceedings." Estudo Das Propriedades Físicas E Térmicas de Materiais Compósitos de Lignina $\quad E \quad$ Poliestireno 1 http://pdf.blucher.com.br/chemicalengineeringproceedings/cobec-ic/06-em105.pdf.

Hinkle, Margaret E. 1994. "Applied Geochemistry." Environmental Conditions Affecting Concentrations of He, CO2, O2 and N2 in Soil Gases 9 (1): 53-63. doi:10.1016/0883-2927(94)90052-3.

ISO. 2004. High-Pressure Decorative Laminates -- Sheets Made from Thermosetting Resins. http://www.iso.org/iso/catalogue_detail.htm?csnumber=38244.

Istek, Abdullah, and Soner Aksu. 2010. "The Effect of Decor Paper and Resin Type on the Physical, Mechanical, and Surface Quality Properties of Particleboards Coated with Impregnated Decor Papers." BioResources 5 (2): 1074-83.

IUPAC. 2005. "IUPAC - International Union of Pure and Applied Chemistry: Project Details." http://www.iupac.org/nc/home/projects/project-db/projectdetails.html?tx_wfqbe_pi1\%5bproject_nr\%5d=2000-004-2-500.

Jain, S., Kumar, R., and Jindal, U.C. 1992. "Journal of Materials Science." Mechanical Behaviour of Bamboo and Bamboo Composite 27 (17): 4598-4604. doi:10.1007/BF01165993.

Jian-Guo Dai, Y. Akira, F.H. Wittmann, H. Yokota, and Peng Zhang. 2010. "Water Repellent Surface Impregnation for Extension of Service Life of Reinforced Concrete Structures in Marine Environments: The Role of Cracks," 32 edition.

John, V. M., and Sérgio Cirelli Ângulo. 2003. Coletânea Habitare - Utilização de Resíduos Na Construção Habitacional. Vol. 4.7 vols. Porto Alegre, Rio Grande do Sul.

John Wiley. 2004. "The Internet Jounal of Vibrational Spectroscopy." The Internet Jounal of Vibrational Spectroscopy. http://www.ijvs.com/volume3/edition3/section1.html.

Kaddami, H., A. Dufresne, B. Khelifi, A. Bendahou, M. Taourirte, M. Raihane, N. Issartel, H. Sautereau, J.F. Gérard, and N. Sami. 2006. "Short Palm Tree Fibers - Thermoset Matrices Composites." Composites Part A: Applied Science and Manufacturing 37 (9): 1413-22. doi:10.1016/j.compositesa.2005.06.020.

Kandelbauer, Andreas, Primoz Petek, Sergej Medved, Antonio Pizzi, and Alfred Teischinger. 2009. "European Journal of Wood and Wood Products." On the Performance of a Melamine-urea-formaldehyde Resin for Decorative Paper Coatings 68 (1): 63-75.

Karana, Elvin. 2010. "METU JFA.” How Do Materials Obtain Their Meanings? 27 (2): 271-85. doi:10.4305/METU.JFA.2010.2.15.

Karana, Elvin, Paul Hekkert, and Prabhu Kandachar. 2008. "Materials \& Design." Material Considerations in Product Design: A Survey on Crucial Material Aspects Used by Product Designers 29 (6): 1081-89. doi:10.1016/j.matdes.2007.06.002. 
Khalil, H.P.S. Abdul, I.U.H. Bhat, M. Jawaid, A. Zaidon, D. Hermawan, and Y.S. Hadi. 2012. "Materials \& Design." Bamboo Fibre Reinforced Biocomposites: A Review 42: 353-68. doi:10.1016/j.matdes.2012.06.015.

Kriker, A., A. Bali, G. Debicki, M. Bouziane, and M. Chabannet. 2008. "Cement and Concrete Composites." Durability of Date Palm Fibres and Their Use as Reinforcement in Hot Dry Climates 30 (7): 639-48. doi:10.1016/j.cemconcomp.2007.11.006.

Kriker, A., G. Debicki, A. Bali, M.M. Khenfer, and M. Chabannet. 2005. "Cement and Concrete Composites." Mechanical Properties of Date Palm Fibres and Concrete Reinforced with Date Palm Fibres in Hot-Dry Climate, Natural fibre reinforced cement composites, 27 (5): 554-64. doi:doi:10.1016/j.cemconcomp.2004.09.015.

Liu, Yi, Lingmin Shao, Jianmin Gao, Hongwu Guo, Yao Chen, Qingzheng Cheng, and Brian K. Via. 2015. "Applied Surface Science." Surface Photo-Discoloration and Degradation of Dyed Wood Veneer Exposed to Different Wavelengths of Artificial Light 331: 353-61. doi:10.1016/j.apsusc.2015.01.091.

Liu, Y., J. Shen, and X. D. Zhu. 2015. "Evaluation of Mechanical Properties and Formaldehyde Emissions of Particleboards with Nanomaterial-Added Melamine-Impregnated Papers." Journal of Wood Products 73: 449-55. doi:10.1007/s00107-015-0910-4.

Liu, Yu, and Xiaodong Zhu. 2014. "Measurement of Formaldehyde and VOCs Emissions from Wood-Based Panels with Nanomaterial-Added MelamineImpregnated Paper." Construction and Building Materials 66: 132-37. doi:10.1016/j.conbuildmat.2014.05.088.

Man Singh. 2004. "Journal of Applied Polymer Science." Preparation and Structural Characterization of Melamine-Methylurea-Formaldehyde Resin and Its Blends Separatelywith Ethyl Cellulose, Starch, Teakwood, and Almond ShellPowders by13C NMR, IR, TGA, and SEM Techniques 92: 3437-46.

Marinho, Nelson Potenciano. 2012. "Características das fibras do bambu (dendrocalamus giganteus) e potencial de aplicação em painéis de fibra de média densidade (mdf)." Disertação de Mestrado, Curitiba, Paraná: Universidade Tecnologica Federal do Paraná. http://www.ppgem.ct.utfpr.edu.br/dissertacoes/MARINHO,\%20Nelson\%20Pote nciano.pdf.

Marinho N. P., E. M. Nascimento, S. Nisgoski, Magalhães W. L. E., Neto S. C., and Azevedo E. C. 2013. "Polímeros." Caracterização Física E Térmica de Compósito de Poliuretano Derivado de Óleo de Mamona Associado Com Partículas de Bambu 23 (2): 201-5.

Martin, Adriana R., Maria A. Martins, Luiz H. C. Mattoso, and Odilon R. R. F. Silva. 2009. "Polímeros." Chemical and Structural Characterization of Sisal Fibers from Agave Sisalana Variety 19. doi:10.1590/S0104-14282009000100011.

Martins Carvalho, Silvia Thais. 2012. "Propriedades Térmicas Do Painel Aglomerado de Bagaço de Cana-de-Açucar (Saccharum Officinarum L.)."

Melo, R.R., D.M. Stangerlin, A.P. Sousa, P.G. Cademartori, and E. Schneid. 2015. "Ciência Rural." Propriedades Físico-Mecânicas de Painéis Aglomerados Madeira-Bambu 45 (1): 35-42. doi:10.1590/0103-8478cr20120970.

Mendes, Rafael Farinassi, Lourival Marin Mendes, and Natalie Ferreira de Almeida. 2011. "Produção de Painéis Aglomerados de Bagaço de Cana." http://www.remade.com.br/br/revistadamadeira_materia.php?num=1529\&subjec 
$\mathrm{t}=\mathrm{E} \% 20$ mais\&title $=$ Produ $\%$ E7\%E3o\%20de\%20pain\%E9is\%20aglomerados\%2 0de\%20baga\%E7o\%20de\%20cana.

Menegazzo, Quinteiro, Dias, Armani, Silva, Lima, Buissa, and Ribeiro. 2006. "Ceramina Industrial." Resistências Ao Ataque Químico E Ao Manchamento: Comparação Dos Procedimentos E Resultados Dos Ensaios Das Normas ISO E ASTM 11 (2): 19-23.

Mohanty, Amar, Manjusri Misra, and Lawrence T Drzal. 2001. "Surface Modifications of Natural Fibers and Performance of the Resulting Biocomposites: An Overview." Instrumentation Science \& Technology 8 (5): 313-43. doi:10.1163/156855401753255422.

Molina-Montenegro M.A. 2008. "Revista Ecosistemas." Variación de La Pubescencia Foliar En Plantas Y Sus Implicaciones Funcionales a Lo Largo de Gradientes Altitudinales 17 (1): 146-54.

Mondal, Dilip Kumar, Barun Kumar Nandi, and M.K. Purkait. 2013. "Journal of Environmental Chemical Engineering." Removal of Mercury (II) from Aqueous Solution Using Bamboo Leaf Powder: Equilibrium, Thermodynamic and Kinetic Studies 1 (4): 891-98. doi:10.1016/j.jece.2013.07.034.

Monteiro de Barros, R., L. Marin Mendes, K. Monteiro Novack, L. Oliveira Aprelini, and V. R. Botaro. 2011. "Industrial Crops and Products." Hybrid Chipboard Panels Based on Sugarcane Bagasse, Urea Formaldehyde and Melamine Formaldehyde Resin, 369-73.

Müller, Uwe, Manfred Rätzsch, Manfred Schwanninger, Melanie Steiner, and Harald Zöbl. 2003. "Journal of Photochemistry and Photobiology B: Biology." Yellowing and IR-Changes of Spruce Wood as Result of UV-Irradiation 69 (2): 97-105. doi:10.1016/S1011-1344(02)00412-8.

Nadir Ayrilmis, Turker Dundar, Nadir Ayrilmis, Zeki Candan, and Turgay Akbulut. 2009. "Bioresources." Wettability of Fire Retardant Treated Laminated Veneer Lumber (lvl) Manufactured from Veneers Dried at Different Temperatures. https://beta.openaire.eu/search/publication?articleId=doajarticles::0f7e2985531c $31 \mathrm{f} 491735$ cec6e $37365 f$.

Nemli, Gokay. 2016. "Journal of Materials Processing Technology." Factors Affecting Some Quality Properties of the Decorative Surface Overlays. Accessed January 27. http://www.sciencedirect.com/science/article/pii/S0924013607005110.

Nemli, Gökay, Yalçin Örs, and Hülya Kalaycıŏlu. 2005. "Construction and Building Materials." The choosing of suitable decorative surface coating material types for interior end use applications of particleboard 19 (4): 307-12. doi:10.1016/j.conbuildmat.2004.07.015.

Nemli, Gökay, and Mustafa Usta. 2004. "Building and Environment." Influences of Some Manufacturing Factors on the Important Quality Properties of MelamineImpregnated Papers 39 (5): 567-70. doi:10.1016/j.buildenv.2003.12.008.

Niro Higuchi, Joaquim dos Santos, Ralfh João Ribeiro, Luciano, Luciano Minette, and Yvan Biot. 1998. "Acta Amazonica.” Biomassa Da Parte Aérea Da Vegetação Da Floresta Tropical úmida de Terra-Firme Da Amazônia Brasileira. 28 (2): 1809-4392.

Nunes S., K. 2008. "Resíduo do processamento da palmeira-real (archontophoenix alexandrae) orgânica: caracterização físico-química, aplicação em biscoitos fibrosos sem glúten e avaliação sensorial pelo consumidor celíaco.” Disertação de Mestrado, Florianopolis, SC, Brasil: Federal de Santa Catarina.

O'Carroll C. 2004. "European Market Update." In Proceedings of the European Laminates Conference and Workshop. 
Patachia, Silvia, Catalin Croitoru, and Christian Friedrich. 2012. "Applied Surface Science." Effect of UV Exposure on the Surface Chemistry of Wood Veneers Treated with Ionic Liquids $258 \quad$ (18): 6723-29. doi:10.1016/j.apsusc.2011.12.050.

Peng, Hong, Mengyang Zhou, Ziping Yu, Jinsheng Zhang, Roger Ruan, Yiqin Wan, and Yuhuan Liu. 2013. "Carbohydrate Polymers." Fractionation and Characterization of Hemicelluloses from Young Bamboo (Phyllostachys Pubescens Mazel) Leaves 95 (1): 262-71. doi:DOI: 10.1016/j.carbpol.2013.03.007.

Pereira Jr, Nei, Maria Antonia Peixoto G. Couto, and Lídia Maria Melo Santa Anna. 2008. Biomass of Lignocellulosic Composition for Fuel Production Witnin the Context of Biorefinery. http://www.ladebio.org.br/download/series-embiotecnologia-vol-ii-lignocellulosic-biomass.pdf.

Porras, A., and A. Maranon. 2012. "Composites Part B: Engineering." Development and Characterization of a Laminate Composite Material from Polylactic Acid (PLA) and Woven Bamboo Fabric $43 \quad$ (7): 2782-88. doi:10.1016/j.compositesb.2012.04.039.

Ragesh, Prathapan, Anand Ganesh, Shantikumar V. Nair, and A. Sreekumaran Nair. 2014. "Journal of Materials Chemistry A." A Review on "self-Cleaning and Multifunctional Materials" 2: 14773. doi:10.1039/c4ta02542c.

Rios, S, R Chicurel, and L.F Del Castillo. 2001. "Materials \& Design." Potential of Particle and Fibre Reinforcement of Tyre Tread Elastomers 22 (5): 369-74. doi:doi:10.1016/S0261-3069(00)00103-5.

Roberts, R.J., and P.D. Evans. 2005. "Effects of Manufacturing Variables on Surface Quality and Distribution of Melamine Formaldehyde Resin in Paper Laminates." Composites Part A: Applied Science and Manufacturing 36 (1): 95-104. doi:10.1016/j.compositesa.2003.05.001.

Rúgolo, Z. E., and M. F. Rodriguez. 2002. "Botanical Journal of the Linnean Society." Cauline Anatomy of Native Woody Bamboos in Argentina and Neighbouring Areas: Epidermis 138 (1): 45-55. doi:10.1046/j.1095-8339.2002.00004.x.

Sampaio, Juliana Abrantes de. 2013. "Caracterização de fibras de celulose tratadas por plasma." Projeto de Graduação, Rio de Janeiro: Federal do Rio de Janeiro. http://monografias.poli.ufrj.br/monografias/monopoli10005982.pdf.

Sartori, Diogo de Luca. 2012. "Painel portante estrutural com chapa de partículas de bagaço de cana de açucar e resina de mamona para centro de manejo bovino." Disertação de Mestrado, Pirassununga: Universidade de São Paulo.

Seye, O., L. A. Cortez, and E. Olivares G. 2003. "Estudo Cinético Da Biomassa a Partir de Resultados Termogravimétricos." In . http://www.proceedings.scielo.br/scielo.php?pid=MSC00000000220000002000 22\&script=sci_arttext.

Shengcheng Zhai, Yoshiki Horikawa, Tomoya Imai, and Junji Sugiyama. 2014. "IAWA Journal." Cell Wall Ultrastructure of Palm Leaf Fibers, 127-37. doi:10.1163/22941932-00000054.

Shigeru Deguchi, Kaoru Tsuji, and Koki Horikoshi. 2006. "Communication." Cooking cellulose in hot and compressed water, 3293-95. doi:10.1039/b605812d.

Silva, A.L., Costa Junior, A.E., Nascimento, D.M., Silva, M.A.S., Sombra, A.S.B., Rosa M.P., and Mazetto, S.E. 2013. "Modificações Espectroscópicas Vibracionais E Nas Propriedades Dielétricas Em Fibras de Bucha Vegetal (luffa Cylindrica) Após Tratamento Químico." In . Rio de Janeiro. http://www.abq.org.br/cbq/2013/trabalhos/12/2408-16576.html. 
Silva, Graciane Angélica da, Lourival Marin Mendes, Natalino Calegário, Fábio Akira Mori, José Reinaldo Moreira da Silva, and Izaías Fernandes dos Santos. 2006. "Scientia Forestalis." Estimativa Da Umidade de Equilíbrio de Painéis de Madeira 70: 23-29.

Song, Fei, Chen Xu, Wen-Yi Bao, Xiu-Li Wang, and Yu-Zhong Wang. 2015. "Carbohydrate Polymers." Bamboo (Neosinocalamus Affinis)-Based Thin Film, a Novel Biomass Material with High Performances 119: 167-72. doi:10.1016/j.carbpol.2014.11.055.

Sreekala, M. G. Kumaran, Seena Joseph, Maya Jacob, and Sabu Thomas. 2000. "Applied Composite Materials." Oil Palm Fibre Reinforced Phenol Formaldehyde Composites: Influence of Fibre Surface Modifications on the Mechanical Performance 7: 295-329.

Subhani Syed. 2016. "BAMBOO SHEATH CUP MAKING AN INNOVATIVE APPROACH TO TAP THE UNTAPPED NR." Working with Community: http://ashachinturu.blogspot.com.br/2016/01/bamboo-sheath-cup-making-wholeprocess.html.

Taiz, Lincoln, and Eduardo Zeiger. 2006. Fisiología Vegetal. Universitat Jaume.

Tian-Ming Yen, Yi-Jia Ji, and Joou-Shian Lee. 2010. "Forest Ecology and Management." Estimating Biomass Production and Carbon Storage for a FastGrowing Makino Bamboo (Phyllostachys Makinoi) Plant Based on the Diameter Distribution Model 260 (3): 339-44. doi:10.1016/j.foreco.2010.04.021.

Tramonte, Karina Cardoso. 2009. "Caracterização Físico Química E Avaliação Sensorial Do Suco Da Bainha Foliar (resíduo Agroindustrial) Da Palmeira Real Australiana (Archontophoenix Alexandrae).” Disertação de Mestrado, Florianopolis, SC, Brasil: Universidade Federal de Santa Catarina. http://repositorio.ufsc.br/xmlui/handle/123456789/93283.

Turkoglu, Turkay, Ergun Baysal, and Hilmi Toker. 2015. "The Effects of Natural Weathering on Color Stability of Impregnated and Varnished Wood Materials." Advances in Materials Science and Engineering, 9. doi:10.1155/2015/526570.

Vieira, Rodrigo José de Andrade. 2008. "Desenvolvimento de Painéis Confeccionados a Partir de Fibras de Coco Para Controle Acústico de Recintos." Disertação de Mestrado, Belém, Pará, Brasil: Universidade Federal do Pará.

Vilar, W. 1998. “Capítulo 1 - Poliois.” In Química E Tecnologia Dos Poliuretanos, 2nd ed. http://www.poliuretanos.com.br/Cap1/15Poliois.htm.

Villar-Cociña, Ernesto, Moisés Frías, Eduardo Valencia Moralesa, Sergio F. Santos, and Holmer Savastano Jr. 2011. "Cement and Concrete Composites." Pozzolanic Behavior of Bamboo Leaf Ash: Characterization and Determination of the Kinetic Parameters. 33 (1): 68-73. doi:10.1016/j.cemconcomp.2010.09.003.

Vital, B.R., and Wilson, J.B. 1980. “Àrvore.” Efeito Da Forma Geométrica Dos Flocos E Partículas, Da Densidade Das Chapas E Do Tipo de Adesivo Nas Propriedades Mecânicas Das Chapas de Madeira Aglomerada. 4 (2): 179-87.

Vu, Lam Tran, and Tran Thanh Cao. 2013. "Study on Technology of Chipboard from Rice Husk and Short Fibers of Coconut Shell." Accessed May 6. http://agris.fao.org/openagris/search.do?recordID=VN2012000006.

Wang, Brad Jianhe, and Ying Hei Chui. 2012. "Wood and Fiber Science." Performance Evaluation of Phenol Formaldehyde Resin-Impregnated Veneers and Laminated Veneer Lumber 1. http://wfs.swst.org/index.php/wfs/article/view/320.

Wang, S.-Y., Yang, T.-H, Lin, L.-T, Lin, C.-J., and Tsai, M.-J. 2007. "Properties of Low-Formaldehyde-Emission Particleboard Made from Recycled Wood-Waste 
Chips Sprayed with PMDI/PF Resin.” Building and Environment 42 (7): 247279.

Wiglusz, R., E. Sitko, G. Nikel, I. Jarnuszkiewicz, and B. Igielska. 2002. "Building and Environment." The Effect of Temperature on the Emission of Formaldehyde and Volatile Organic Compounds (VOCs) from Laminate Flooring — Case Study 37 (1): 41-44. doi:10.1016/S0360-1323(00)00091-3.

Yang, Hailing. 2015. "Adhesion Studies of Polymers: (I) Autohesion of Ethylene/1Octene Copolymers; (II) Method Development and Adhesive Characterization of Pressure Sensitive Adhesive in Paper Laminates for Postage Stamps.” PhD Degree. Accessed June 24. https://www.researchgate.net/publication/277210684_Adhesion_Studies_of_Pol ymers_\%28I\%29_Autohesion_of_Ethylene1-

Octene_Copolymers_\%28II\%29_Method_Development_and_Adhesive_Charact erization_of_Pressure_Sensitive_Adhesive_in_Paper_Laminates_for_Postage_S tamps.

Yu, C., and D. Crump. 1998. "Building and Environment." A Review of the Emission of VOCs from Polymeric Materials Used in Buildings 33 (6): 357-74.

$\mathrm{Yu}$, L.Y. 1995. "Biomass and Nutrient Accumulation of Makino Bamboo (Phyllostachys Makinoi) Stand in Hui-Sun Experimental Forest Station.” Master thesis, Taiwan: National Chung-Hsing University.

Zhu, J., J. Jia, F. Kwong, and H.L. Dickon. 2013. "Diamond and Related Materials." Synthesis of 6H-SiC Nanowires on Bamboo Leaves by Carbothermal Method 33: $5-11$. 